WORKING PAPER \#637

PRINCETON UNIVERSITY

INDUSTRIAL RELATIONS SECTION

FEBRUARY 2020

http://arks.princeton.edu/ark:/88435/dsp01df65vb747

\title{
The Long-Term Effects of Labor Market Entry in a Recession: Evidence from the Asian Financial Crisis*
}

\author{
Eleanor Jawon Choi ${ }^{\dagger}$ \\ Hanyang University
}

\author{
Jaewoo Choi $\ddagger$ \\ KDI
}

February 3, 2020

\author{
Hyelim Son $\S$ \\ University of Seoul
}

\begin{abstract}
This study investigates the long-term effects of initial labor market conditions by comparing cohorts who graduated from college before, during, and after the 1997-1998 Asian financial crisis in South Korea. We measure the overall welfare effect by examining their labor market activities, family formation, and household finances. Using data from 20 waves of the Korean Labor and Income Panel Study, we find a substantial and persistent reduction in employment, earnings, marriage, fertility, and asset building among men who graduated during a recession. For women, limited job opportunities at graduation result in an increase in childbearing. Our results suggest that labor market entry in a large-scale recession has prolonged effects on a young worker's life course even after the penalties in the labor market have disappeared.
\end{abstract}

JEL Codes: E32, J10, E21, J20, J31

Keywords: recession, financial crisis, long-term effects, college graduates

*We thank Youngsoo Bae, Jesse Bruhn, Amie Chin, Jiwon Choi, Marie Connolly, Rebecca Diamond, Hank Farber, Federico Gutierrez, Catherine Haeck, Joseph Han, Jisoo Hwang, Lisa Kahn, Seik Kim, David Lee, Pauline Leung, Elaine Liu, Seunghoon Na, Cheolsung Park, Zhuan Pei, Mallika Thomas, Miguel Urquiola, Jungmo Yoon, and conference and seminar participants at AASLE, AEA, AMES, Asian Workshop on Economic Policy, EALE, Hanyang University, KLEA-KAAE-KASIO Joint Workshop, Princeton University, Seoul Labor Economics Working Group, University of Houston, University of Seoul, UQAM, and WEAI for helpful comments and discussions. We also thank Weonhyeok Chung, Elizabeth Kayoon Hur, Hanbin Kim, and Sae Won Om for outstanding research assistance. Preliminary results on male college graduates' labor market and family formation outcomes appeared in J. Choi's M.A. thesis at Hanyang University, supervised by E. Choi and Son. The manuscript has been substantially changed and expanded from the earlier version with respect to analysis and writing. E. Choi and Son gratefully acknowledge financial support from the W.E. Upjohn Institute for Employment Research. E. Choi's research was also supported by the Industrial Relations Section at Princeton University. A portion of this research was conducted while E. Choi was visiting the Industrial Relations Section and the Department of Economics at Princeton University. All remaining errors are our own.

${ }^{\dagger}$ College of Economics and Finance, Hanyang University, 222 Wangsimni-ro, Seongdong-gu, Seoul 04763, South Korea. Email: choiej@ hanyang.ac.kr. Phone: +82-2-2220-1019. Fax: +82-2-2296-9587.

${ }_{\dagger}^{\ddagger}$ Korea Development Institute, 263 Namsejong-ro, Sejong 30149, South Korea. Email: cjw0801@kdi.re.kr.

${ }^{\S}$ School of Economics, University of Seoul, 163 Seoulsiripdae-ro, Dongdaemun-gu, Seoul 02504, South Korea. Email: hlson@uos.ac.kr. Phone: +82-2-6490-2073. Fax: +82-2-6490-2054. 


\section{Introduction}

The Great Recession has sparked a growing discussion in academic and policy circles on the longterm effects of entering the labor market during a deep recession. Despite well-documented evidence on the substantial loss of income for recession graduates, little is known about how this labor market shock will extend to other aspects of personal welfare, such as family formation and financial decisions. Research shows that the earnings penalty disappears after about 10 years for a typical college graduate, but it is unclear whether this catch-up would also occur outside the labor market. In addition, since most previous research has focused on modest recessions and regular business cycles, the consequences of large-scale recessions have not been fully explored. Recent evidence on the Great Recession suggests that the disadvantages of graduating during a severe economic downturn may be more serious; however, because this major event occurred relatively recently, the scope of research has been limited to short- and medium-term labor market outcomes. 1

This paper examines the long-term consequences of entering the labor market during a deep recession on career trajectory, family formation, and household finances, by studying the 1997-1998 Asian financial crisis, which created a historic economic meltdown in the region. In particular, we focus on South Korea, which was hit by the financial crisis in the last quarter of 1997 and experienced the worst contraction of its economy since the Korean War. The macroeconomic indicators in Figure 1 show a sharp and deep decline in economic activity during the period from 1997 to 1998. The real GDP growth rate fell precipitously from 4.4 percent in the fourth quarter of 1997 to -3.4 percent in the first quarter of 1998 , and further down to -7.3 percent in the second quarter of 1998. The unemployment rate soared from 2.7 percent in November 1997 to 6.1 percent in February 1998. The economic growth started to pick up from the first quarter of 1999 and the recovery took about three years.

To the best of our knowledge, this study is the first to use the occurrence of the Asian financial

\footnotetext{
${ }^{1}$ Altonji et al. (2016) find a disproportionately larger reduction in the early-career earnings of college graduates who entered the labor market during the Great Recession relative to those who graduated during previous recessions.
} 


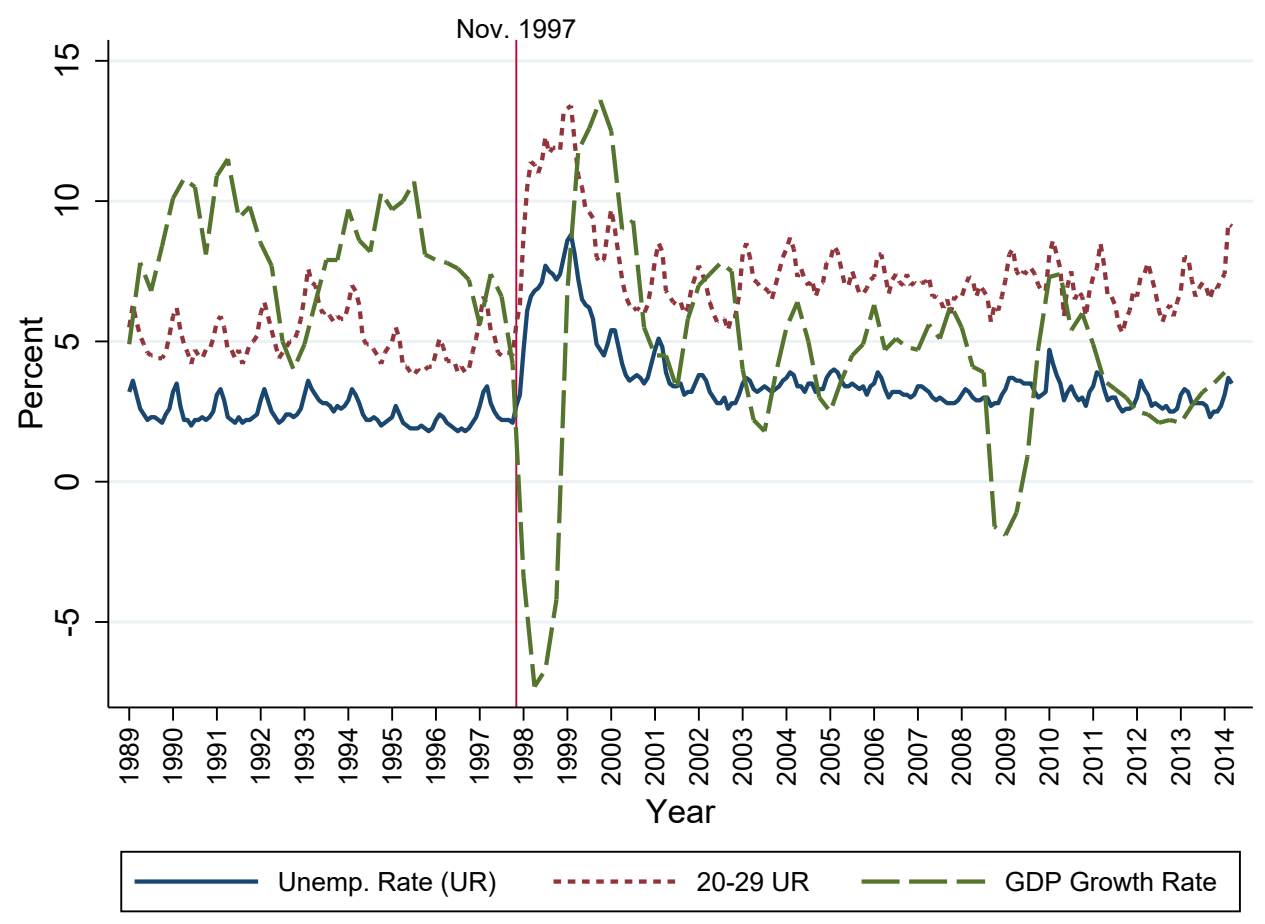

Figure 1: Macroeconomic Statistics

Notes. Monthly unemployment rates are from Statistics Korea. Quarterly real GDP growth rate is from the Bank of Korea, and measures the growth rate compared to the same quarter of the previous year.

crisis to identify the long-term effects of labor market entry conditions. As the timing of the crisis was unexpected and the magnitude of the shock was historically large, the crisis induced sharp deviations of the unemployment rate from its smooth national trend, as shown in Figure 1. We use this variation by comparing detrended outcomes across cohorts who graduated from college before, during, and after the crisis. This identification strategy enables us to exploit unemployment variation unconfounded with secular changes in cohort characteristics. This way, we can also focus on the labor market shock at the national level, which is the most relevant for college graduates who have high regional mobility in response to labor market opportunities.

Another advantage of studying the Asian financial crisis is that we can measure the overall impact of labor market entry conditions on individuals' welfare by examining a comprehensive set of outcomes on work, family, household finances, and living arrangements. As more than two decades have passed since the crisis, we can consider longer-term outcomes beyond early career status, such as family formation and asset accumulation, by tracking the crisis cohorts up to their 
mid-40s. In particular, having a sufficient amount of time between the severe economic downturn and today enables us to distinguish permanent changes from temporary adjustments in marriage, fertility, and asset building.

We use data from the Korean Labor and Income Panel Study (KLIPS), an annual longitudinal study of a representative sample of South Korean households (and individuals therein) in urban areas. Pooling all 20 waves of the KLIPS spanning the period from 1998 to 2017, we construct our analysis sample of men and women who graduated from college between 1989 and 2010, and for whom follow-up data are available for up to 19 years after graduation. We estimate a regression model exploiting across-cohort variation in the national unemployment rate at college graduation. Various robustness checks show that our estimates are unaffected by endogenous selection into the timing of college graduation, alternative measures of labor market conditions, functional form assumptions, or sample restrictions.

Our results show that labor market entry conditions have a substantial long-term effect on a broad range of outcomes, well beyond employment and earnings. In addition, the effects of a recession are heterogeneous by gender, because men and women face different choice sets and constraints when making decisions related to work, family, and household finances. For men, we find that recession cohorts experience a large and persistent reduction in employment and earnings for up to 12 years after graduation. A 1 percentage point higher unemployment rate at graduation results in a 1.9 percent lower employment probability and 2.6 percent lower earnings during the first 10 years of potential experience. This deterioration in career outcomes leads to a permanent decline in the marriage and childbearing rates by 3.1 and 2.5 percent, respectively. While consumption is insulated from reduced earnings, males who graduate during a recession hold lower levels of financial assets, are less likely to be homeowners, and are more likely to live with their parents.

For women, the recession penalty in the labor market is more subtle than that for men, because even those graduating in good times have weak labor force attachment due to family considerations. Female recession cohorts suffer from sizable reductions in employment and earnings im- 
mediately after graduation, but the negative recession effect disappears within two years. Among female wage workers who remain employed, we observe a recession penalty on job security around the time they get married and have children. Female recession graduates respond to the limited job opportunities by substituting into motherhood. Women graduating from college with a 1 percentage point higher unemployment rate accelerate their first childbirth by 0.36 years and have 0.05 more children. While there is a delay in building financial assets, it is not as substantial as that of their male counterparts. As a coping mechanism, female recession cohorts tend to find a spouse from a more advantaged economic background, as opposed to remaining unmarried or living with their parents.

This study relates to three strands of literature. First, a large body of literature seeks to identify labor market penalties for young workers who graduate in adverse economic conditions (e.g., Kahn, 2010; Oreopoulos et al., 2012). ${ }^{2}$ The consequences of such adverse conditions are known as a "scarring effect," owing to their long-lasting damage on the careers of affected individuals. We add to the literature on scarring effects by showing that a large-scale recession leads to a substantially larger and more persistent reduction in employment probability among male college graduates. The large extensive margin effect on earnings is also observed by Altonji et al. (2016) and Rothstein (2019), who examine the impact of the Great Recession; however, the employment adjustment is rarely documented in previous studies, which tend to focus on more modest variations in regular business cycles. In addition, our study is one of very few that analyze men and women separately. We show that the effect of initial labor market conditions on female career outcomes is considerably smaller than that for males, as in Kondo (2015) and Schwandt and von Wachter (2020).

Second, we add to a small but growing literature on the long-term effects of initial labor market conditions on family formation. Prior results are mixed in terms of the sign and magnitude of the

\footnotetext{
${ }^{2} \mathrm{CoCkx}$ (2016) provides an overview of the literature on losses in employment and earnings experienced by those entering the labor market in economic downturns. Well-known studies include Genda et al. (2010), Kahn (2010), Hershbein (2012), Altonji et al. (2016), and Schwandt and von Wachter (2019) for the United States, Oreopoulos et al. (2012) for Canada, Genda et al. (2010) for Japan, Brunner and Kuhn (2014) for Austria, Cockx and Ghirelli (2016) for Flanders, van den Berge (2018) for the Netherlands, Raaum and Røed (2006) for Norway, and Fernández-Kranz and Rodríguez-Planas (2018) for Spain.
} 
effect (Hashimoto and Kondo, 2012; Hershbein, 2012; Kondo, 2012; Currie and Schwandt, 2014; Hofmann and Hohmeyer, 2016; Maclean et al., 2016; Schwandt and von Wachter, 2020). Our study contributes to the literature by showing that reduced labor market opportunities early in one's career can lead to a permanent change in marriage probability and fertility, especially in the case of a large-scale recession. Furthermore, we find that labor market entry conditions may affect the choice of spouse, especially among women. This result fills a gap in the literature, where previous studies have noted a sizable response in fertility, despite the short-lived reduction in own earnings among female recession cohorts (Kondo, 2015; Maclean et al., 2016; Schwandt and von Wachter, 2020).

Lastly, our results on the financial outcomes of scarred cohorts are closely related to Kawaguchi and Kondo (2020), the only existing study on the effects of labor market entry conditions on asset holdings and living arrangements. ${ }^{3}$ Kawaguchi and Kondo (2020) find that recession graduates migrating to low cost-of-living areas limits the effect of initial labor market conditions on family net worth. We show that recession graduates' asset building is substantially delayed in settings where such migration pattern is absent. Our result complements evidence in the recent unemployment insurance literature that asset holdings buffer consumption decline when unemployment occurs (e.g., Kolsrud et al., 2018; Ganong and Noel, 2019). In addition, we provide evidence that recession cohorts rely on their parents or spouse to protect their living conditions against the initial negative shock.

The remainder of the paper is organized as follows. Section 2 outlines the 1997-1998 Asian financial crisis and its impacts on the South Korean economy. Section 3 explains the empirical strategy used to measure the long-term effects of initial labor market conditions. Section 4 describes the KLIPS data and the analysis sample. Section 5 presents and discusses the estimation results on labor market, family, and financial outcomes. Section 6 provides several robustness checks. Section 7 concludes.

\footnotetext{
${ }^{3}$ Kawaguchi and Kondo (2020) find that penalties in the labor market do not affect living arrangements or asset building, using a sample of white male college graduates from the National Longitudinal Survey of Youth 1979 Cohort (NLSY79).
} 


\section{Background on the Asian Financial Crisis in South Korea}

The Asian financial crisis triggered the worst recession in Korean history since the Korean War in the 1950s. The high growth potential throughout the 1990s in South Korea and other East Asian countries attracted strong inflows of foreign funds, until the onset of the crisis (Radelet and Sachs, 2000). The sudden reversal of capital flows at the beginning of the crisis led to a sharp and deep downturn that had a devastating impact on the South Korean economy.

The Asian financial crisis began with a currency crisis in Thailand in July 1997, which spread rapidly to other countries. South Korea was one of the hardest hit, owing to its high proportion of short-term debt. ${ }^{4}$ With plummeting investor confidence, foreign creditors refused to roll over loans, which meant the government was forced to draw down foreign currency reserves to help financial institutions meet their short-term obligations. As foreign reserves dried up, the South Korean government requested financial assistance, agreeing to a bailout package worth USD 60 billion from the International Monetary Fund (IMF) on November 21, 1997.

The shock to the economy was substantial. South Korea's currency lost 46 percent of its value, and the stock market index dropped by 50 percent. The crisis spread rapidly beyond the financial sector. Eleven large conglomerates (i.e., chaebols) collapsed, and ten more were on the verge of bankruptcy (Lee, 1998). The crisis was particularly devastating for small and medium- sized companies (SMEs), which had no access to credit during the peak of the crisis. As a result, the number of SMEs filing for bankruptcy roughly doubled, from 11,600 in 1996 to 22,800 in $1998 .^{5}$

The crisis was not only severe, but also unexpected. The macroeconomic indicators before the crisis were sound; as a result, neither credit rating agencies nor the IMF expected such a rapid deterioration in the South Korean economy. Before the crisis, South Korea had enjoyed a sustained period of high economic growth, with a real GDP growth rate of more than 5 percent per year since 1981. For three consecutive years, from 1994 to 1996, the annual GDP growth rate reached 7-9 percent. Other economic measures were also robust: the inflation rate was stable at around

\footnotetext{
${ }^{4}$ In South Korea, 67 percent of total debt was short-term as of June 1997 (Goldstein, 1998).

${ }^{5}$ See Gregory et al. (2002) for a detailed discussion on the performance of SMEs in South Korea during the Asian financial crisis.
} 
5 percent per year, and the public sector budget was sound (Barnes et al., 2003); furthermore, the foreign debt-to-GDP ratio was below 30 percent (Kim, 2006). Reports on the South Korean economy showed optimism in 1996, and even in the first half of 1997 (Radelet and Sachs, 2000). As a result, individuals were largely unprepared for the crisis.

The Asian financial crisis had an acutely negative impact on the South Korean labor market. Employee downsizing was widespread, and massive layoffs occurred, with about 1.8 million workers (8.6 percent of all workers) losing their jobs (Lee, 2000). The unemployment rate more than doubled, from 2.6 in 1997 to 7.0 percent in 1998, and remained high at 6.4 percent in 1999. Young workers and first-time job seekers were particularly hard hit by the lack of job openings during the crisis. In 1998 and 1999, the unemployment rate for those aged 20 to 29 was over 10 percent, about 4 percentage points higher than the overall unemployment rate.

The impact of the Asian financial crisis on the South Korean economy is comparable to the effect of the Great Recession on the United States, in multiple dimensions. First, both crises resulted in the worst recession over the past half century in the affected country. In the United States, the economy lost 8.8 million payroll jobs, a decline of about 6 percent between January 2008 and February 2010 (Kalleberg and von Wachter, 2017). Young workers particularly suffered, with youth unemployment rate increasing by about 6 percentage points in both countries. ${ }^{6}$ Also, a wide breadth of industries was affected by the two crises. During the Great Recession, a significant decline in employment was observed not only in the traditionally procyclical sectors, such as manufacturing or construction, but also in the financial sector, which had been relatively intact in previous recessions (U.S. Bureau of Labor Statistics, 2012). Similarly, the banking sector in South Korea went through extensive restructuring, with numerous financial institutions closed or merged shortly after the crisis.

\footnotetext{
${ }^{6}$ The youth unemployment rate in South Korea doubled from 5.3 percent in 1997 to 11.4 percent in 1998 . In the United States, the proportion of individuals aged 20 to 25 who were neither working nor in school rose from 13.1 percent in 2007 to a peak of 19.0 percent in 2013 (Rothstein, 2019).
} 


\section{Empirical Strategy}

In this section, we describe the regression models used to measure the recession effects, and elaborate on the identification assumption. To measure the long-term effect of graduating during a recession on various individual outcomes, we estimate a standard regression model in the scarring literature, exploiting across-cohort variation in national or regional unemployment rates at college graduation.

The regression specifications vary depending on the type of outcome variable, because there is far more year-to-year variation in labor market and financial outcomes than there is in family formation outcomes. First, we measure the effect of labor market entry conditions on time-varying outcomes (e.g., employment, earnings, expenditures, and asset holdings) by estimating the following regression equation:

$$
y_{i t}=\alpha+\beta_{e} U R_{c}+\mathbf{X}_{i}^{\prime} \gamma+f(c)+\delta_{r}+\phi_{t}+\tau_{e}+\varepsilon_{i t},
$$

where $y_{i t}$ is the outcome of interest for person $i$ (who graduated from college in year $c$ and region $r$ ) in calendar year $t .^{7} U R_{c}$ is the national unemployment rate, measured in the year of graduation $c$. When we use the regional unemployment rate instead of the national rate, $U R_{c}$ is replaced by $U R_{c r}$, measured in the year $c$ and region $r$ of college graduation. The index $e$ denotes years of potential labor market experience (i.e., years since college graduation, $e \equiv t-c$ ). A vector of person $i$ 's predetermined characteristics $\mathbf{X}_{i}$, such as father's education level, parents' job status at age 14, the type of college attended (two- vs. four-year), controls for baseline ability and family background. $f(c)$ is a cubic function of college graduation year $c$ (i.e., graduation cohort) that captures a smooth national cohort trend in the economic conditions at labor market entry. The regression also includes fixed effects for region of college graduation $\left(\delta_{r}\right)$, calendar year $\left(\phi_{t}\right)$, and years of potential experience $\left(\tau_{e}\right){ }^{8} \varepsilon_{i t}$ is the error term representing the remaining unobserved

\footnotetext{
${ }^{7}$ The region in which a person graduates from college is given by the location of the college.

${ }^{8}$ It is not feasible to control for cohort, calendar year, and years of potential experience in the same regression without imposing a restriction (Deaton, 1997). To avoid the perfect multicollinearity problem, we follow the literature (e.g., Oreopoulos et al., 2012; Cockx and Ghirelli, 2016; Schwandt and von Wachter, 2019) and exclude one additional
} 
determinants of the outcome. Standard errors are clustered at the level of graduation year by region.

We allow for the effect of initial labor market conditions to be heterogeneous with potential experience by interacting the initial unemployment rate (i.e., $U R_{c}$ or $U R_{c r}$ ) with indicator variables for years since college graduation. Here, $\beta_{e}$ represents a set of coefficients on these interaction terms. Given the included controls, $\beta_{e}$ measures changes in the experience profile of a timevarying outcome (e.g., employment, earnings, expenditures, or asset values) associated with a 1 percentage point increase in the unemployment rate at labor market entry.

When we estimate the overall effect, instead of heterogeneous effects by years since graduation, equation (1) simplifies to:

$$
y_{i t}=\alpha+\beta U R_{c}+\mathbf{X}_{i}^{\prime} \gamma+f(c)+\delta_{r}+\phi_{t}+\tau_{e}+\varepsilon_{i t},
$$

where $\beta$ measures the average effect of a 1 percentage point change in the initial unemployment rate on the time-varying outcome over a certain period of one's career. We calculate the average effect over the first 10 years of potential experience in the labor market, to provide point estimates for earnings that can be compared with the results of previous studies. The control variables are the same as those for equation (1).

Second, family formation outcomes exhibit little year-to-year variation after an individual reaches a certain age; thus, we focus on the cumulative status rather than on yearly changes. We collapse multiple waves of the panel data into a single cross section and estimate the following specification:

$$
y_{i}=\alpha+\beta U R_{c}+\mathbf{X}_{i}^{\prime} \gamma+f(c)+\delta_{r}+\tau_{e}+\varepsilon_{i} .
$$

We construct several types of $y_{i}$ related to family formation status, as of the most recent year in which person $i$ participated in the survey. The outcome variables include whether an individual has ever been married, age at first marriage, whether an individual has any children, number of calendar year dummy. This practice implicitly assumes that the magnitudes of the contemporaneous shocks in the labor market are the same in the two omitted years. The results are robust to dropping calendar year fixed effects. 
children, and age at first childbirth. $\tau_{e}$ represents the fixed effects for years since college graduation, as of the most recent year of survey participation. ${ }^{9}$ When the dependent variable is age at first marriage or age at first childbirth, we employ censored regressions and duration analyses instead of the ordinary least squares (OLS) method in order to account for right-censoring in duration until the initiation of marriage or childbirth.

In all regression specifications, the identification relies on sharp deviations from a smooth long-term cohort trend in unemployment rates, driven mainly by the unexpected occurrence of the Asian financial crisis. The key assumption is that this temporal variation in the unemployment rate at labor market entry is not systematically related to the composition of each graduation cohort, once a common smooth trend has been removed. In Section 6.1, we examine the validity of this identification assumption, and show that our results are unlikely to be driven by selection. The cubic function of college graduation year $f(c)$ controls for any smooth changes across cohorts, not only in initial labor market conditions, but also in the composition of graduation cohorts and in the outcome variables. Examples include changes in the average quality of college graduates, due to a secular increase in college enrollment rate and a long-term decline in the fertility rate. $f(c)$ also captures any spillover effects of a recession, distributed smoothly across cohorts.

We use a polynomial function $f(c)$ rather than fixed effects for college graduation year, to control for a national cohort trend, because there is a strong comovement in regional unemployment rates in South Korea, unlike in the United States or Canada. The correlations between the regional and national annual unemployment rates for the period between 1989 and 2014 range from 0.89 to 0.98. In this case, the fixed effects for college graduation year would attribute most of the variation from business cycles to a secular trend. ${ }^{10}$ The comovement in unemployment rates is presented in Figure 2, where the solid line denotes the national unemployment rate, and the various bullet

\footnotetext{
${ }^{9} \mathrm{By}$ controlling for college graduation year $f(c)$ and years of potential experience $\tau_{e}$, we effectively control for the survey year in which each person's family formation outcome is observed. The results are robust to controlling for fixed effects for the most recent year of survey participation, which are equivalent to the calendar year fixed effects in equation (1) or (2).

${ }^{10}$ Studies on the "scarring effect" in small European countries also use a parametric specification for cohort trends. For example, see Cockx and Ghirelli (2016) for the case of Belgium.
} 


\section{A. Raw}

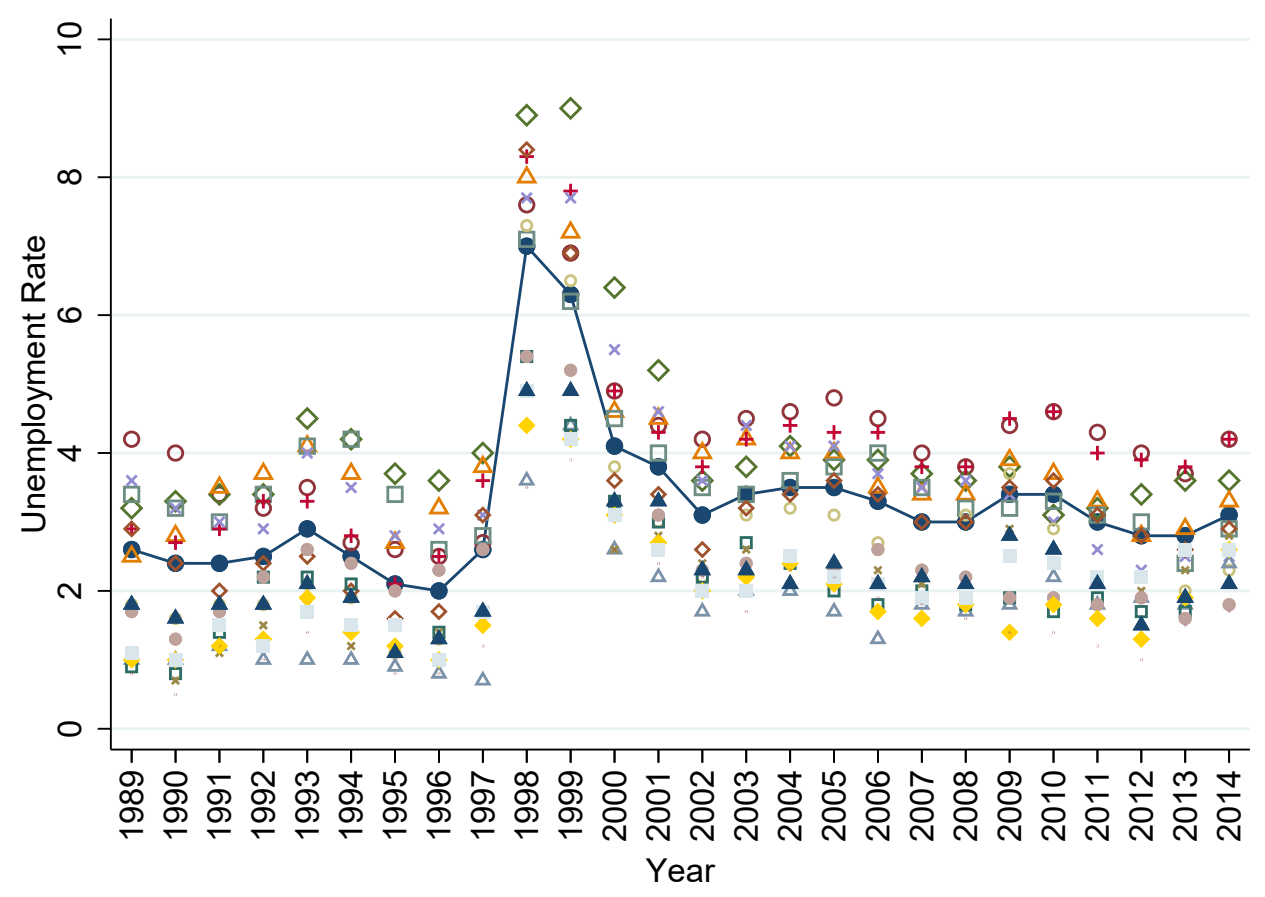

\section{B. Detrended}

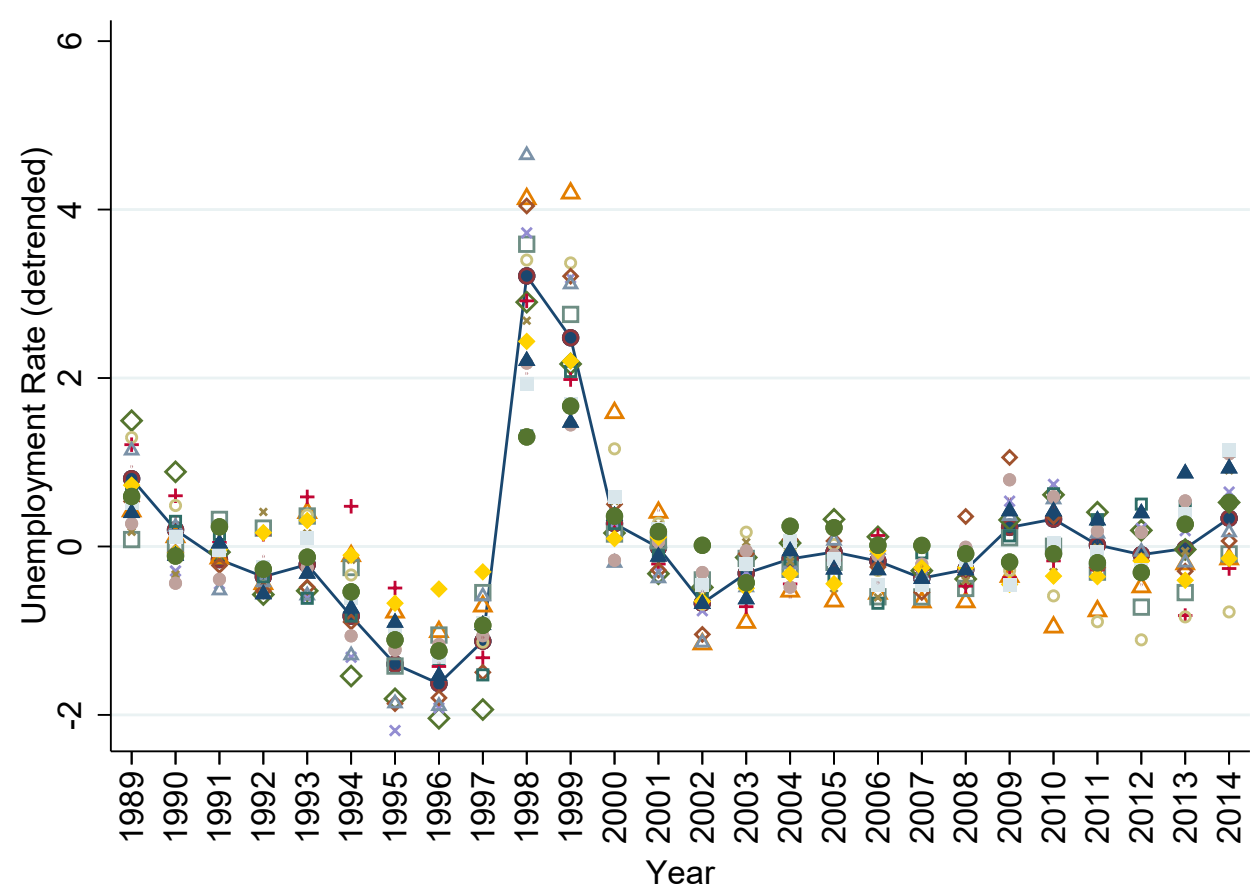

Figure 2: National and Regional Unemployment Rates

Notes. The solid line displays the national unemployment rate, and the various bullet shapes indicate regional unemployment rates. Regions refer to major administrative divisions, which include 9 provinces (Gyeonggi, Gangwon, North Chungcheong, South Chungcheong, North Jeolla, South Jeolla, North Gyeongsang, South Gyeongsang, and Jeju) and 7 major cities (Seoul, Busan, Daegu, Incheon, Gwangju, Daejeon, and Ulsan). The detrended series in panel $\mathrm{B}$ shows the residuals from a regression in which we control for a cubic function of years and region fixed effects. 
shapes indicate the unemployment rates in 16 regions. ${ }^{11}$ Panel A presents the raw unemployment rates, and panel $\mathrm{B}$ shows the residuals after a cubic time trend and the region fixed effects have been removed.

Although we use both national and regional unemployment rates in the regression analysis, following Kahn (2010), Oreopoulos et al. (2012), and Altonji et al. (2016), we consider the national unemployment rate to be the main treatment variable, and report the results for the regional regressions in the online appendix. ${ }^{12}$ Studies on the U.S. labor market note that the national rather than the local economy is more relevant for college graduates, because they exhibit high regional mobility in response to labor market opportunities (Wozniak, 2010; Altonji et al., 2016). The inter-regional mobility among college graduates is expected to be higher in South Korea than in the United States or Canada, because South Korea is relatively small (geographically, about the same size as the state of Indiana in the United States), and jobs for college graduates are concentrated in and near Seoul, the capital and largest city in the country. Indeed, about 60 percent of individuals in our analysis sample moved to a different region after college graduation.

\section{Data and Analysis Sample}

We use the yearly unemployment rates from 1989 to 2010, compiled from the Economically Active Population Survey (EAPS) by Statistics Korea. ${ }^{13}$ The national unemployment rates are available from 1963 onward. The regional unemployment rates are calculated from the labor force statistics on the size of the working age population, number of people in the labor force, and employmentto-population ratio by region. These regional statistics are also constructed from the EAPS by Statistics Korea, and are available from 1989 onward.

\footnotetext{
${ }^{11}$ A "region" in our study refers to a major administrative division. South Korea consists of 16 administrative divisions, including 9 provinces (Gyeonggi, Gangwon, North Chungcheong, South Chungcheong, North Jeolla, South Jeolla, North Gyeongsang, South Gyeongsang, Jeju) and 7 major cities (Seoul, Busan, Daegu, Incheon, Gwangju, Daejeon, Ulsan).

${ }^{12}$ When we use the regional unemployment rate $U R_{c r}$, we exploit region-specific deviations from national changes over time, rather than using nation-wide variations.

${ }^{13}$ The EAPS is comparable to the Current Population Survey (CPS) in the United States.
} 
We construct our analysis sample using data from the Korean Labor and Income Panel Study (KLIPS). The KLIPS is an annual longitudinal study of a representative sample of South Korean households (and individuals therein) in urban areas. ${ }^{14}$ The Korea Labor Institute has collected, maintained, and published the KLIPS data since 1998. We pool waves 1 through 20 of the KLIPS, spanning 1998-2017. The first wave includes 5,000 households (13,321 individuals aged 15 and over), and the 20th wave includes 7,066 households (14,477 individuals aged 15 and over). In 2009 (the 12th wave), 1,415 households were added to the original sample.

Our analysis sample includes individuals who graduated from two- or four-year colleges between 1989 and 2010. We restrict our analysis to those who graduated between the ages of 20 and 32 to focus on first-time labor market entrants, and to exclude atypical cases in which a college degree is pursued long after completing secondary education. We also exclude individuals who graduated from college outside of South Korea. This leaves a sample of 2,474 men and 2,320 women. The number of observations at the person-year level is 22,856 for males and 20,795 for females.

To construct the treatment, outcome, and control variables, we use information from three components of the KLIPS: the household survey, person survey, and work history record. The household survey collects demographic information on all household members and household characteristics, such as income, expenditures, wealth, and housing arrangements. The person survey data contains detailed information on work, education, and family formation for household members aged 15 or above. The work history record provides a full employment history of the person survey respondents from their first to their most recent jobs.

Table 1 reports the summary statistics for the variables used in the main analysis. The variables are classified into five categories. Panel A presents the treatment variables, including the national and regional unemployment rates and a dummy variable indicating whether an individual graduated from college in 1998 or 1999 (during the Asian financial crisis). Panel B shows time-invariant

\footnotetext{
${ }^{14}$ The KLIPS is comparable to the Panel Study of Income Dynamics (PSID) in the United States with respect to its panel structure and the scope of questions. Both the PSID and the KLIPS are included in the Cross-National Equivalent File, along with household longitudinal studies from several other countries.
} 
Table 1: Summary Statistics

\begin{tabular}{|c|c|c|c|c|c|c|}
\hline & \multicolumn{3}{|c|}{ Men } & \multicolumn{3}{|c|}{ Women } \\
\hline & Mean & SD & Obs. & Mean & SD & Obs. \\
\hline \multicolumn{7}{|l|}{ A. Treatment variables } \\
\hline Year of graduation & 2,000 & [5.958] & 2,474 & 2,000 & {$[5.526]$} & 2,320 \\
\hline National unemployment rate at graduation & 3.476 & [1.379] & 2,474 & 3.587 & [1.419] & 2,320 \\
\hline Regional unemployment rate at graduation & 3.544 & [1.633] & 2,474 & 3.667 & [1.709] & 2,320 \\
\hline Graduation in 1998 or 1999 & 0.127 & {$[0.333]$} & 2,474 & 0.144 & {$[0.351]$} & 2,320 \\
\hline \multicolumn{7}{|l|}{ B. Background characteristics } \\
\hline Attended 4-year college & 0.656 & {$[0.475]$} & 2,474 & 0.546 & {$[0.498]$} & 2,320 \\
\hline Father's years of education & 10.32 & [3.780] & 2,426 & 11.11 & [3.463] & 2,292 \\
\hline Father's education missing & 0.019 & {$[0.138]$} & 2,474 & 0.012 & {$[0.109]$} & 2,320 \\
\hline \multicolumn{7}{|l|}{ Parents' job status at age 14} \\
\hline Standard worker & 0.410 & [0.492] & 2,401 & 0.446 & [0.497] & 2,262 \\
\hline Non-standard worker & 0.072 & {$[0.259]$} & 2,401 & 0.069 & {$[0.253]$} & 2,262 \\
\hline Business owner (with employees) & 0.125 & {$[0.330]$} & 2,401 & 0.145 & {$[0.353]$} & 2,262 \\
\hline Business owner (no employee) & 0.376 & [0.485] & 2,401 & 0.326 & [0.469] & 2,262 \\
\hline Parents' job status at age 14 missing & 0.030 & [0.169] & 2,474 & 0.025 & {$[0.156]$} & 2,320 \\
\hline \multicolumn{7}{|l|}{ C. Labor market outcomes } \\
\hline Employed & 0.897 & {$[0.304]$} & 22,856 & 0.578 & [0.494] & 20,795 \\
\hline Monthly earnings $a$ & 2,871 & {$[2,277]$} & 22,617 & 1,145 & {$[1,350]$} & 20,686 \\
\hline Monthly earnings (employed only) ${ }^{a}$ & 3,206 & {$[2,171]$} & 20,254 & 1,990 & {$[1,219]$} & 11,906 \\
\hline Log monthly earnings $b$ & 13.17 & [4.736] & 22,617 & 8.04 & [7.160] & 20,686 \\
\hline Log monthly earnings (employed only) ${ }^{b}$ & 14.86 & {$[0.505]$} & 20,051 & 14.40 & {$[0.538]$} & 11,549 \\
\hline Work hours per week (employed only) & 49.01 & [11.81] & 20,483 & 42.29 & {$[11.77]$} & 12,004 \\
\hline Full-time employment (wage workers only) & 0.984 & {$[0.127]$} & 17,132 & 0.922 & {$[0.268]$} & 10,192 \\
\hline Standard employment (wage workers only) & 0.898 & {$[0.302]$} & 16,678 & 0.788 & {$[0.409]$} & 9,922 \\
\hline Self-employed & 0.137 & {$[0.344]$} & 22,856 & 0.069 & {$[0.254]$} & 20,795 \\
\hline \multicolumn{7}{|l|}{ D. Family formation outcomes } \\
\hline Ever married & 0.726 & [0.446] & 2,474 & 0.714 & {$[0.452]$} & 2,320 \\
\hline Age at first marriage & 30.00 & [3.584] & 1,715 & 27.85 & [3.359] & 1,589 \\
\hline Any children & 0.639 & {$[0.480]$} & 2,474 & 0.625 & {$[0.484]$} & 2,320 \\
\hline Any children (ever married only) & 0.880 & {$[0.325]$} & 1,796 & 0.876 & {$[0.330]$} & 1,656 \\
\hline Number of children & 1.126 & [0.981] & 2,474 & 1.096 & {$[0.985]$} & 2,320 \\
\hline Number of children (ever married only) & 1.551 & [0.817] & 1,796 & 1.535 & {$[0.828]$} & 1,656 \\
\hline Age at first childbirth & 31.31 & [3.518] & 1,581 & 29.18 & [3.394] & 1,450 \\
\hline \multicolumn{7}{|l|}{ E. Financial outcomes and living arrangements } \\
\hline Monthly expenditure per capita ${ }^{a}$ & 885.8 & [469.3] & 20,706 & 865.5 & [436.0] & 18,808 \\
\hline Value of debt ${ }^{a}$ & 46,039 & {$[112,724]$} & 22,268 & 49,847 & {$[107,755]$} & 20,305 \\
\hline Value of financial assets ${ }^{a}$ & 28,539 & {$[65,462]$} & 22,267 & 29,456 & {$[63,059]$} & 20,302 \\
\hline Value of deposits $a$ & 19,051 & {$[51,967]$} & 22,089 & 19,814 & {$[48,158]$} & 20,128 \\
\hline Value of financial assets excluding deposits $a$ & 9,641 & {$[31,080]$} & 22,266 & 9,812 & {$[34,385]$} & 20,302 \\
\hline Log monthly expenditure per capita ${ }^{b}$ & 13.57 & {$[0.495]$} & 20,706 & 13.56 & [0.482] & 18,808 \\
\hline $\log \operatorname{debt}^{b}$ & 9.28 & [8.848] & 22,268 & 9.36 & [8.889] & 20,305 \\
\hline Log financial assets ${ }^{b}$ & 12.97 & [7.012] & 22,267 & 13.22 & {$[6.865]$} & 20,302 \\
\hline Log deposits ${ }^{b}$ & 11.11 & [7.726] & 22,089 & 11.36 & [7.648] & 20,128 \\
\hline Log financial assets excluding deposits $b$ & 6.68 & [8.012] & 22,266 & 6.83 & {$[8.036]$} & 20,302 \\
\hline Home ownership & 0.626 & {$[0.484]$} & 22,256 & 0.642 & {$[0.480]$} & 20,296 \\
\hline Living with parents & 0.261 & {$[0.439]$} & 22,856 & 0.291 & {$[0.454]$} & 20,795 \\
\hline
\end{tabular}

Notes. The number of observations varies due to missing values. The analysis sample includes 2,474 men and 2,320 women. The number of observations at the person-year level is 22,856 for males and 20,795 for females. Family formation outcomes are as of the most recent year in which an individual participated in the survey. Standard deviations in brackets.

${ }^{a}$ In thousands of $2015 \mathrm{KRW}$, where 1 USD is worth approximately 1,100 KRW.

${ }^{b}$ Before taking the logarithm, the values are inflation-adjusted to $2015 \mathrm{KRW}$ and zeros are imputed with $1 \mathrm{KRW}$. 
background characteristics. Labor market, family formation, and asset formation outcomes are described in panels $\mathrm{C}, \mathrm{D}$, and E, respectively.

The treatment variables in panel A and the control variables in panel B are constructed using the person survey data. The year and region of college graduation are merged with the national and regional unemployment rates. An average person in our analysis sample experienced an unemployment rate of around 3.5 percent at college graduation. Background characteristics, including father's educational attainment and parents' job status at age 14, are also available from the person survey data. ${ }^{15}$

Panel $\mathrm{C}$ reports the variables on labor market outcomes, including employment status and monthly earnings (in thousands of 2015 South Korean won (KRW)). ${ }^{16}$ The annual person survey collects information on each individual's current labor market outcomes, including work status and average monthly earnings, at the time of the survey. Because the KLIPS started in 1998, the early career outcomes for those who graduated from college prior to 1998 are not available in the person survey data. For employment status, this gap can be filled by information on retrospective jobs from the work history record. However, earnings and other characteristics of retrospective jobs recorded in the work history file are mostly missing or are too crude for our analysis. ${ }^{17}$ Therefore, we use the person survey data for the main analysis, and use the work history record to check whether missing information on retrospective jobs biases our results. In the online appendix, we show that our regression results on employment outcomes are robust to including observations from the work history record (see Figure S1).

Panel D shows the marriage and fertility variables from the person and household surveys. In the person survey, respondents report their marital status every year, but describe fertility history only once when entering the KLIPS for the first time. Because of this survey structure, the per-

\footnotetext{
${ }^{15}$ The KLIPS data also include variables on other background characteristics, such as mother's education and socioeconomic status at age 14. We do not use these variables in the main regression analysis because they are added in later waves of the KLIPS and, thus, are missing for 14-25 percent of the individuals in the analysis sample.

${ }^{16}$ One U.S. dollar (USD) is worth approximately 1,100 KRW.

${ }^{17}$ For example, the work history file records a single average of monthly earnings from all retrospective jobs that each person had over the entire pre-KLIPS period. Although respondents are asked to report working hours, fringe benefits, and establishment characteristics of retrospective jobs, the response rate is extremely low on these questions.
} 
son survey is unable to capture subsequent changes in childbearing. Thus, we supplement each respondent's fertility history by matching the person survey respondents with their children in the household survey using information on household membership.

In panel $\mathrm{E}$, we report the variables on consumption and asset holdings from the household survey. ${ }^{18}$ As a proxy for consumption, we use average monthly household expenditure per capita in the year of the survey. The survey also collects detailed information on the stock of debt, financial assets, and real estate at the time of the survey. Total debt is calculated as the sum of debt outstanding from financial institutions and nonfinancial agents. We have data on asset balances by financial asset type (i.e., bank deposit accounts, stocks, bonds, mutual funds, savings insurance, rotating savings and credit associations, or private lending). Information on home ownership and the market value of housing is also reported in the survey. All monetary values are inflationadjusted to $2015 \mathrm{KRW}$.

We conduct a separate analysis by gender, because men and women face different choice sets and constraints in work and family life. With the country's deeply rooted Confucian tradition, traditional gender roles are still prevalent in South Korea. Men are considered the breadwinners, and bear more of the financial burden at the time of marriage by purchasing a house or contributing a much larger share of the housing price. Women carry out most of the housework and childcare duties, and tend to drop out of the labor force after marriage or childbirth. Notably, only men, unless granted exemption, are required to fulfill a military service obligation, a term of 2-3 years. These gender differences are reflected in Table 1. While 80 percent of men are employed, only 59 percent of women are working. Despite the equal likelihood of marriage and childbirth for men and women, there is a two-year gender difference in the age at first marriage and in the age of having the first child. On average, men (women) get married at age 30 (28) and have their first childbirth at age 31 (29).

\footnotetext{
${ }^{18}$ The information on expenditures, debt, financial assets, and home ownership is reported from the second wave onward in the KLIPS.
} 


\section{Results}

\subsection{Employment and Earnings}

We begin by examining the effects of labor market entry conditions on employment and earnings. Although our main focus is on longer-term social and financial outcomes, such as marriage, childbearing, consumption, and asset building, it is important to first compare our results on labor market outcomes with those of previous studies on the scarring effect.

During a recession, new labor market entrants experience prolonged unemployment or placement in lower quality or mismatched jobs. The scarring literature shows that earnings losses resulting from limited job opportunities at the beginning of an individual's career can last for a decade. This is because search frictions tend to prevent earnings from catching up through job-tojob moves. This delay can be exacerbated by slower post-schooling human capital accumulation if job market entrants in a recession have fewer training opportunities during the period of initial unemployment or in a poorly matched job.

Estimation Results. Figure 3 measures changes in the experience profiles of employment and earnings due to variations in the initial unemployment rate by estimating equation (1). Figure 4 shows the estimated effects on the experience profiles of various job quality measures. ${ }^{19}$ In Table 2, we average out the estimated recession effects on employment and earnings for the first 10 years since college graduation by estimating equation (2).

The results on employment and earnings for men are displayed in the left column of Figure 3. Panel A1 shows that men who graduate from college in a recession are less likely to be employed for up to 12 years after graduation. A 1 percentage point higher unemployment rate at college graduation is associated with a 4.8 percentage point lower employment probability (5.4 percent relative to the sample average of 0.897 ) in the first year after graduation. The negative effect temporarily disappeared in experience years 2-3 due to an increase in self-employment (see panel

\footnotetext{
${ }^{19}$ Tables S1 and S2 in the online appendix report the coefficient estimates, standard errors, and dependent variable averages for the labor market outcomes described in Figures 3 and 4, respectively.
} 

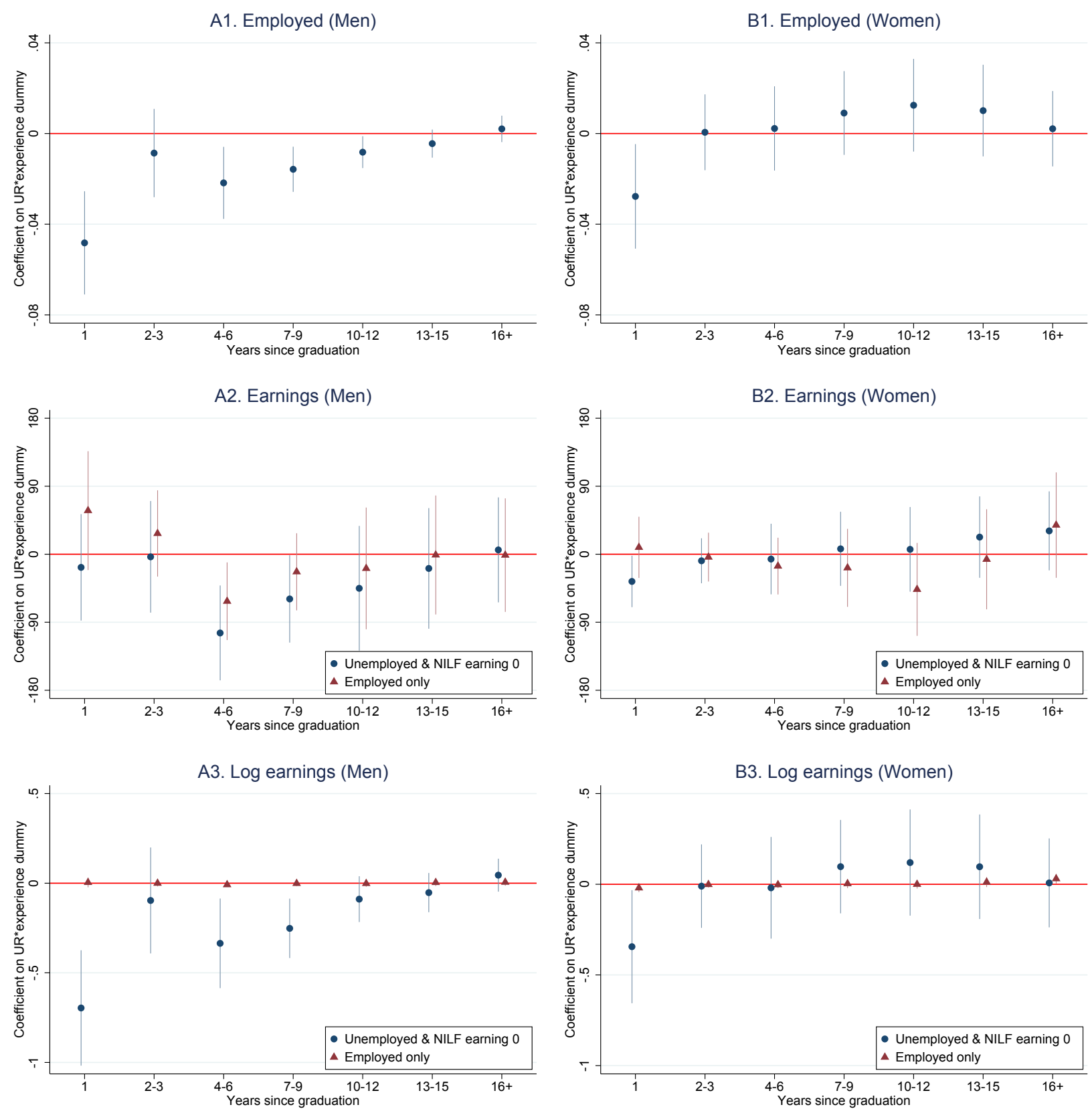

Figure 3: Effects of National Unemployment Rate at Graduation on Employment and Earnings

Notes. Monthly earnings in levels are in thousands of 2015 KRW, where 1 USD is worth approximately 1,100 KRW. We take the logarithm of monthly earnings in $2015 \mathrm{KRW}$. When constructing log monthly earnings for individuals who are unemployed or not in the labor force, we impute zero earnings with $1 \mathrm{KRW}$ before taking the logarithm. Each dot represents the coefficient estimate on an interaction term between the national $U R$ and a potential experience dummy. Vertical spikes around each point estimate represent the $95 \%$ confidence interval, constructed using robust standard errors clustered at the level of graduation year by region. Regressions include a cubic function of college graduation year, and fixed effects for the region of college graduation, years since graduation, and calendar year. Controls for background characteristics include father's years of education, father's years of education squared, dummies for parents' job status at age 14 (standard worker, non-standard worker, business owner hiring employees, business owner with no employee), and an indicator for 4-year college graduates. Missing values in background covariates are imputed using mean values, and dummies for missing observations are also controlled for. 
A1 of Figure 4); however, it becomes statistically significant again, with a point estimate of -2.2 percentage points, in experience years $4-6$. The effect gradually decays to -0.8 percentage points during the subsequent 7 to 12 years after graduation, and becomes statistically indistinguishable from zero thereafter.

Panels A2 and A3 of Figure 3 present the recession effects on the experience profiles of male earnings. We examine monthly earnings (in thousands of $2015 \mathrm{KRW}$ ) in panel A2, and the natural logarithm of monthly earnings (in $2015 \mathrm{KRW}$ ) in panel A3. When we consider both extensive and intensive margin effects, assuming that nonworkers have zero earnings, a high unemployment rate at graduation causes lower earnings, both in levels and in logs, for 9 years since graduation. ${ }^{20}$ The negative effect on earnings converges to zero at around the 10th year after graduation. When we restrict our analysis to the employed only, the negative effect on earnings in levels is statistically significant at the 5 percent level only for 4-6 years after graduation. In addition, there is no significant effect on log earnings at the 10 percent level. This result implies that the earnings penalty for male recession cohorts is mainly on the extensive margin.

In panels A1 and A2 of Figure 4, we find no evidence of lower job quality for male recession cohorts in terms of weekly hours of work or the probability of having a full-time or standard employment arrangement. ${ }^{21}$ In panel A3, we find an increase in the likelihood of being self-employed in experience years $2-3$, suggesting that those who could not find a job in the first year after graduation may have resorted temporarily to being self-employed. The absence of deterioration in job quality among recession graduates can potentially be explained by the pattern that fewer job openings in an economic downturn are likely to be filled by candidates with higher earnings potential. This is consistent with the recession effect on earnings being small for those who have found a job.

The next set of results show the labor market outcomes for female college graduates. In the

\footnotetext{
${ }^{20}$ Zero earnings for individuals who are unemployed or not in the labor force are imputed as 1 KRW before taking the logarithm.

${ }^{21}$ Work hours are reported for the employed, including wage workers and the self-employed. The probability of having a full-time or standard employment arrangement is conditioned on being a wage worker. The International Labour Organization (ILO) defines non-standard forms of employment as employment arrangements that deviate from standard employment, listing temporary employment, part-time and on-call work, temporary agency work and other multiparty employment relationships as examples. In South Korea, workers on a non-standard employment contract are often called "non-regular" workers, as apposed to "regular" workers on a standard employment contract.
} 

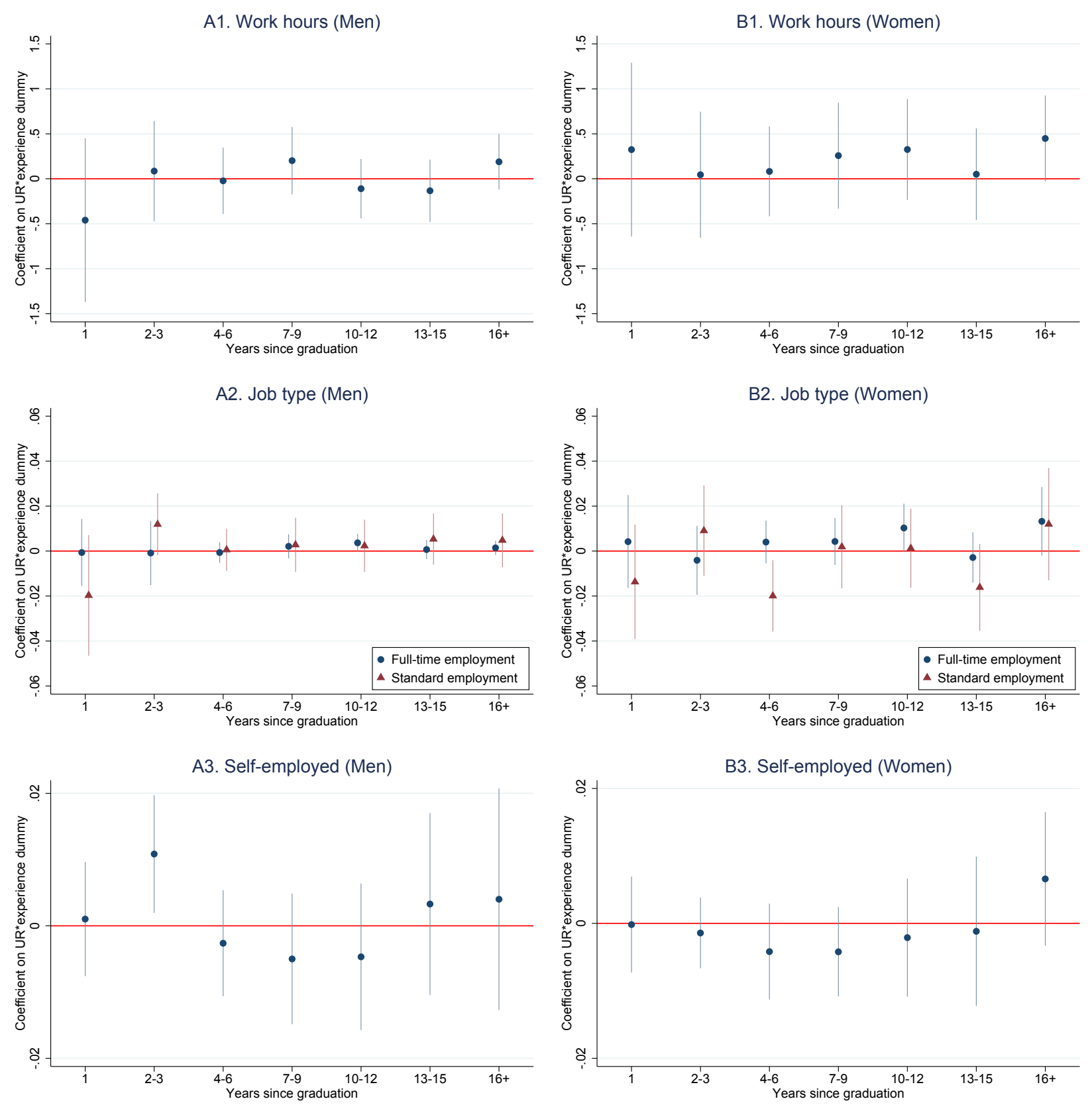

Figure 4: Effects of National Unemployment Rate at Graduation on Job Quality

Notes. Work hours are examined for the employed. The probability of having a full-time or standard employment arrangement is analyzed for wage workers. Each dot represents the coefficient estimate on an interaction term between the national $U R$ and a potential experience dummy. Vertical spikes around each point estimate represent the 95\% confidence interval, constructed using robust standard errors clustered at the level of graduation year by region. Regressions include a cubic function of college graduation year, and fixed effects for the region of college graduation, years since graduation, and calendar year. Controls for background characteristics include father's years of education, father's years of education squared, dummies for parents' job status at age 14 (standard worker, non-standard worker, business owner hiring employees, business owner with no employee), and an indicator for 4-year college graduates. Missing values in background covariates are imputed using mean values, and dummies for missing observations are also controlled for. 
right column of Figure 3, we find that the effects of the initial labor market conditions on the employment and earnings of women are smaller in magnitude and less persistent than those of men. Panel B1 shows that a 1 percentage point higher unemployment rate at graduation lowers the first-year employment likelihood by 2.8 percentage points ( 4.8 percent relative to the sample average of 0.578). The negative effect disappears in two years because a substantial number of women in South Korea drop out of the labor force after marriage or childbirth. ${ }^{22}$ The experience profile of a typical non-recession graduate in our data shows a decrease in employment probability from two years after graduation, with the largest decrease occurring in the 10th year of potential experience. This pattern reflects the M-shaped age profile of female labor force participation. Panels B2 and B3 present that the negative effect on earnings disappears within two years of labor market entry.

Although the penalties for women on employment and earnings are short-lived, female recession cohorts who remain employed have less job security than their luckier counterparts. Panel B2 of Figure 4 shows that female wage workers from recession cohorts are significantly less likely to have a standard employment arrangement in experience years 4-6, which is approximately when a typical female college graduate gets married and gives birth to her first child. Other measures of job quality, including work hours in panel B1 or self-employment probability in panel B3, are not affected by the initial labor market conditions.

In Table 2, we compute the average effect of the initial unemployment rates on employment and earnings during the first 10 years of potential experience to facilitate a comparison with the results of previous research. We find statistically significant effects only for men, and only when the extensive margin effects are applicable. Panel A shows our benchmark estimates of labor market penalties for men, averaged over 10 years after graduation: a 1 percentage point increase in the unemployment rate at graduation reduces the likelihood of employment by 1.6 percentage points (1.9 percent relative to the sample average of 0.856$)$, and reduces real monthly earnings by

\footnotetext{
${ }^{22}$ The female labor force participation rate in South Korea has gradually increased during the past few decades, but is still below 53 percent as of 2019 (source: ILOSTAT database).
} 
Table 2: Average Effects of National Unemployment Rate at Graduation on Employment and Earnings (Experience Years 1-10)

\begin{tabular}{lccccc}
\hline & Employed & Earnings $^{a}$ & $\begin{array}{c}\text { Earnings }^{a} \\
\text { (employed only) }\end{array}$ & Log earnings $^{b}$ & $\begin{array}{c}\text { Log earnings } \\
\text { (employed only) }\end{array}$ \\
\hline $\boldsymbol{A . ~ M e n ~}$ & $(1)$ & $(2)$ & $(3)$ & $(4)$ & $(5)$ \\
National $U R$ & $-0.016^{* * * *}$ & $-58.7^{* * *}$ & -26.9 & $-0.245^{* * *}$ & -0.002 \\
& $(0.005)$ & $(21.3)$ & $(19.3)$ & $(0.077)$ & $(0.006)$ \\
Adjusted $R^{2}$ & 0.078 & 0.161 & 0.140 & 0.087 & 0.224 \\
Observations & 11,954 & 11,807 & 10,080 & 11,807 & 9,976 \\
Mean of $Y$ & 0.856 & $2,234.1$ & $2,616.9$ & 12.408 & 14.685 \\
\hline B. Women & & & & & \\
National $U R$ & 0.005 & 2.0 & -14.6 & 0.044 & -0.002 \\
& $(0.007)$ & $(17.4)$ & $(16.5)$ & $(0.097)$ & $(0.009)$ \\
Adjusted $R^{2}$ & 0.028 & 0.042 & 0.140 & 0.032 & 0.151 \\
Observations & 11,339 & 11,278 & 6,764 & 11,278 & 6,665 \\
Mean of $Y$ & 0.602 & $1,086.3$ & $1,811.2$ & 8.464 & 14.322 \\
\hline Notes. Mons & & & & & \\
\hline
\end{tabular}

Notes. Monthly earnings are inflation-adjusted to $2015 \mathrm{KRW}$, where 1 USD is worth approximately 1,100 KRW. Regressions include a cubic function of college graduation year, and fixed effects for the region of college graduation, years since graduation, and calendar year. Controls for background characteristics include father's years of education, father's years of education squared, dummies for parents' job status at age 14 (standard worker, non-standard worker, business owner hiring employees, business owner with no employee), and an indicator for 4-year college graduates. Missing values in background covariates are imputed using mean values, and dummies for missing observations are also controlled for. Robust standard errors in parentheses are clustered at the level of graduation year by region. * $p<0.10, * * p<0.05, * * * p<0.01$

${ }^{a}$ In thousands of $2015 \mathrm{KRW}$.

${ }^{b}$ When constructing log earnings for individuals who are unemployed or not in the labor force, we impute zero earnings with $1 \mathrm{KRW}$ before taking the logarithm.

$59 \mathrm{~K}$ KRW (2.6 percent relative to the sample average of $2,234 \mathrm{~K} \mathrm{KRW)}{ }^{23}$

Discussion. Our estimate on male earnings is in line with the results of Kahn (2010) and Oreopoulos et al. (2012) with respect to the magnitude and persistence. ${ }^{24}$ These studies focus on male college graduates in the United States and Canada, respectively, finding that a 1 percentage point increase in the initial unemployment rate leads, on average, to a $1-5$ percent reduction in earnings

\footnotetext{
${ }^{23}$ Given that the earnings penalty is mainly the result of nonemployment, it is difficult to interpret the large negative estimates on log earnings in column (4) of Table 2, because they are sensitive to how zero earnings are imputed.

${ }^{24}$ In contrast to our study, Han (2018) finds no effect of initial labor market conditions on employment or earnings among college graduates in South Korea. He focuses on more recent cohorts, most of whom graduated in the 2000s, and relies on an identification strategy that exploits region-specific changes in the unemployment rate. It is also likely that, in his study, a large portion of the meaningful variation in the national-level business cycles is absorbed by cohort fixed effects, as we point out in Section 3.
} 
over the first 10 years of potential experience; furthermore, the negative effect persists for 9-15 years.

In our setting, however, the decline in earnings is mainly through the adjustment in employment, contrary to the limited effect on the employment probability reported in Kahn (2010) and Oreopoulos et al. (2012). There are two potential explanations for the earnings losses being concentrated on the extensive margin in our study. First, the Asian financial crisis created South Korea's worst recession in the postwar era, during which job opportunities were substantially reduced even for high-skilled labor. ${ }^{25}$ Similarly, recent studies have documented a large and persistent reduction in employment among college graduates affected by the Great Recession (Altonji et al., 2016; Rothstein, 2019).

Second, South Korea's labor market is characterized by nominal wage rigidity and employment protection laws. As a result, demand shocks translate mainly into employment losses rather than wage reductions. ${ }^{26}$ Given these institutional features, as well as the South Korean firms' strong preference for recruiting young college graduates, those who did not find a job shortly after graduation were largely bypassed by firms, even after the economy had recovered. A substantial and persistent reduction in employment among those finishing college during a recession is indeed more commonly observed in countries with more rigid labor market institutions, such as Japan (Genda et al., 2010), Belgium (Cockx and Ghirelli, 2016), and Spain (Fernández-Kranz and Rodríguez-Planas, 2018). ${ }^{27}$

Very few studies have examined labor market outcomes separately for men and women who graduate during a recession. The relatively small and short-lived effects on earnings and employment we find in our female sample are consistent with evidence from the U.S. data. Kondo (2015) finds that initial economic conditions have no significant effect on employment and wages among

\footnotetext{
${ }^{25}$ Large conglomerates that hired a large proportion of the South Korean white collar workforce collapsed during the crisis. Six of the largest 30 conglomerates filed for bankruptcy protection in 1997 (Sharma, 2003).

${ }^{26}$ The OECD indicators of employment protection legislation show that, among the 34 OECD countries in 1997, South Korea had the third least flexible labor market (index value 3.04), after Portugal (4.58) and the Czech Republic (3.31). The United States and Canada had the most flexible labor market institutions in the same year, with index values of 0.26 and 0.92 , respectively.

${ }^{27}$ See Kawaguchi and Murao (2014) for a cross-country comparison of the scarring effect on employment among 20 OECD countries (excluding South Korea).
} 
white females in the NLSY79. Hoynes et al. (2012) describe that women's employment and unemployment rates are less responsive than men's to overall economic conditions. As we have explained above, the difference in career outcomes between recession and non-recession cohorts is compressed among females, because even those graduating in a good economy tend to detach from the labor force early in their career, due to family considerations.

\subsection{Marriage and Fertility}

Next, we investigate whether and how reduced labor market opportunities early in one's career affect family formation behaviors using the regression framework in equation (3). Only a small number of studies have examined the long-term consequences of initial labor market conditions on marriage and childbearing, and there is, as yet, no consensus in the literature on the sign and magnitude of the effect. ${ }^{28}$ As pointed out by Kondo (2016), it is especially challenging to identify a long-term causal relationship between unemployment and fertility, because both variables change gradually and are often confounded with a long-term trend. In this sense, our identification strategy that exploits a sharp deviation in the unemployment rate from a smooth cohort trend can be particularly useful.

Economic theory suggests that labor market conditions have competing income and substitution effects on family formation (Becker, 1960, 1965, 1973; Becker and Lewis, 1973; Willis, 1973). A decrease in income during a recession makes marriage and childbearing less affordable. At the same time, lower potential earnings could facilitate family formation by reducing the opportunity costs of housework and children. Among men, the income effect is expected to dominate, because they are typically the family breadwinner, and are less committed to housework and childcare.

\footnotetext{
${ }^{28}$ The results are mixed, especially for women. Multiple studies have examined the effects of labor market conditions in the mid-to-late 1970s and the 1980s on long-term marital and fertility outcomes using U.S. data. Maclean et al. (2016) and Schwandt and von Wachter (2020) find an increase in long-term fertility among recession graduates, using a sample of college-educated women from the NLSY79, and a combined sample of white women from the CPS, Decennial Census, and American Community Survey, respectively.In contrast, using data on white females from the Survey of Income and Program Participation, Kondo (2012) finds intertemporal adjustments in family formation behaviors, but no change in the marital or fertility rate. Currie and Schwandt (2014) analyze the 1975-2010 U.S. birth records, finding a persistent negative effect of unemployment on total fertility. See Kondo (2016) for an overview of the literature on the relationship between labor market conditions and family formation.
} 
Table 3: Effects of National Unemployment Rate at Graduation on Age of Family Formation

\begin{tabular}{|c|c|c|c|c|c|c|}
\hline & \multicolumn{3}{|c|}{ Age at first marriage } & \multicolumn{3}{|c|}{ Age at first childbirth } \\
\hline & $\begin{array}{c}\text { Censored } \\
\text { reg. } \\
(1)\end{array}$ & $\begin{array}{l}\text { Acc. fail. } \\
\text { time } \\
\text { (2) }\end{array}$ & $\begin{array}{l}\text { Cox } \\
\text { PH } \\
(3)\end{array}$ & $\begin{array}{c}\text { Censored } \\
\text { reg. } \\
(4)\end{array}$ & $\begin{array}{l}\text { Acc. fail. } \\
\text { time } \\
(5)\end{array}$ & $\begin{array}{l}\text { Cox } \\
\text { PH } \\
(6)\end{array}$ \\
\hline \multicolumn{7}{|l|}{ A. Men } \\
\hline National $U R$ & $\begin{array}{c}0.343 * * \\
(0.149)\end{array}$ & $\begin{array}{c}0.049 * * \\
(0.021)\end{array}$ & $\begin{array}{c}-0.060 * \\
(0.031)\end{array}$ & $\begin{array}{c}0.185 \\
(0.155)\end{array}$ & $\begin{array}{l}0.034 * \\
(0.020)\end{array}$ & $\begin{array}{l}-0.041 \\
(0.031)\end{array}$ \\
\hline Log likelihood & $-5,875$ & $-2,251$ & $-12,092$ & $-5,645$ & $-2,214$ & $-11,215$ \\
\hline Observations & 2,393 & 2,393 & 2,393 & 2,474 & 2,474 & 2,474 \\
\hline Median of $Y$ & 30.0 & 30.0 & 30.0 & 32.0 & 32.0 & 32.0 \\
\hline \multicolumn{7}{|l|}{ B. Women } \\
\hline National $U R$ & $\begin{array}{l}-0.170 \\
(0.173)\end{array}$ & $\begin{array}{c}0.002 \\
(0.022)\end{array}$ & $\begin{array}{c}0.038 \\
(0.033)\end{array}$ & $\begin{array}{c}-0.363 * * \\
(0.176)\end{array}$ & $\begin{array}{l}-0.033 \\
(0.024)\end{array}$ & $\begin{array}{c}0.075^{* *} * \\
(0.033)\end{array}$ \\
\hline Log likelihood & $-5,319$ & $-2,068$ & $-11,048$ & $-5,062$ & $-2,003$ & $-10,114$ \\
\hline Observations & 2,253 & 2,253 & 2,253 & 2,320 & 2,320 & 2,320 \\
\hline Median of $Y$ & 28.0 & 28.0 & 28.0 & 29.0 & 29.0 & 29.0 \\
\hline
\end{tabular}

Notes. Regressions include a cubic function of college graduation year, and fixed effects for the region of college graduation and years since graduation. Controls for background characteristics include father's years of education, father's years of education squared, dummies for parents' job status at age 14 (standard worker, non-standard worker, business owner hiring employees, business owner with no employee), and an indicator for 4-year college graduates. Missing values in background covariates are imputed using mean values, and dummies for missing observations are also controlled for. Robust standard errors in parentheses are clustered at the level of graduation year by region. * $p<0.10, * * p<0.05, * * * p<0.01$

However, for women, it is theoretically ambiguous which of the two competing effects would be stronger.

Estimation Results. We analyze the effect of labor market conditions at college graduation on the timing of marriage and childbirth in Table 3. To account for right censoring in age at first marriage or age at first childbirth, we employ a censored regression, an exponential survival analysis, and the Cox proportional hazards model. In Table 4 and Figure 5, we further investigate whether a shift in the timing of family formation leads to a permanent change in the marriage or fertility rates.

In Table 3, panel A provides evidence that men entering the labor market in an economic downturn postpone both marriage and having children. A 1 percentage point higher initial unemployment rate is associated with a delay in marriage by 0.34 years (column 1). Although men 
seem to postpone having children, the magnitude of the effect is only about half that on age at first marriage, and is not statistically significant at the 10 percent level (column 4). The results of the duration analyses are consistent with the corresponding censored regression estimates. The duration of remaining unmarried or childless increases significantly (columns 2 and 5) and the hazard rate decreases (columns 3 and 6) for those who graduate during a recession.

Panel B of Table 3 shows that adverse economic conditions at labor market entry accelerate the timing of family formation among female college graduates. Columns (1)-(3) suggest that women graduating from college in a recession tend to get married at a slightly younger age, although the coefficients are statistically indistinguishable from zero at the 10 percent significance level. Columns (4)-(6) show that the intertemporal adjustment is more distinct for childbearing. Specifically, a 1 percentage point higher national unemployment rate at college graduation leads to a 0.36 year decrease in the age at first childbirth.

In Table 4, we examine the effect of the national unemployment rate at labor market entry on the probability of having ever been married, propensity to have a child, and number of children. ${ }^{29}$ We find that labor market conditions at college graduation not only shift the timing of family formation, but also have long-term effects on marriage and fertility outcomes. Panel A shows that male college graduates entering the labor market under a 1 percentage point higher unemployment rate are 2.2 percentage points less likely to be married (3.1 percent relative to the sample average of 0.726 in column 1$)$, and 1.7 percentage points less likely to have children (2.5 percent relative to the sample average of 0.639 in column 2). The decline in fertility in the male sample can almost entirely be attributed to the decline in marriage, for the following reasons. First, out-ofwedlock births are rare in South Korea (1-2 percent in the period from 2000 to 2018). Second, labor market entry conditions have little effect on fertility behaviors among men who have been married, as shown in columns (3) and (5). Third, the recession effect on the intensive margin of fertility is small, as shown by the estimated effect on the number of children (in column 4) not

\footnotetext{
${ }^{29}$ We find no systematic differences in the separation and divorce rates between recession and non-recession graduates. Thus, the recession effect on the probability of being currently married is very similar to that on the probability of having ever been married.
} 
Table 4: Long-Term Effects of National Unemployment Rate at Graduation on Marriage and Fertility

\begin{tabular}{lccccc}
\hline & $\begin{array}{c}\text { Ever } \\
\text { married } \\
(1)\end{array}$ & $\begin{array}{c}\text { Any } \\
\text { children } \\
(2)\end{array}$ & $\begin{array}{c}\text { Any children } \\
\text { (ever married) }\end{array}$ & $\begin{array}{c}\text { Num. of } \\
\text { children } \\
(3)\end{array}$ & $\begin{array}{c}\text { Num. of children } \\
\text { (ever married) }\end{array}$ \\
\hline A. Men & & & & & $(5)$ \\
National $U R$ & $-0.022^{* *}$ & $-0.017 *$ & -0.003 & -0.028 & -0.016 \\
& $(0.011)$ & $(0.010)$ & $(0.013)$ & $(0.019)$ & $(0.027)$ \\
Adjusted $R^{2}$ & 0.271 & 0.278 & 0.084 & 0.287 & 0.142 \\
Observations & 2,474 & 2,474 & 1,796 & 2,474 & 1,796 \\
Mean of $Y$ & 0.726 & 0.639 & 0.880 & 1.126 & 1.551 \\
\hline B. Women & & & & & \\
National $U R$ & -0.011 & 0.009 & $0.030 * * *$ & $0.046 * *$ & $0.097 * * *$ \\
& $(0.011)$ & $(0.010)$ & $(0.010)$ & $(0.018)$ & $(0.021)$ \\
Adjusted $R^{2}$ & 0.339 & 0.348 & 0.128 & 0.344 & 0.183 \\
Observations & 2,320 & 2,320 & 1,656 & 2,320 & 1,656 \\
Mean of $Y$ & 0.714 & 0.625 & 0.876 & 1.096 & 1.535 \\
\hline
\end{tabular}

Notes. Regressions include a cubic function of college graduation year, and fixed effects for the region of college graduation and years since graduation. Controls for background characteristics include father's years of education, father's years of education squared, dummies for parents' job status at age 14 (standard worker, non-standard worker, business owner hiring employees, business owner with no employee), and an indicator for 4-year college graduates. Missing values in background covariates are imputed using mean values, and dummies for missing observations are also controlled for. Robust standard errors in parentheses are clustered at the level of graduation year by region. * $p<0.10, * * p<0.05, * * * p<0.01$

being substantially different from that on the probability of having a child (in column 2).

In panel B of Table 4, we find that weak economic conditions at college graduation do not significantly affect marriage probability, but do significantly increase long-term fertility among women. In column (1), the small and statistically insignificant effect on marriage probability suggests that the negative income effect of reduced earnings on marriage is mostly muted for women. Columns (2)-(4) show that substitution into childbearing is especially pronounced among married women. Conditional on getting married, women who graduate from college in an economic downturn have higher fertility along both the extensive and the intensive margins (columns 3 and 5). On average, a woman graduating from college with a 1 percentage point higher unemployment rate has 0.046 more children (4.2 percent increase relative to the sample average of 1.096 in column 4).

In Figure 5, we estimate the effect of initial labor market conditions on the likelihood of having 
A. Men

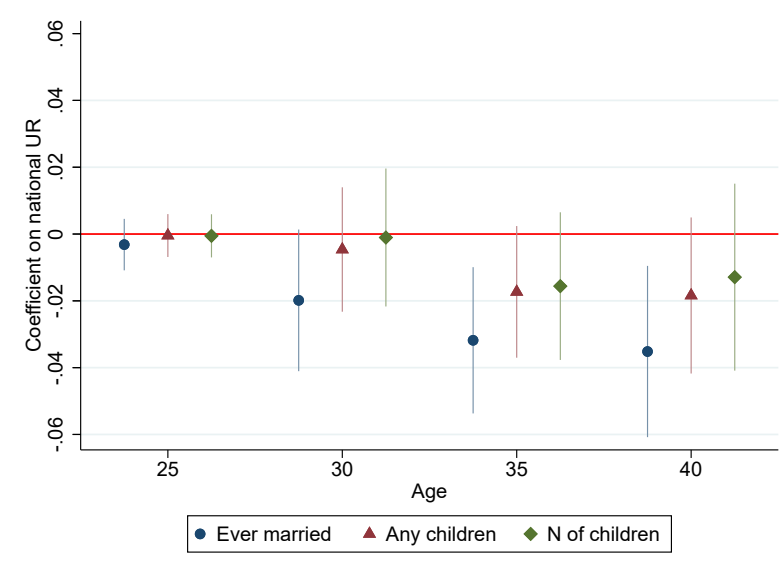

B. Women

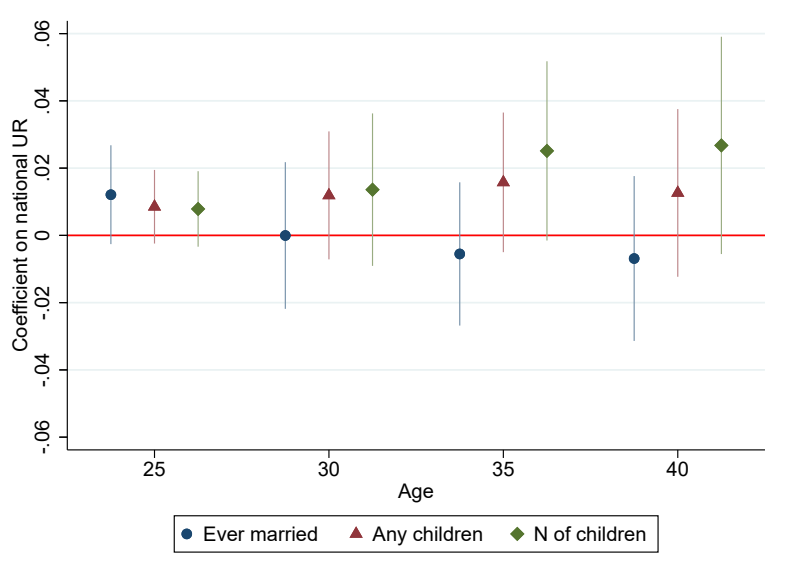

Figure 5: Effects of National Unemployment Rate at Graduation on Family Formation by a Certain Age

Notes. Each bullet shape represents the coefficient estimate on the national $U R$ from a separate regression estimating equation (3). Vertical spikes around each point estimate represent the $95 \%$ confidence interval, constructed using robust standard errors clustered at the level of graduation year by region. Regressions include a cubic function of college graduation year, and fixed effects for the region of college graduation and years since graduation. Controls for background characteristics include father's years of education, father's years of education squared, dummies for parents' job status at age 14 (standard worker, non-standard worker, business owner hiring employees, business owner with no employee), and an indicator for 4-year college graduates. Missing values in background covariates are imputed using mean values, and dummies for missing observations are also controlled for.

ever been married, probability of having children, and number of children by age 25, 30, 35, and $40 .^{30}$ We perform this exercise to address the concern that we do not observe completed marriage or fertility outcomes for those who exited the KLIPS in their early career. Selective attrition may introduce bias into our estimates in Table 4. If recession cohorts shift the timing of marriage and having children, but eventually catch up with other cohorts, our estimates in Table 4 would capture the large short-term effects among attrited individuals, and overstate the true long-term effect. The overstated bias would be smaller if family formation outcomes are measured at an older age. However, Figure 5 shows the opposite pattern, namely, that the recession effect on family formation accumulates up to age 40. This pattern is especially pronounced on the likelihood of marriage among males and the number of children among females, where we find the most distinct recession effects. This result indicates that our estimates in Table 4 do not merely reflect a shortterm adjustment in family formation behaviors. Rather, we are likely to provide a lower bound

\footnotetext{
${ }^{30} \mathrm{We}$ compare the recession effect estimates across samples comprising individuals aged 25 and over, 30 and over, 35 and over, and 40 and over.
} 
estimate of the permanent change in marriage and fertility outcomes due to unfavorable economic conditions at labor market entry.

Discussion. For male college graduates, we find that the initial unemployment rate has a sizable negative effect on family formation. In contrast, previous studies using data from the United States and Germany show a delay only in the timing of family formation, but no long-term change in marriage and fertility rates (Kondo, 2012; Hofmann and Hohmeyer, 2016; Maclean et al., 2016; Kawaguchi and Kondo, 2020). This is because, in our case, earnings losses experienced by recession cohorts stem mainly from the substantial drop in employment probability, whereas the extensive margin effect is negligible among male college graduates in these countries. Our results are more consistent with the declines in employment, marriage, and fertility observed among early-career males during the "Lost 20 Years" in Japan (Raymo and Shibata, 2017), or among young male workers in the U.S. manufacturing sector, who are subject to import competition (Autor et al., 2019). ${ }^{31}$ It is also possible that the male breadwinner norm prevalent in South Korea may render male recession graduates with lower earnings even less attractive in the marriage market, which reinforces the negative income effect.

The earlier marriages and higher fertility we find among female recession graduates are also observed in the United States (Maclean et al., 2016; Schwandt and von Wachter, 2020) and Japan (Hashimoto and Kondo, 2012; Raymo and Shibata, 2017). In these studies, as well as in ours, common cultural and institutional features may strengthen the positive substitution effect of reduced labor market opportunities on family formation behaviors among women. First, breadwinnerhomemaker couples remain common among the population of interest in the aforementioned studies: college graduate or white women in the United States during the late 1970s and 1980s, or female college graduates in patriarchal Asian countries. In this case, marriage tends to make women less credit-constrained, and childcare responsibilities fall mostly to the mother. Second, family-friendly policies are not well-established in the United States or in East Asian countries,

\footnotetext{
${ }^{31}$ Although not focusing specifically on the effect of early-career labor market conditions, Lindo (2010) shows that a large negative income shock from a husband's job displacement reduces completed fertility.
} 
making it more difficult for women to pursue their own career once becoming a mother. Del Bono et al. $(2012,2015)$ make a similar point that substitution into childbearing is less pronounced when women are more career-oriented, and when gender-based specialization within couples is weaker.

If economic conditions at labor market entry change the patterns of marital matching, there may be an additional income effect on fertility through an increase or reduction in the (potential) spouse's income. We find evidence that this channel is active among women. Conditioned on having ever been married, women who graduate from college in a higher unemployment rate are more likely to have a spouse who was raised by parents with regular jobs at his age 14 or with a high school degree or higher (see Table S3). The positive selection on the husband's economic background among female recession graduates implies a positive income effect on fertility. ${ }^{32}$ This can potentially explain why we see a sizable increase in fertility, despite the short-lived reduction in earnings among female recession cohorts. Among men, we find no systematic difference in the spouse's economic background by labor market entry condition.

\subsection{Household Expenditures and Asset Holdings}

As the final set of outcomes, we examine whether unlucky cohorts have different trajectories of consumption and asset holdings relative to their luckier counterparts by estimating equation (1). ${ }^{33}$ Despite its importance for public policy, particularly related to retirement preparedness, research on asset accumulation among recession graduates remains limited, with the only exception of Kawaguchi and Kondo (2020).

Theoretically, in a traditional representative agent model assuming a complete market where individuals can freely borrow or lend, idiosyncratic or transitory income shocks should not affect

\footnotetext{
${ }^{32}$ It is not feasible to conduct this exercise on a more direct measure of the husband's own economic status at the beginning of the marriage. Time-varying spousal characteristics (e.g., income) at the start of a marriage are missing for 36.4 percent of married women in our sample. This is because some people entered the KLIPS after getting married, while others did not report the date of their marriage.

${ }^{33}$ Note that the outcome variables on consumption and asset holdings are measured at the household level. Given that unmarried adults commonly live with their parents in South Korea, the early career effect of initial job market conditions on consumption and asset formation may subsume the effect on parents' consumption and asset holdings. If parents and adult children are risk-sharing, our estimated effects are likely to be a lower bound rather than an overestimate, in absolute value.
} 
consumption. However, when markets are incomplete, labor market shocks may not be insurable, and hence, might generate a sizable cost of business cycles (Krebs, 2007). The consumption risk from labor market shocks may be greater for new college graduates in particular, because unemployment insurance is not available for new job market entrants. ${ }^{34}$

In response to a labor market shock, individuals may also adjust their asset holdings. Studies have documented that consumption is less sensitive to a fall in income among those with more liquid assets (Kolsrud et al., 2018; Ganong and Noel, 2019). During an unemployment spell, individuals deplete their bank accounts or cut their savings for consumption smoothing (Kolsrud et al., 2018). However, if the decline in earnings is smaller than the drop in the price of risky assets during a recession, young recession cohorts may be able to purchase risky assets at a greatly depressed price and become asset-rich when the asset price recovers (Glover et al., 2011). Thus, the overall impact of adverse economic conditions at the labor market entry on consumption paths and wealth formation is theoretically ambiguous.

Estimation Results. Figure 6 examines the estimated changes in the experience profile of household expenditure per capita due to a 1 percentage point increase in the unemployment rate at graduation. ${ }^{35}$ For men in panel $\mathrm{A}$, the effect of the initial unemployment rate is precisely zero in most experience groups, implying that there is limited welfare loss in terms of consumption. For women in panel B, we observe a small but statistically significant drop (between -0.02 and -0.01 ) in consumption at experience years 4-6 and 10-12. The drop in consumption in experience years 4-6 overlaps roughly with the timing of the birth of the first child. ${ }^{36}$

Figure 7 plots the estimated effects of initial labor market conditions on debt, financial assets, and home ownership for men (left column) and women (right column). In panels A1 and B1, we

\footnotetext{
${ }^{34}$ Unemployment protection was weak in South Korea until the late 1990s. Before the government's expansion of the coverage in March 1998, only 33 percent of wage workers were covered by the unemployment insurance program (International Monetary Fund, 2000).

${ }^{35}$ Table S4 in the online appendix reports the coefficient estimates, standard errors, and dependent variable averages for the outcomes described in Figures 6, 7, and 8. The average effects of unemployment rate at graduation on consumption and asset holdings over the first 10 years since college graduation are presented in panel C of Table S5.

${ }^{36}$ For females in our sample, the average age at graduation is 23 and the average age at first childbirth is 29. Because a 1 percentage point increase in the initial unemployment rate reduces first childbirth age by 0.36 years, female recession graduates would have their first child well within the 4-6 year range after graduation.
} 
A. Men

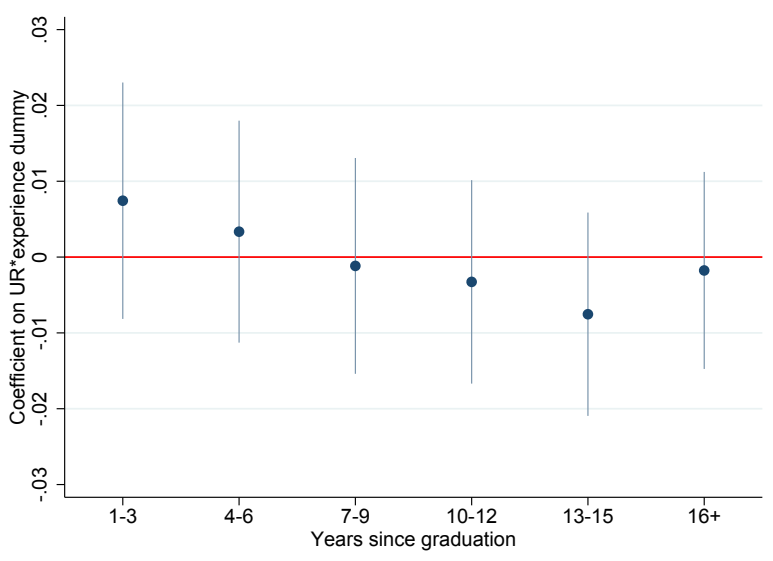

B. Women

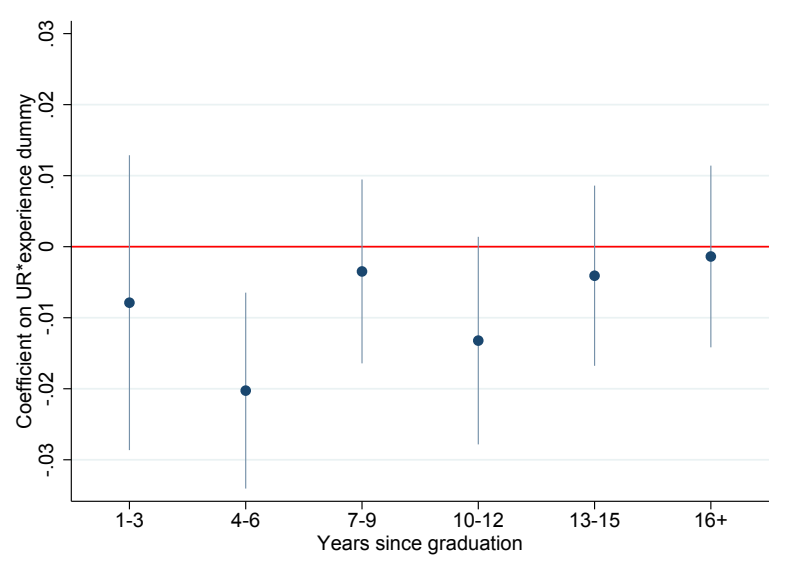

Figure 6: Effects of National Unemployment Rate at Graduation on Log Expenditure Per Capita Notes. Monthly expenditure per capita is inflation-adjusted to $2015 \mathrm{KRW}$, where 1 USD is worth approximately 1,100 KRW. Each dot represents the coefficient estimate on an interaction term between the national $U R$ and a potential experience dummy. Vertical spikes around each point estimate represent the $95 \%$ confidence interval, constructed using robust standard errors clustered at the level of graduation year by region. Regressions include a cubic function of college graduation year, and fixed effects for the region of college graduation, years since graduation, and calendar year. Controls for background characteristics include father's years of education, father's years of education squared, dummies for parents' job status at age 14 (standard worker, non-standard worker, business owner hiring employees, business owner with no employee), and an indicator for 4-year college graduates. Missing values in background covariates are imputed using mean values, and dummies for missing observations are also controlled for.

first investigate whether there is a systematic difference in the amount of debt by labor market entry conditions. For men, we find no evidence of increasing debt as a means to smooth consumption. ${ }^{37}$ The effect is also absent for women, with the exception of a temporary increase in the value of debt during experience years 13-15. The latter increase corresponds approximately to the timing of decreased consumption reported in panel B of Figure 6. This period also coincides with the timing of the first home purchase. ${ }^{38}$ That there is no effect on debt is unsurprising, given that young college graduates are unlikely to have sufficient collateral shortly after their labor market entry, and thus, have limited access to credit. Instead of getting a loan, young graduates may obtain liquidity at a lower transaction cost by adjusting their financial asset holdings, which we examine next.

In panels A2 and B2, we report the effects of initial job market conditions on the value of

\footnotetext{
${ }^{37}$ Ganong and Noel (2019) find that debt financing plays a limited role in consumption smoothing among unemployed individuals subject to local labor market shocks.

${ }^{38}$ Given that the average age of the household head at the first home purchase is about 40 , and the wives are about 2.3 years younger than their husbands in our data, the first home purchase would occur about 14-17 years after graduation for women.
} 

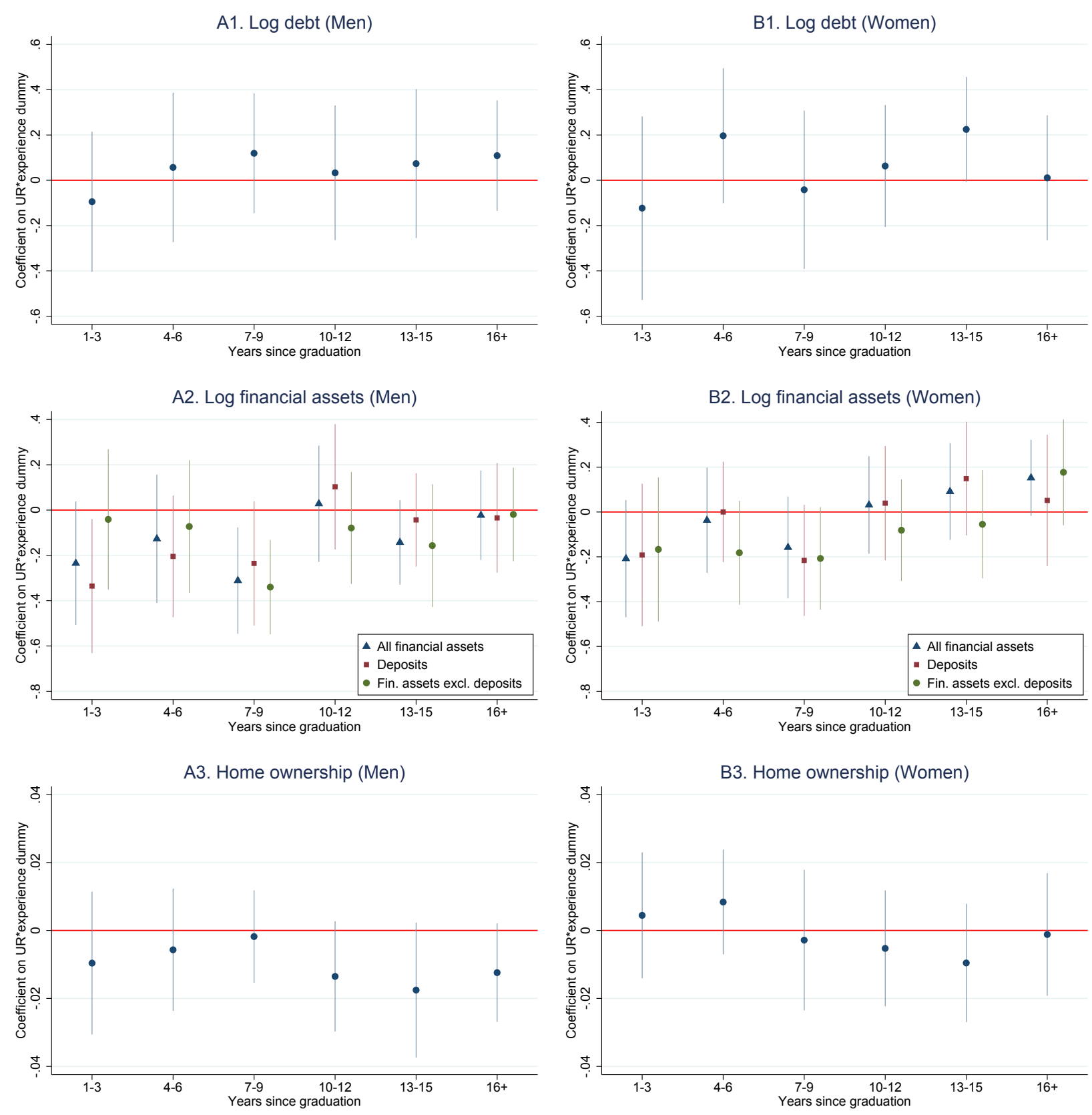

Figure 7: Effects of National Unemployment Rate at Graduation on Asset Holdings

Notes. The values of debt and financial assets are inflation-adjusted to 2015 KRW, where 1 USD is worth approximately $1,100 \mathrm{KRW}$. Zero values are imputed with $1 \mathrm{KRW}$ before taking the logarithm. Each dot represents the coefficient estimate on an interaction term between the national $U R$ and a potential experience dummy. Vertical spikes around each point estimate represent the $95 \%$ confidence interval, constructed using robust standard errors clustered at the level of graduation year by region. Regressions include a cubic function of college graduation year, and fixed effects for the region of college graduation, years since graduation, and calendar year. Controls for background characteristics include father's years of education, father's years of education squared, dummies for parents' job status at age 14 (standard worker, non-standard worker, business owner hiring employees, business owner with no employee), and an indicator for 4-year college graduates. Missing values in background covariates are imputed using mean values, and dummies for missing observations are also controlled for. 
financial assets. We first estimate the recession effect on the total value of all financial assets, including bank deposits, stocks, bonds, mutual funds, savings insurance, rotating savings and credit associations, and private lending. To further examine which type of financial asset is readily adjusted for consumption smoothing, we divide financial assets into bank deposits, and other forms of financial assets, excluding deposits. The former can be easily converted to cash, whereas it may take longer to exchange or sell the latter at a desired price. In the male sample, we observe a 13-31 percent drop in the value of all financial assets during the first 9 years of potential experience per 1 percentage point increase in the initial unemployment rate. The duration of the negative impact on asset values is equivalent to that on earnings, suggesting that men from cohorts that graduate during a recession protect their consumption levels mainly by adjusting their financial asset holdings. Liquid assets, in particular, are more readily adjusted - during the first 6 years after graduation, the negative recession effect on bank deposits is more substantial than that on other forms of financial assets. For females, a higher unemployment rate at graduation appears to have a negative effect on financial asset accumulation for up to 9 years after graduation, although the effect is dampened compared to men, and is statistically significant at the 10 percent level only in experience years 7 to 9 .

In panels A3 and B3, we examine home ownership as a measure of an illiquid asset and a durable consumption good. ${ }^{39}$ For men, although all recession effect estimates are negative, only the coefficients on experience years 13 or higher are significant at the 10 percent level. We interpret this as evidence of reduced home ownership among male recession graduates. According to the Korea Housing Survey, the first home purchase is made when the head of a household is about age 40 , which is $14-16$ years after graduation for male college graduates. We find no statistically significant effect of initial labor market conditions on home ownership among women.

In addition to adjusting asset holdings, another way in which young college graduates protect their consumption is coresidence with their parents. In panel A of Figure 8, we find evidence

\footnotetext{
${ }^{39}$ Note that information on home ownership status was not collected in the first wave of the survey. We find similar results when we use ownership of current residence, available in all waves, as an alternative measure of home ownership.
} 
A. Men

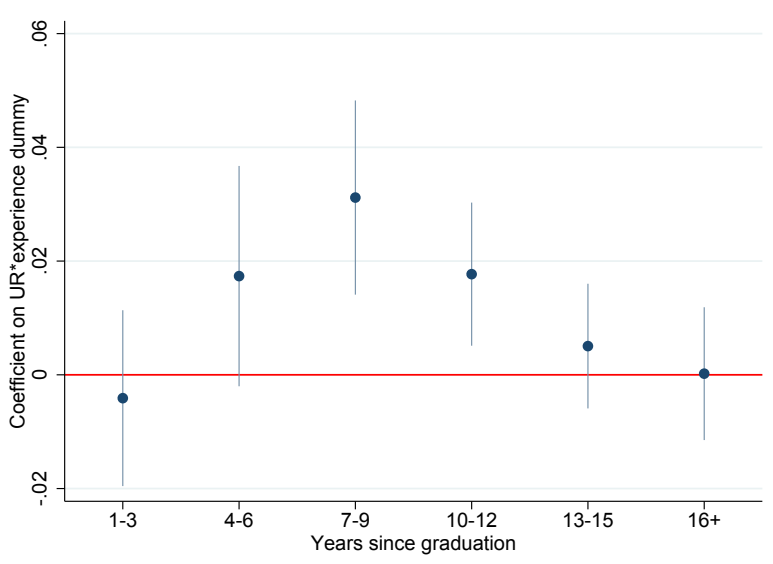

B. Women

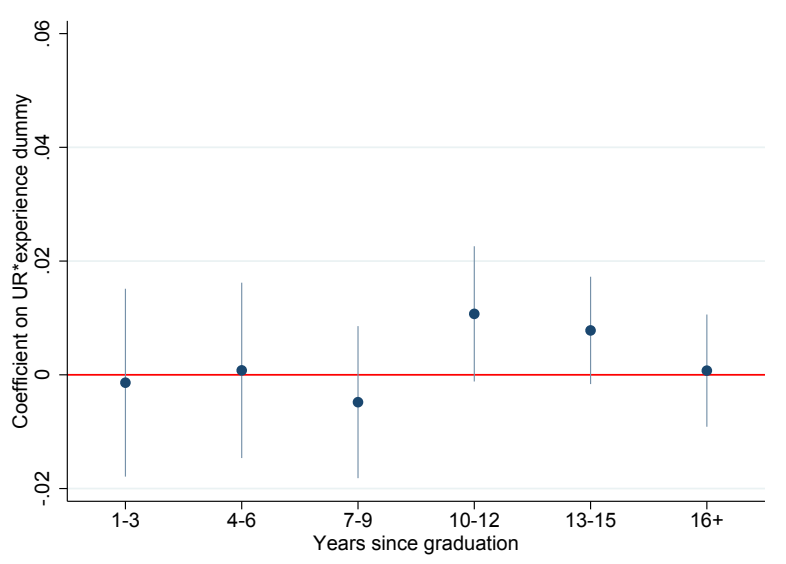

Figure 8: Effects of National Unemployment Rate at Graduation on Coresidence with Parents

Notes. Each dot represents the coefficient estimate on an interaction term between the national $U R$ and a potential experience dummy. Vertical spikes around each point estimate represent the $95 \%$ confidence interval, constructed using robust standard errors clustered at the level of graduation year by region. Regressions include a cubic function of college graduation year, and fixed effects for the region of college graduation, years since graduation, and calendar year. Controls for background characteristics include father's years of education, father's years of education squared, dummies for parents' job status at age 14 (standard worker, non-standard worker, business owner hiring employees, business owner with no employee), and an indicator for 4-year college graduates. Missing values in background covariates are imputed using mean values, and dummies for missing observations are also controlled for.

supporting this for men. For a 1 percentage point increase in the national unemployment rate at college graduation, the probability of living with at least one parent of their own or with one of their in-laws increases by 1.7-3.1 percentage points between 4 and 12 years after college graduation. ${ }^{40}$ The effect is sizable, given that the mean coresidence probability is 0.261 in the male sample. This result is consistent with our findings in Section 5.2, that men from recession cohorts are less likely to be married, which precludes forming an independent household. In panel B, unlike male recession cohorts, who extend their stay at their parents' homes well after graduation, we observe no such pattern among female recession cohorts. This lack of an increase in parental coresidence is again consistent with the findings in Section 5.2, where we show that adverse economic conditions at graduation do not affect marriage rates among women. ${ }^{41}$

Discussion. Overall, cohorts entering the labor market in a deep recession tend to give up some

\footnotetext{
${ }^{40}$ The absence of an effect between 1-3 years after college graduation is likely because unmarried South Korean adults tend to live at home with their parents. That is, between 1 and 3 years after graduation, all cohorts are likely to be living with their parents.

${ }^{41}$ Card and Lemieux (2000) also examine gender differences in parental coresidence, finding that the increase in coresidence is more pronounced for men than it is for women.
} 
of their liquid assets to protect consumption from reduced earnings during the first 9 years after graduation. This result differs from Kawaguchi and Kondo (2020), who, using NLSY79 data, find a weak increase in home and vehicle ownership and no effect on net household asset values among recession graduates, because these graduates tend to migrate to areas with a lower cost of living. We do not find such migration patterns in our data. Our finding is consistent with those of previous studies on the effect of income shocks on consumption and household asset portfolio adjustments in the development literature. While income is volatile in developing countries, consumption is remarkably stable (Townsend, 1994; Fafchamps et al., 1998). Household resources are found to play an important role in insuring consumption against income shocks. Sales of livestock, informal credit from family and friends, or dissaving are used to smooth consumption (Rosenzweig and Wolpin, 1993; Fafchamps et al., 1998; Fafchamps and Lund, 2003).

Male college graduates have an additional consumption smoothing mechanism against the negative income shock, namely, coresiding with their parents. Young adults who live in their parents' homes can reduce housing and other living expenses, and may receive intergenerational transfers from their parents. ${ }^{42}$ Similar patterns of increased coresidence by young adults and their parents during adverse economic conditions are also observed in Canada and the United States (Card and Lemieux, 2000). During the Great Recession, coresidence with parents became especially common among young adults who were credit-constrained or had high levels of debt (Dettling and Hsu, 2018).

Our results suggest that a cohort-specific labor market shock can translate into a cohort-specific shock to wealth accumulation. Indeed, on top of the reduction in financial asset holdings for up to 9 years after graduation, male graduates from recession cohorts face an additional decline in home ownership rates from their 13th year after graduation. Given that economic security over the life course depends not only on income, but also on asset ownership, the substantial delay in asset formation may have lasting repercussions on individual welfare and old age security. The negative effects on asset holdings may prevent recession graduates from accumulating a sufficient buffer

\footnotetext{
${ }^{42}$ McGarry (2016) and Edwards (2019) document that the likelihood of receiving private transfers from parents increases with unemployment incidence.
} 
against future negative income shocks, leaving them more vulnerable to financial distress as they age, compared to their luckier counterparts.

\section{Robustness Checks}

\subsection{Selection into Graduation Year}

A potential threat to the identification assumption is differential selection into the timing of college graduation. ${ }^{43}$ Individuals might postpone their graduation during a recession to avoid adverse labor market conditions, or might graduate early in a boom to take advantage of favorable labor market conditions. Furthermore, this adjustment behavior might be correlated with their earnings potential. Recession cohorts would be positively selected if those with higher abilities or from wealthier families are less likely to adjust their timing of graduation in response to economic conditions. On the other hand, if those from disadvantaged backgrounds cannot delay their college graduation because of credit constraints, recession cohorts would be negatively selected.

We first examine whether individuals endogenously select their graduation year in response to labor market conditions, using the following balancing regression:

$$
x_{i}=\alpha+\beta U R_{c}+f(c)+\delta_{r}+\tau_{e}+\varepsilon_{i}
$$

where $x_{i}$ is an individual characteristic predetermined at college entry, such as years of father's and mother's education, parents' job status and socioeconomic status at age 14, and the type of college attended (two- vs. four-year). We check the individual and joint significance of the coefficient on the treatment variable in each balancing regression. Pei et al. (2019) show that this

\footnotetext{
${ }^{43}$ Many previous studies have pointed out that the location of college graduation might also be endogenous. These studies use residential location in the year of graduation, which partly reflects the relocation choice immediately after graduation in response to different job perspectives across regions. However, our results are unlikely to be subject to this problem, for the following two reasons. First, when we control for the region of college graduation, we use the location of the college, which is predetermined at college entry, thus, unlikely to be endogenous with respect to labor market conditions at college graduation. Second, our main treatment variable is the national unemployment rate, which is orthogonal to endogenous sorting across regions, unlike the regional unemployment rate.
} 
Table 5: Balance Check on Baseline Characteristics, by National Unemployment Rate at Graduation

\begin{tabular}{|c|c|c|c|c|c|c|c|c|}
\hline \multirow[b]{2}{*}{ A. Individual balance test: } & \multicolumn{4}{|c|}{ Men } & \multicolumn{4}{|c|}{ Women } \\
\hline & $\begin{array}{c}\text { Coeff. on } \\
\text { national } U R\end{array}$ & SE & Mean & Obs. & $\begin{array}{c}\text { Coeff. on } \\
\text { national } U R\end{array}$ & SE & Mean & Obs. \\
\hline Attended 4-year college & 0.009 & $(0.010)$ & 0.656 & 2,474 & $0.027 * * *$ & $(0.010)$ & 0.546 & 2,320 \\
\hline Father's years of education & 0.091 & $(0.071)$ & 10.32 & 2,426 & 0.012 & $(0.085)$ & 11.11 & 2,292 \\
\hline Mother's years of education & 0.090 & $(0.097)$ & 8.52 & 1,988 & 0.069 & $(0.091)$ & 9.41 & 1,994 \\
\hline \multicolumn{9}{|l|}{ Parents' job status at age 14} \\
\hline Standard worker & 0.016 & $(0.012)$ & 0.410 & 2,401 & -0.010 & $(0.011)$ & 0.446 & 2,262 \\
\hline Non-standard worker & -0.004 & $(0.005)$ & 0.072 & 2,401 & 0.003 & $(0.005)$ & 0.069 & 2,262 \\
\hline Business owner (with employees) & -0.002 & $(0.008)$ & 0.125 & 2,401 & 0.006 & $(0.008)$ & 0.145 & 2,262 \\
\hline Business owner (no employee) & -0.007 & $(0.010)$ & 0.376 & 2,401 & 0.000 & $(0.011)$ & 0.326 & 2,262 \\
\hline \multicolumn{9}{|l|}{ Socioeconomic status at age 14} \\
\hline Above average & -0.010 & $(0.011)$ & 0.156 & 1,863 & 0.008 & $(0.013)$ & 0.176 & 1,836 \\
\hline About average & 0.018 & $(0.013)$ & 0.582 & 1,863 & -0.008 & $(0.015)$ & 0.620 & 1,836 \\
\hline Below average & -0.009 & $(0.014)$ & 0.262 & 1,863 & -0.000 & $(0.013)$ & 0.203 & 1,836 \\
\hline B. Joint balance test: & $\begin{array}{c}\chi^{2} \text {-statistic } \\
8.033\end{array}$ & $\begin{array}{c}p \text {-value } \\
{[0.531]}\end{array}$ & & & $\begin{array}{c}\chi^{2} \text {-statistic } \\
13.902\end{array}$ & $\begin{array}{c}p \text {-value } \\
{[0.126]}\end{array}$ & & \\
\hline
\end{tabular}

Notes. The analysis sample includes 2,474 men and 2,320 women, but the number of observations for each variable varies because of missing values. Regressions include a cubic function of college graduation year, and fixed effects for the region of college graduation and years since graduation. Robust standard errors in parentheses are clustered at the level of graduation year by region. $p$-values in brackets. $* p<0.10, * *$ $p<0.05, * * * p<0.01$

method provides a more powerful test for detecting selection in regression-based research designs than an alternative method does; in the alternative approach, they check the stability of the estimated coefficient on the treatment variable in the main regression, with and without controlling for background characteristics.

Table 5 presents the estimates from the balancing regression using the national unemployment rate $U R_{c}$ on the right-hand side. We find no statistically significant difference between recession cohorts and their non-recession peers in most of the background characteristics listed above. Except for the type of college attended in the female sample, the coefficient on $U R_{c}$ from each of the individual balancing regressions is close to zero and statistically insignificant at the 10 percent level. In addition, the joint test cannot reject the null hypothesis that all the characteristics considered are balanced, with a $p$-value of 0.531 for men and 0.126 for women. ${ }^{44}$ These results suggest that the recession effects measured using regression equations (1)-(3) are unlikely to be driven by selection.

\footnotetext{
${ }^{44}$ These background characteristics are also balanced with respect to alternative measures of economic conditions, including the regional unemployment rate, denoted by $U R_{c r}$, and an indicator for the 1998 or 1999 graduation cohort, denoted by $D C_{c}$. The results are available upon request.
} 
Although the baseline covariates are, in general, well balanced across recession and nonrecession cohorts, there may be a remaining concern about selection on unobservables. In the female sample, the fraction graduating from a four-year institution is disproportionately higher during an economic downturn, suggesting that recession cohorts might be positively selected (if at all). Then, even if there is differential selection into graduation years, recession effects are likely understated, and the estimates in Section 5 can be viewed as a lower bound in magnitude.

To further explore the potential selection bias, we also employ an instrumental variables (IV) strategy, similar to that of Kahn (2010). We use the unemployment rate in the predicted year of college graduation as an instrument for the unemployment rate in the actual year of graduation. ${ }^{45}$ The predicted year of college graduation is constructed by computing the year an individual turned the typical college graduation age, which differs by college type and sex in South Korea. The typical age at college graduation is 26 for male four-year college graduates, 24 for male two-year college graduates, 23 for female four-year college graduates, and 21 for female two-year college graduates. The three-year gender difference in the typical age at college graduation is due to military service being compulsory for men. We conduct the IV estimation of equation (2) for labor and financial outcomes, averaged over the first 10 years of potential experience, and of equation (3) for family outcomes. The results are presented in the online appendix (see Table S5). Compared with the corresponding OLS estimates, the IV estimates are, in general, in the same direction with similar statistical significance, but larger in magnitude. This corroborates the results from the balance check exercise.

\subsection{Regression Specifications and Estimation Samples}

We conduct additional robustness checks to show that our results are not sensitive to alternative measures of economic conditions at graduation, other functional form specifications, or alternative sample restrictions. This exercise is performed on equation (2) for labor and financial outcomes

\footnotetext{
${ }^{45}$ In the IV estimation, a cubic function of college graduation year and years since graduation are instrumented with a cubic function of predicted college graduation year and years since the predicted year of graduation, respectively. Standard errors are clustered at the level of predicted graduation year by region of college.
} 
averaged over the first 10 years of potential experience, and on equation (3) for family formation outcomes as of the most recent survey year. The results are reported in the online appendix.

Measures of Economic Conditions. In addition to the national and regional unemployment rates in the year of college graduation, we use an indicator for college graduation in 1998 or 1999 as a treatment variable to measure the direct influence of the Asian financial crisis. We choose 1998 and 1999 because the Hodrick-Prescott (HP) filtered series of the national and regional unemployment rates indicate that the two year period during and shortly after the crisis constitute a sharp downturn. The recession effects measured by the regional unemployment rates $U R_{c r}$ or the crisis cohorts dummy $D C_{c}$ are presented in Table S6.

The estimated effects of the regional unemployment rate $U R_{c r}$ are qualitatively similar, but, in general, smaller in magnitude than those from the benchmark regressions in Section 5, which use the national unemployment rate $U R_{c}$ (with an exception of results on financial asset holdings). This is consistent with the substantial degree of geographic relocation after college graduation, described in Section 3.

From the regressions based on the 1998 or 1999 cohort dummy, we find that the estimated coefficients on $D C_{c}$ are about four times those on the national unemployment rate $U R_{c}$ from the regression analyses in Section 5. This confirms that the sharp downturn in the economy during the crisis is the main source of the identifying variation, given that the unemployment rates were, on average, 4 percentage points higher in 1998 and 1999 than in the rest of the analysis period.

Specifications for Cohort Trend. To gauge whether our results are driven by the cubic functional form of $f(c)$, we use an alternative way to remove a smooth national trend in the unemployment rates that does not impose a functional form assumption. We apply the HP filter to the unemployment rate series, as in Hofmann and Hohmeyer (2016). We use the smoothing parameter values of $\lambda=6.5$ suggested by Ravn and Uhlig (2002) for annual U.S. data and $\lambda=100$ suggested by Uribe and Schmitt-Grohé (2017) for annual data from an emerging market. The regression results using the HP-filtered data are very similar to our baseline results described in Section 5, for both of the 
smoothing parameter values. See Figure S2 for results on employment and earnings, Figure S3 for marriage and fertility, and Figure S4 for consumption and asset holdings.

Region-Specific Trends. The cohort trend $f(c)$ is assumed to be parallel across regions in regression models described in Section 3 and estimated in Section 5. To relax this assumption, we additionally control for region-specific cohort trends $\delta_{r} \times c$ in equations (2) and (3). Figures S2, S3, and S4 show that this alternative specification yields very similar results to the baseline regressions.

Structural Break after the Crisis. Figure 1 shows that there was a lasting increase in the national unemployment rate even after the South Korean economy had recovered from the Asian financial crisis. The national unemployment rate never returned to the pre-crisis level: the post-crisis rates in 2000-2014 are on average 0.8 percentage points higher than the pre-crisis rates in 1989-1997. The South Korean labor market has experienced a structural change after the crisis, such as an introduction of institutions improving labor market flexibility (Lee, 2017), and a substantial increase in non-standard work arrangements (Keum, 2012). Some of the institutional changes were demanded by the IMF as a condition of the bailout package.

To take into account the post-crisis transformation of the South Korean labor market, we allow the cohort trend to be different after the crisis by interacting $f(c)$ with a dummy variable indicating 2000-2014 cohorts. As presented in Figures S2, S3, and S4, results are robust to allowing a structural break in 2000 .

Sample Restriction. We repeat our analysis in Section 5 using graduation cohorts up to 2007 only to exclude those who graduated from college during or shortly after the Great Recession. The results are robust to imposing this restriction on the estimation sample (see Figures S2, S3, and S4). This is possibly because the Great Recession did not have a substantial impact on the South Korean labor market (Lee, 2017). The national unemployment rate has remained below 4 percent since 2001, and was largely unaffected by the Great Recession.

Using Large Cross-Sectional Data. The sample size of the KLIPS is not very large to begin 
with, and observations are excluded when outcome variables are missing. Thus, there might be a concern about the representativeness of our KLIPS sample. In the online appendix, we show that the analysis sample and results from the KLIPS data are comparable to those from larger datasets, such as the EAPS or Census data (see Table S7). However, because the EAPS and Census do not report the year of college graduation, we can only compute the reduced form effect of the unemployment rate in the predicted year of college graduation. The predicted graduation year is constructed in the same way as in Section 6.1. Also note that we can only examine a small subset of the outcome variables on employment, marriage, and fertility using the EAPS or Census data. Sections S1.1 and S1.2 in the online appendix provide further details on our EAPS and Census samples, respectively.

\section{Conclusion}

This study investigates the long-term effects of initial labor market conditions, exploiting the across-cohort variation in the unemployment rates induced by the unexpected 1997-1998 Asian financial crisis. Our analysis of college graduates from the Korean Labor and Income Panel Study finds that labor market entry conditions have a large and lasting impact on individuals' career, family, and financial outcomes. Men who graduate from college in a poor economy experience a large and persistent reduction in employment, earnings, and the likelihood of getting married and having children. Women who face limited job opportunities at college graduation substitute into childbearing, having more children at a younger age. Neither male nor female college graduates suffer from reductions in consumption, proxied by household expenditure per capita, but this is achieved by giving up some liquid asset holdings. We also find that recession graduates insure against reduced consumption by living with their parents (men), or by finding a spouse from an advantaged economic background (women).

These empirical results suggest the following. First, labor market entry in a recession has

lingering effects, and may even leave a permanent mark on a young worker's life course, even after 
the penalties in the labor market have disappeared. Second, a large-scale recession has a greater impact than modest recessions, because the affected cohorts suffer not only from reduced earnings but also from prolonged unemployment. Lastly, family provides a risk-sharing mechanism through which recession graduates can protect their living conditions against the initial negative shock. Investigating the spillover effects on the spouse or parents of recession graduates would be an interesting area for future research.

\section{References}

Altonji, Joseph G., Lisa B. Kahn, and Jamin D. Speer, "Cashier or Consultant? Entry Labor Market Conditions, Field of Study, and Career Success," Journal of Labor Economics, 2016, 34 (S1), S361-S401.

Autor, David, David Dorn, and Gordon Hanson, "When Work Disappears: Manufacturing Decline and the Falling Marriage Market Value of Young Men," American Economic Review: Insights, September 2019, 1 (2), 161-178.

Barnes, Kevin, Ali Mansoor, Benjamin Cohen, and Shinji Takagi, The IMF and Recent Capital Account Crises: Indonesia, Korea, Brazil Independent Evaluation Office Reports, International Monetary Fund, September 2003.

Becker, Gary S., “An Economic Analysis of Fertility," in George B. Roberts, ed., Demographic and Economic Change in Developed Countries, Columbia University Press, 1960, pp. 209-240.

_ , "A Theory of the Allocation of Time," The Economic Journal, 1965, 75 (299), 493-517.

_ , “A Theory of Marriage: Part I,” Journal of Political Economy, 1973, 81 (4), 813-846.

- and H. Gregg Lewis, "On the Interaction between the Quantity and Quality of Children," Journal of Political Economy, 1973, 81 (2), S279-S288.

Brunner, Beatrice and Andreas Kuhn, "The Impact of Labor Market Entry Conditions on Initial Job Assignment and Wages," Journal of Population Economics, 07 2014, 27 (3), 705-738.

Card, David and Thomas Lemieux, "Adapting to Circumstances: The Evolution of Work, School, and Living Arrangements among North American Youth," in David G. Blanchflower and Richard B. Freeman, eds., Youth Employment and Joblessness in Advanced Countries, University of Chicago Press, January 2000, chapter 4, pp. 171-214.

CoCkx, Bart, "Do Youths Graduating in a Recession Incur Permanent Losses?," IZA World of Labor, 2016.

Cockx, Bart and Corinna Ghirelli, "Scars of Recessions in a Rigid Labor Market," Labour Economics, 2016, 41, 162-176. 
Currie, Janet and Hannes Schwandt, "Short- and Long-Term Effects of Unemployment on Fertility," Proceedings of the National Academy of Sciences, 2014, 111 (41), 14734-14739.

Deaton, Angus, The Analysis of Household Surveys: A Microeconometric Approach to Development Policy, Washington, D.C.: The World Bank, 1997.

Del Bono, Emilia, Andrea Weber, and Rudolf Winter-Ebmer, "Clash of Career and Family: Fertility Decisions After Job Displacement," Journal of the European Economic Association, 2012, 10 (4), 659-683.

_, , , and _ , "Fertility and Economic Instability: The Role of Unemployment and Job Displacement," Journal of Population Economics, 2015, 28 (2), 463-478.

Dettling, Lisa J. and Joanne W. Hsu, "Returning to the Nest: Debt and Parental Co-Residence among Young Adults," Labour Economics, 2018, 54, 225-236.

Edwards, Kathryn, "Who Helps the Unemployed? Workers' Receipt of Private and Public Transfers," Technical Report WR-1315, RAND, Santa Monica, CA 2019. Education and Labor Working Paper.

Fafchamps, Marcel and Susan Lund, "Risk-Sharing Networks in Rural Philippines," Journal of Development Economics, 2003, 71 (2), 261-287.

_ , Christopher Udry, and Katherine Czukas, "Drought and Saving in West Africa: Are Livestock a Buffer Stock?," Journal of Development Economics, 1998, 55 (2), 273-305.

Fernández-Kranz, Daniel and Núria Rodríguez-Planas, “The Perfect Storm: Graduating during a Recession in a Segmented Labor Market," ILR Review, 2018, 71 (2), 492-524.

Ganong, Peter and Pascal Noel, "Consumer Spending during Unemployment: Positive and Normative Implications," American Economic Review, July 2019, 109 (7), 2383-2424.

Genda, Yuji, Ayako Kondo, and Souichi Ohta, "Long-Term Effects of a Recession at Labor Market Entry in Japan and the United States," Journal of Human Resources, 2010, 45 (1), 157196.

Glover, Andrew, Jonathan Heathcote, Dirk Krueger, and José-Víctor Ríos-Rull, "Intergenerational Redistribution in the Great Recession,' Working Paper 16924, National Bureau of Economic Research April 2011.

Goldstein, Morris, The Asian Financial Crisis: Causes, Cures, and Systemic Implications, Vol. 55, Peterson Institute, 1998.

Gregory, Gary, Charles Harvie, and Hyun-Hoon Lee, "Korean SMEs in the Wake of the Financial Crisis: Strategies, Constraints and Performance in a Global Economy," Economics Working Papers wp02-12, School of Economics, University of Wollongong, NSW, Australia 2002.

Han, Joseph, "Long-Term Effects of Labour Market Entry Conditions: The Case of Korea," Global Economic Review, 2018, 47 (4), 434-463. 
Hashimoto, Yuki and Ayako Kondo, "Long-Term Effects of Labor Market Conditions on Family Formation for Japanese Youth," Journal of the Japanese and International Economies, 2012, 26 (1), 1-22.

Hershbein, Brad J., "Graduating High School in a Recession: Work, Education, and Home Production," The BE Journal of Economic Analysis \& Policy, 2012, 12 (1).

Hofmann, Barbara and Katrin Hohmeyer, "The Effect of the Business Cycle at College Graduation on Fertility," Economics of Education Review, 2016, 55, 88-102.

Hoynes, Hilary, Douglas L. Miller, and Jessamyn Schaller, "Who Suffers during Recessions?," Journal of Economic Perspectives, September 2012, 26 (3), 27-48.

International Monetary Fund, “Korea: Economic and Policy Developments," IMF Staff Country Reports, International Monetary Fund 2000.

Kahn, Lisa B., "The Long-Term Labor Market Consequences of Graduating from College in a Bad Economy," Labour Economics, 2010, 17 (2), 303-316.

Kalleberg, Arne L. and Till M. von Wachter, "The U.S. Labor Market During and After the Great Recession: Continuities and Transformations," RSF: The Russell Sage Foundation Journal of the Social Sciences, 2017, 3 (3), 1-19.

Kawaguchi, Daiji and Ayakos Kondo, "The Effects of Graduating from College during a Recession on Living Standards," Economic Inquiry, 2020, 58 (1), 283-293.

- and Tetsushi Murao, "Labor-Market Institutions and Long-Term Effects of Youth Unemployment," Journal of Money, Credit and Banking, 2014, 46 (S2), 95-116.

Keum, Jae-Ho, "Historial Background Before and After the Financial Crisis," in Joonmo Cho, Richard B. Freeman, Jaeho Keum, and Sunwoong Kim, eds., The Korean Labour Market After the 1997 Economic Crisis, Routledge, 2012, chapter 2, pp. 19-41.

Kim, Kiwhan, "The 1997-98 Korean Financial Crisis: Causes, Policy Response, and Lessons," in "The High-Level Seminar on Crisis Prevention in Emerging Markets" The International Monetary Fund and the Government of Singapore July 2006.

Kolsrud, Jonas, Camille Landais, Peter Nilsson, and Johannes Spinnewijn, "The Optimal Timing of Unemployment Benefits: Theory and Evidence from Sweden," American Economic Review, April 2018, 108 (4-5), 985-1033.

Kondo, Ayako, "Gender-Specific Labor Market Conditions and Family Formation," Journal of Population Economics, 2012, 25 (1), 151-174.

_ , "Differential Effects of Graduating during a Recession across Gender and Race," IZA Journal of Labor Economics, 2015, 4 (23).

_ , "The Effects of Recessions on Family Formation," IZA World of Labor, 2016. 
Krebs, Tom, "Job Displacement Risk and the Cost of Business Cycles," American Economic Review, June 2007, 97 (3), 664-686.

Lee, Jungmin, “The Labor Market in South Korea, 2000-2016,” IZA World of Labor, 2017.

Lee, Keun S., "Financial Crisis in Korea and Imf: Analysis and Perspectives," Proceedings of the Merrill Lynch Center for the Study of International Financial Services and Markets, 1998.

Lee, Phil-Sang, "Economic Crisis and Chaebol Reform in Korea," APEC Study Centre, Discussion Paper Series, 2000, 14.

Lindo, Jason M, “Are Children Really Inferior Goods? Evidence from Displacement-driven Income Shocks," Journal of Human Resources, 2010, 45 (2), 301-327.

Maclean, Johanna Catherine, Reginald Covington, and Asia Sikora Kessler, "Labor Market Conditions at School-Leaving: Long-Run Effects on Marriage and Fertility," Contemporary Economic Policy, 2016, 34 (1), 63-88.

McGarry, Kathleen, "Dynamic Aspects of Family Transfers," Journal of Public Economics, 2016, 137, 1-13.

Oreopoulos, Philip, Till von Wachter, and Andrew Heisz, "The Short- and Long-Term Career Effects of Graduating in a Recession," American Economic Journal: Applied Economics, 2012, $4(1), 1-29$.

Pei, Zhuan, Jörn-Steffen Pischke, and Hannes Schwandt, "Poorly Measured Confounders are More Useful on the Left than on the Right," Journal of Business \& Economic Statistics, 2019, 37 (2), 205-216.

Raaum, Oddbjørn and Knut Røed, "Do Business Cycle Conditions at the Time of Labor Market Entry Affect Future Employment Prospects?," The Review of Economics and Statistics, 2006, 88 (2), 193-210.

Radelet, Steven and Jeffrey Sachs, "The Onset of the East Asian Financial Crisis," in Paul Krugman, ed., Currency Crises, University of Chicago Press, January 2000, chapter 4, pp. 105-153.

Ravn, Morten O. and Harald Uhlig, "On Adjusting the Hodrick-Prescott Filter for the Frequency of Observations," The Review of Economics and Statistics, 2002, 84 (2), 371-376.

Raymo, James M. and Akihisa Shibata, "Unemployment, Nonstandard Employment, and Fertility: Insights from Japan's “Lost 20 Years”," Demography, 2017, 54 (6), 2301-2329.

Rosenzweig, Mark and Kenneth I. Wolpin, "Credit Market Constraints, Consumption Smoothing, and the Accumulation of Durable Production Assets in Low-Income Countries: Investment in Bullocks in India," Journal of Political Economy, 1993, 101 (2), 223-44.

Rothstein, Jesse, “The Lost Generation? Scarring after the Great Recession,” May 2019. 
Schwandt, Hannes and Till von Wachter, "Unlucky Cohorts: Estimating the Long-Term Effects of Entering the Labor Market in a Recession in Large Cross-Sectional Data Sets," Journal of Labor Economics, 2019, 37 (S1), S161-S198.

_ and _. "Socioeconomic Decline and Death: Midlife Impacts of Graduating in a Recession," Working Paper 26638, National Bureau of Economic Research January 2020.

Sharma, Shalendra D., The Asian Financial Crisis: Crisis, Reform, and Recovery, Manchester, UK: Manchester University Press, 2003.

Townsend, Robert, “Risk and Insurance in Village India,” Econometrica, 1994, 62 (3), 539-91.

Uribe, Martin and Stephanie Schmitt-Grohé, Open Economy Macroeconomics, Princeton University Press, 2017.

U.S. Bureau of Labor Statistics, "The Recession of 2007-2009," BLS Spotlight on Statistics, 2012.

van den Berge, Wiljan, "Bad Start, Bad Match? The Early Career Effects of Graduating in a Recession for Vocational and Academic Graduates," Labour Economics, 2018, 53, 75-96.

Willis, Robert J., "A New Approach to the Economic Theory of Fertility Behavior," Journal of Political Economy, 1973, 81 (2, Part 2), S14-S64.

Wozniak, Abigail, "Are College Graduates More Responsive to Distant Labor Market Opportunities?," The Journal of Human Resources, 2010, 45 (4), 944-970. 


\title{
Online Supplementary Appendix of \\ "The Long-Term Effects of Labor Market Entry in a Recession: Evidence from the Asian Financial Crisis"
}

\author{
Eleanor Jawon Choi Jaewoo Choi Hyelim Son \\ Hanyang University KDI University of Seoul
}




\section{S1 Additional Data Used for Robustness Checks}

\section{S1.1 Economically Active Population Survey (EAPS)}

The Economically Active Population Survey (EAPS) is a monthly survey of individuals aged 15 and over in approximately 33,000 households, conducted by Statistics Korea. The survey was first conducted in 1957 under the name of "Labor Force Survey," and has been the primary source of labor force statistics for the population of South Korea. The microdata from 1968 to present are available from the Microdata Integrated Service (MDIS) maintained by Statistics Korea.

In Section 6.2, we pool data from the 1989-2017 EAPS to measure the effect of the unemployment rate at college gradation on employment probability over the first 10 years of potential experience. Because the year of degree completion is not reported in the EAPS, we can only compute the reduced form effect of the unemployment rate in the predicted year of college graduation. The predicted college graduation year is constructed based on the typical age at college graduation, as described in Section 6.1. To make the analysis using the EAPS and KLIPS data as comparable as possible, we restrict our EAPS sample to individuals whose predicted graduation year is between 1989 and 2010. In the regression analysis, the outcome variable of interest is the employment dummy. Control variables include a cubic function of predicted college graduation year, fixed effects for years since predicted year of graduation and calendar year, and an indicator for 4-year college graduates. Standard errors are clustered only at the level of predicted graduation year, because no regional information is available in the EAPS data. Although the March and August supplements of the EAPS collect job and income data on wage workers, these supplemental surveys started in 2001 and thus are not suitable for measuring earnings losses due to the Asian financial crisis.

\section{S1.2 Population and Housing Census (Census)}

The Population and Housing Census (Census) is a quinquennial survey collecting information related to population, households, and housing characteristics, conducted by Statistics Korea. The population census started in 1925, and the questions on housing were added to the survey in 1960. The 1960-2015 Census microdata are available from the MDIS.

We use the 2\% sample of the 2010 and 2015 Census for the analysis in Section 6.2. After constructing the predicted year of college graduation, we restrict the sample to those with the predicted graduation year between 1989 and 2010. With no information on the actual year of college graduation, we estimate the reduced form effect of the unemployment rate in the predicted graduation year. The outcome variables of interest include whether an individual has ever been married, whether an individual has any children, and the number of children. Because the information about childbirth exists only for women, we assign men the same number of children as their current spouse. Control variables include a cubic function of predicted college graduation year, fixed effects for years since predicted year of graduation and region of birth, and an indicator for 4-year college graduates. Standard errors are clustered at the level of predicted graduation year by region of birth. 
A. Men

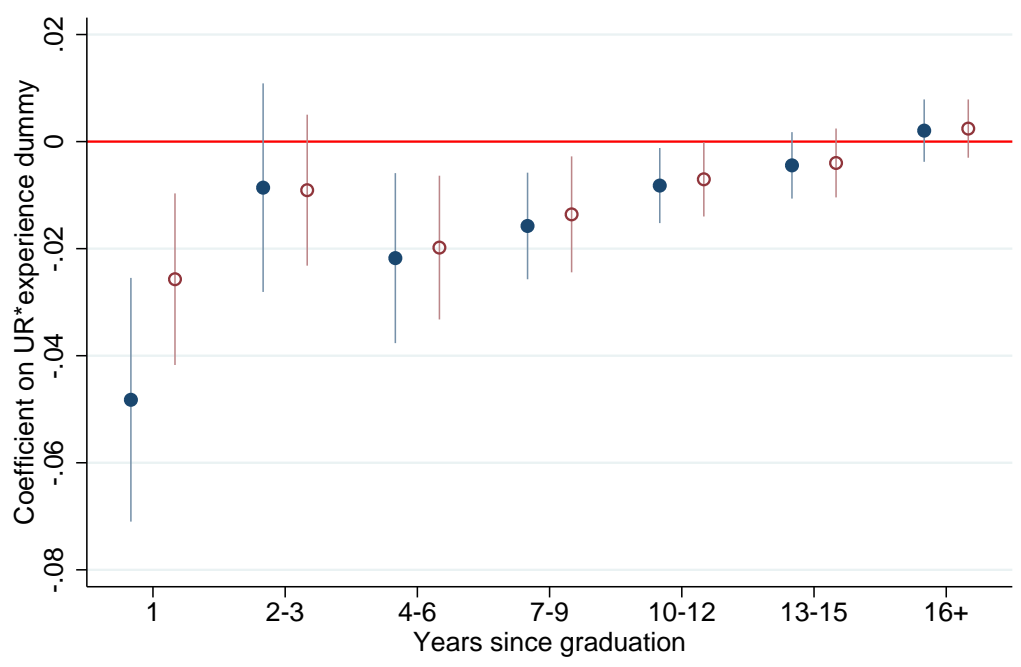

- person survey $\circ$ including work history record
B. Women

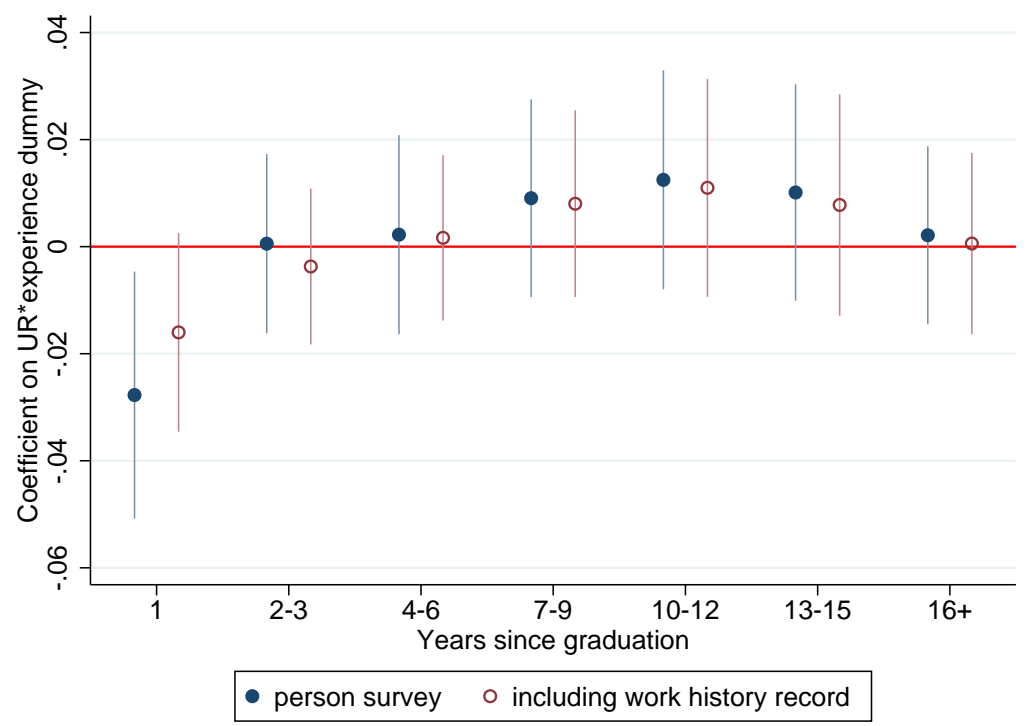

Figure S1: Effects of National Unemployment Rate at Graduation on Employment, by Data Source

Notes. The number of observations (including those from the work history record) are 30,131 for men and 25,795 for women. Each dot represents the coefficient estimate on an interaction term between the national $U R$ and a potential experience dummy. Vertical spikes around each point estimate represent the $95 \%$ confidence interval, constructed using robust standard errors clustered at the level of graduation year by region. Regressions include a cubic function of college graduation year, and fixed effects for the region of college graduation, years since graduation, and calendar year. Controls for background characteristics include father's years of education, father's years of education squared, dummies for parents' job status at age 14 (standard worker, non-standard worker, business owner hiring employees, business owner with no employee), and an indicator for 4-year college graduates. Missing values in background covariates are imputed using mean values, and dummies for missing observations are also controlled for. 
A. Employed

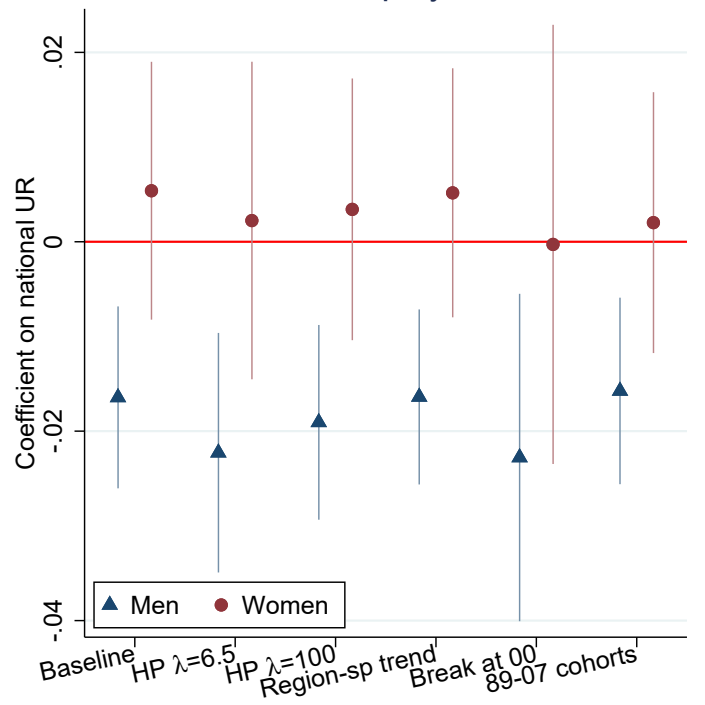

D. Log earnings

$\omega$

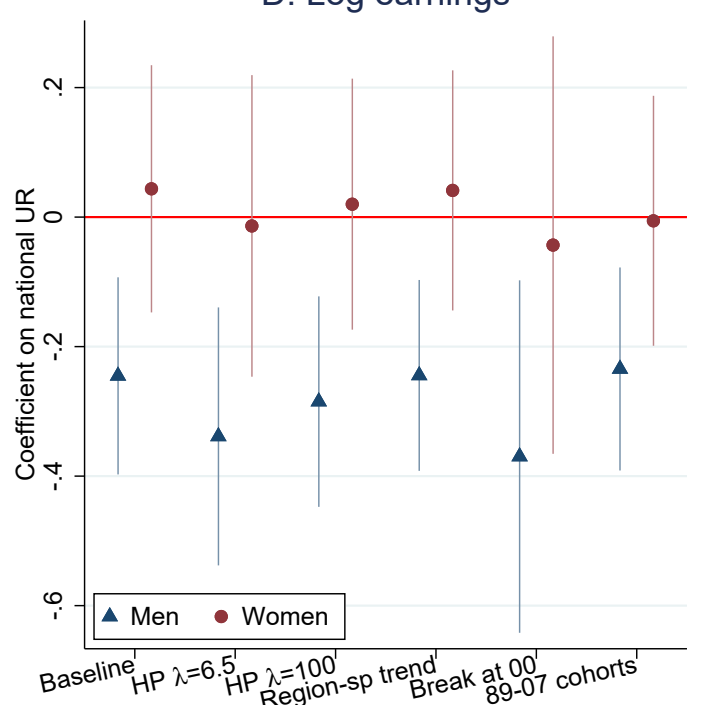

B. Earnings

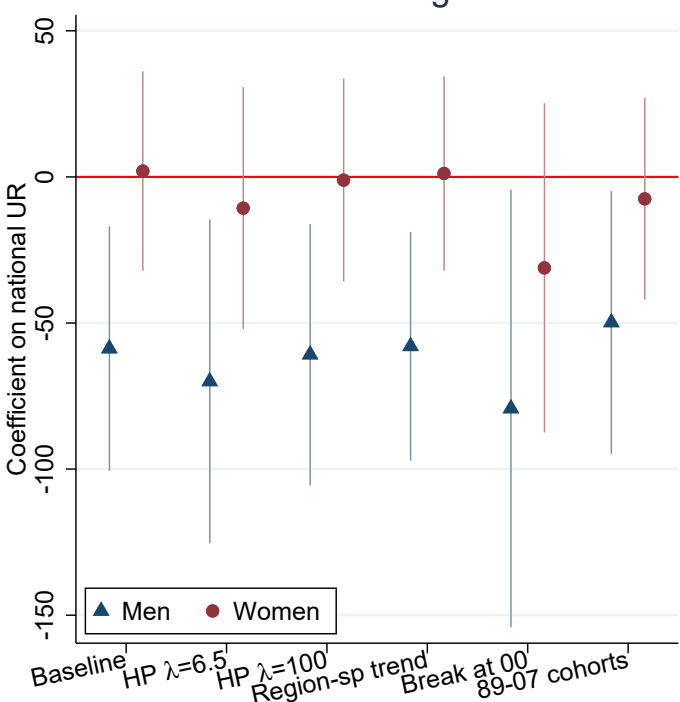

E. Log earnings (employed only)

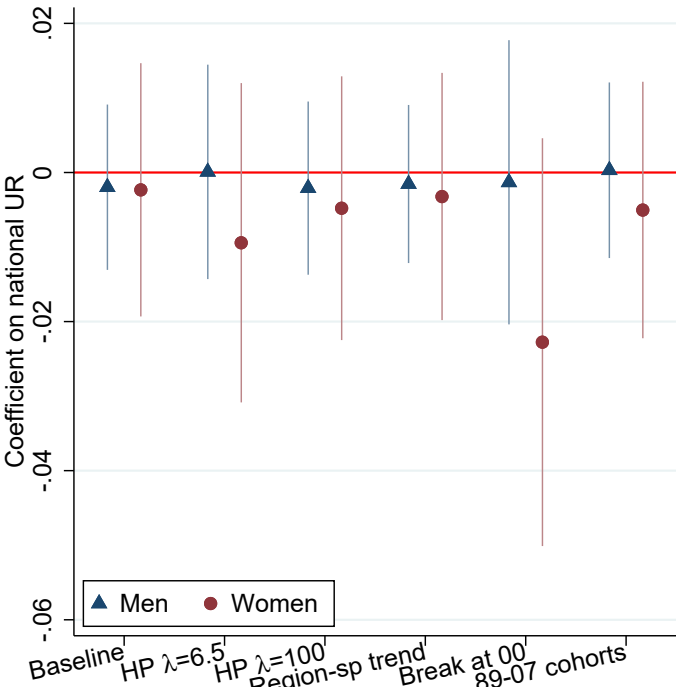

C. Earnings (employed only)

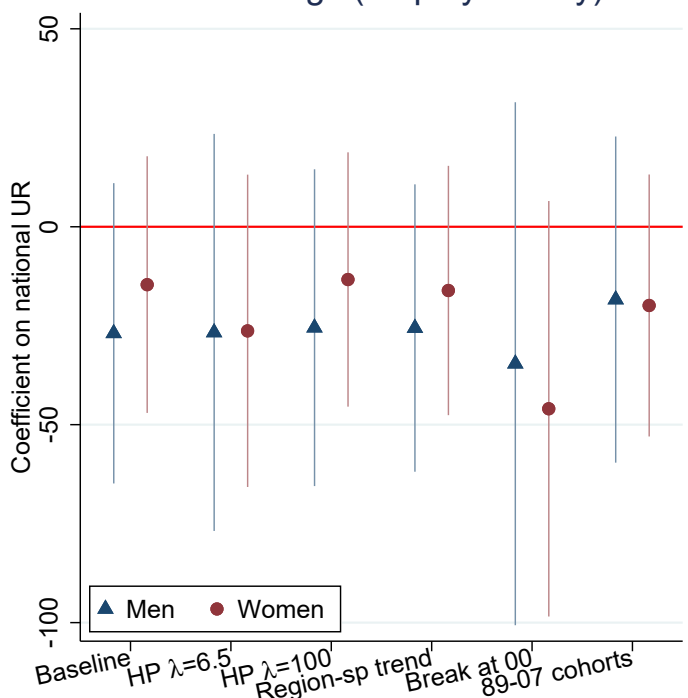

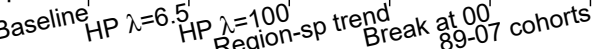

Figure S2: Effects of National Unemployment Rate at Graduation on Employment and Earnings (Experience Years 1-10), Using Alternative Specifications and Sample Restrictions

Notes. In panels B and C, monthly earnings are in thousands of $2015 \mathrm{KRW}$, where 1 USD is worth approximately 1,100 KRW. In panels D and E, we take the logarithm of monthly earnings in $2015 \mathrm{KRW}$ In panel D, to construct log monthly earnings for individuals who are unemployed or not in the labor force, we impute zero earnings with $1 \mathrm{KRW}$ before taking the logarithm. Each bullet shape represents the coefficient estimate on the national $U R$ from a separate regression estimating equation (2). Vertical spikes around each point estimate represent the $95 \%$ confidence interval, constructed using robust standard errors clustered at the level of graduation year by region. Regressions include a cubic function of college graduation year, and fixed effects for the region of college graduation, years since graduation, and calendar year. When we use the HP-filtered series of the national $U R$, the cubic function of college graduation year is dropped from the regression. Controls for background characteristic include father's years of education, father's years of education squared, dummies for parents' job status at age 14 (standard worker, non-standard worker, business owner hiring employees, business owne with no employee), and an indicator for 4 -year college graduates. Missing values in background covariates are imputed using mean values, and dummies for missing observations are also controlled for. 

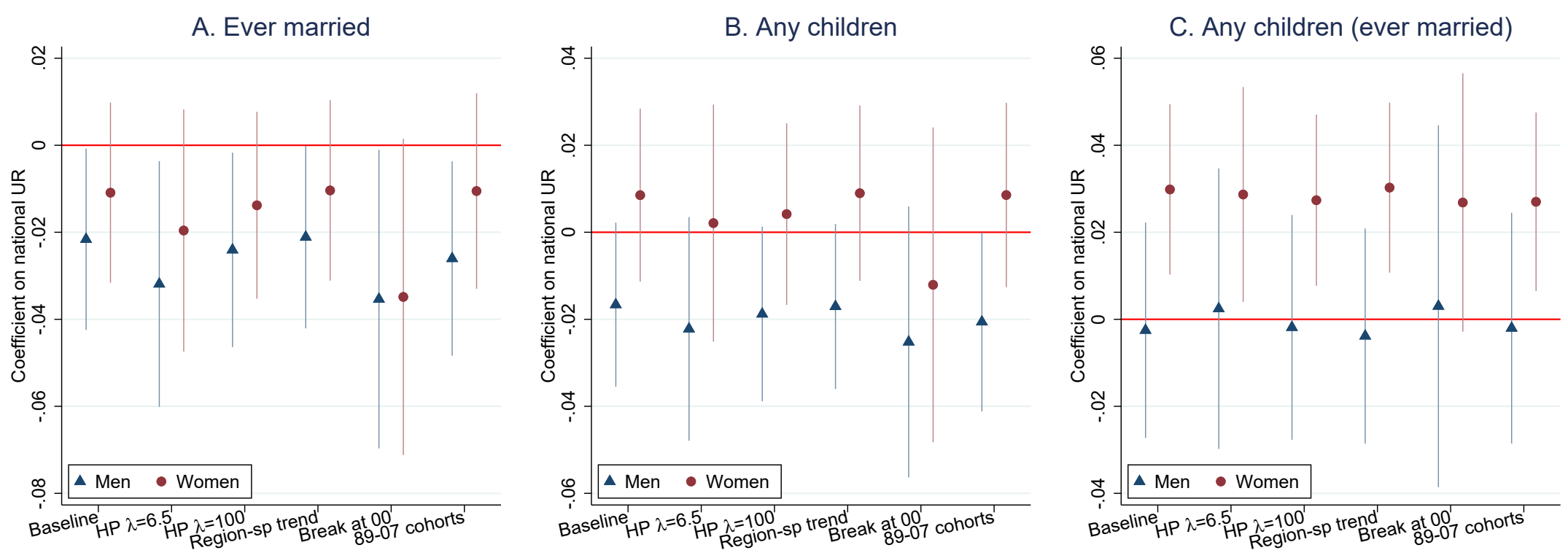

D. Number of children

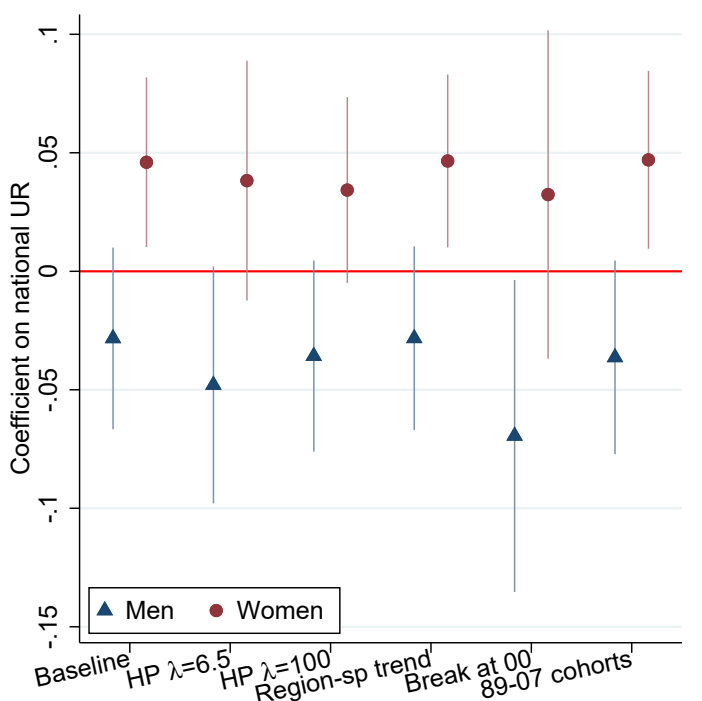

E. Number of children (ever married)

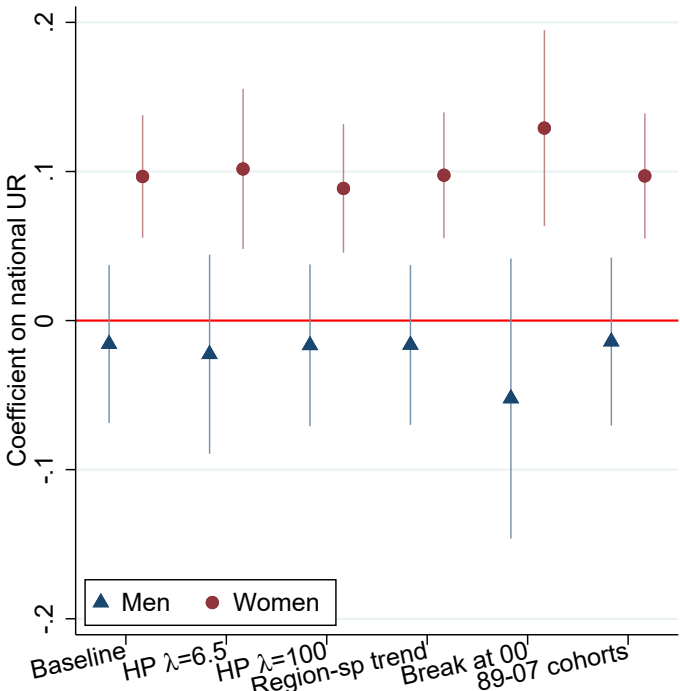

Figure S3: Effects of National Unemployment Rate at Graduation on Marriage and Fertility, Using Alternative Specifications and Sample Restrictions

Notes. Each bullet shape represents the coefficient estimate on the national $U R$ from a separate regression estimating equation (3). Vertical spikes around each point estimate represent the 95\% confidence interval, constructed using robust standard errors clustered at the level of graduation year by region. Regressions include a cubic function of college graduation year, and fixed effects for the region of college graduation and years since graduation. When we use the HP-filtered series of the national $U R$, the cubic function of college graduation year is dropped from the regression. Controls for background characteristics include father's years of education, father's years of education squared, dummies for parents' job status at age 14 (standard worker, non-standard worker, business owner hiring employees, business owner with no employee), and an indicator for 4-year college graduates. Missing values in background covariates are imputed using mean values, and dummies for missing observations are also controlled for. 
A. Log expenditure per capita

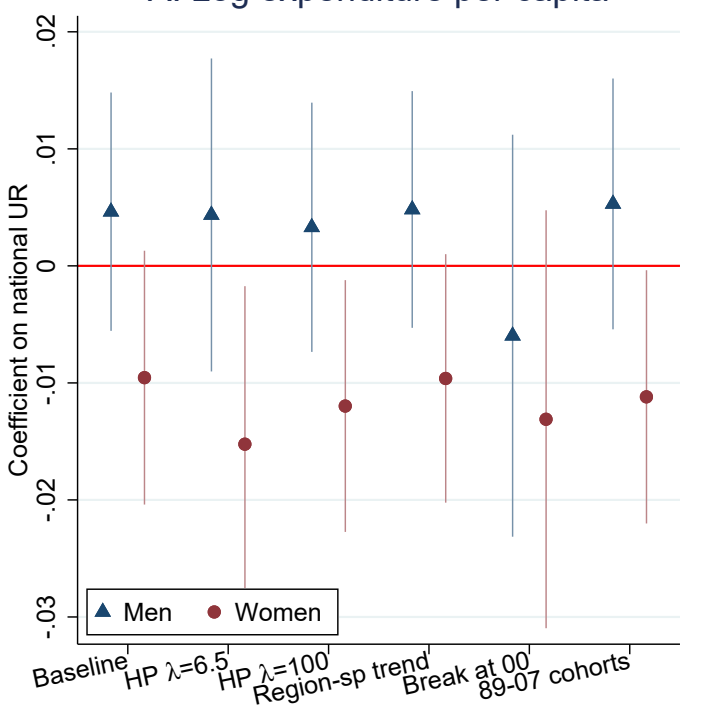

D. Log deposits

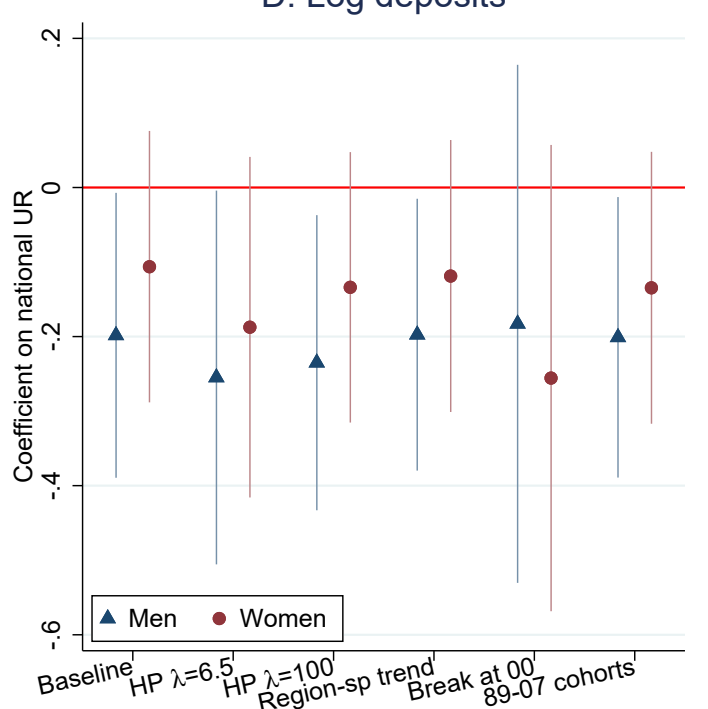

B. Log debt

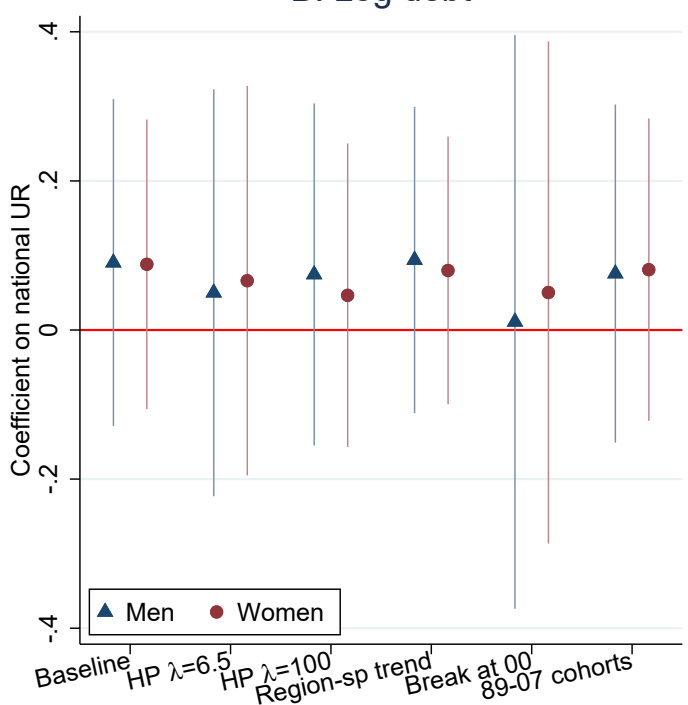

E. Log financial assets (excl. deposits)

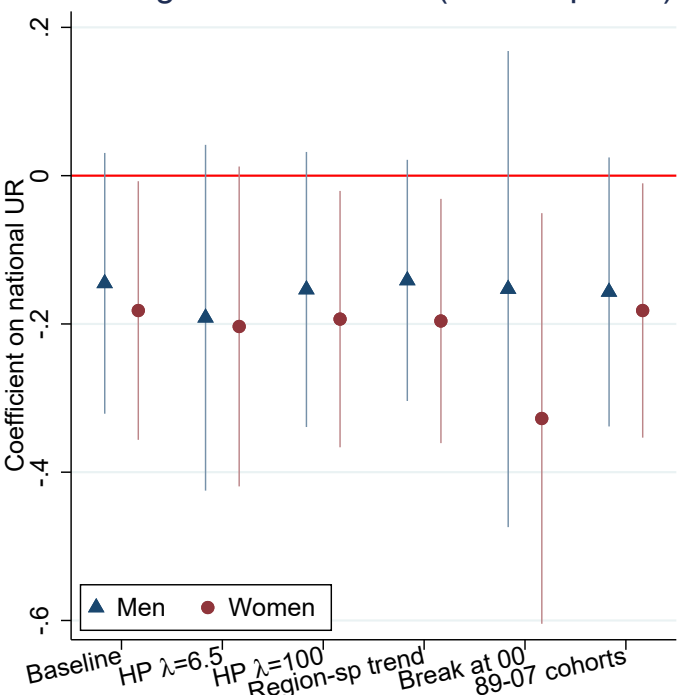

C. Log financial assets

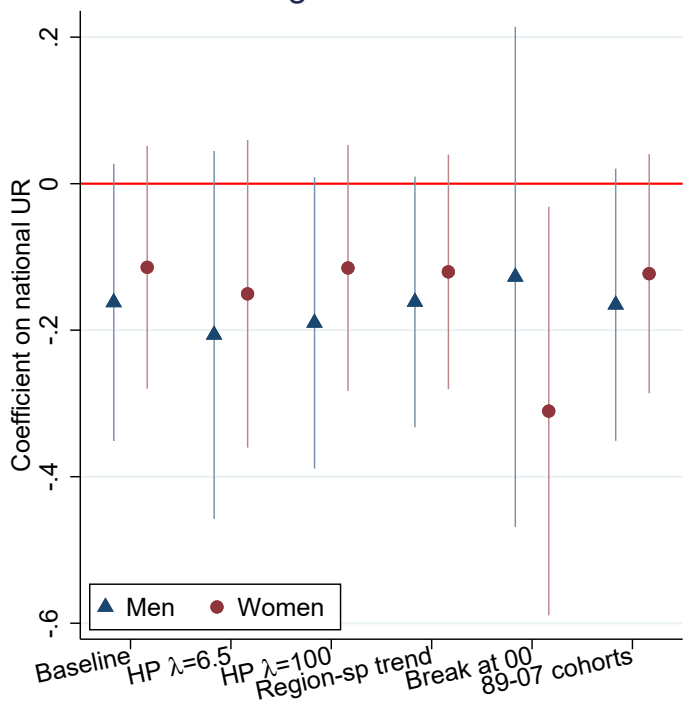

F. Home ownership

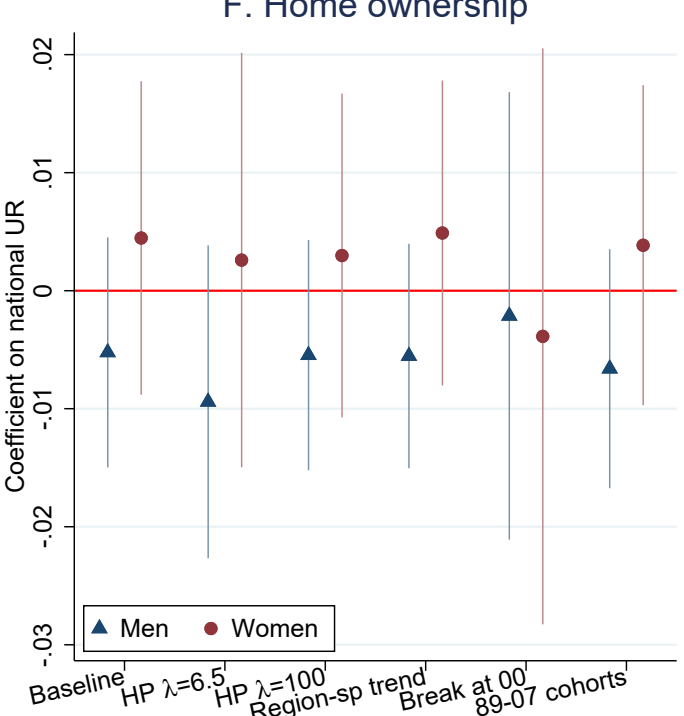

Figure S4: Effects of National Unemployment Rate at Graduation on Consumption and Asset Holdings (Experience Years 1-10), Using Alternative Specifications and Sample Restrictions

Notes. Monthly expenditure per capita and the values of debt and financial assets are inflation-adjusted to $2015 \mathrm{KRW}$, where 1 USD is worth approximately 1,100 KRW. Zero values are imputed with 1 KRW before taking the logarithm. Each bullet shape represents the coefficient estimate on the national $U R$ from a separate regression estimating equation (2). Vertical spikes around each point estimate represent the $95 \%$ confidence interval, constructed using robust standard errors clustered at the level of graduation year by region. Regressions include a cubic function of college graduation year, and fixed effects for the region of college graduation, years since graduation, and calendar year. When we use the HP-filtered series of the national $U R$, the cubic function of college graduation year is dropped from the regression. Controls for background characteristics include father's years of education, father's years of education squared, dummies for parents' job status at age 14 (standard worker, non-standard worker, business owner hiring employees, business owner with no employee), and an indicator for 4 -year college graduates. Missing values in background covariates are imputed using mean values, and
dummies for missing observations are also controlled for. 
Table S1: Effects of National Unemployment Rate at Graduation on Employment and Earnings

\begin{tabular}{|c|c|c|c|c|c|}
\hline & $\begin{array}{c}\text { Employed } \\
(1)\end{array}$ & $\begin{array}{c}\text { Earnings }^{a} \\
(2)\end{array}$ & $\begin{array}{c}\text { Earnings }^{a} \\
\text { (employed only) } \\
\text { (3) }\end{array}$ & $\begin{array}{c}\text { Log earnings }^{b} \\
\text { (4) }\end{array}$ & $\begin{array}{c}\text { Log earnings } \\
\text { (employed only) } \\
(5)\end{array}$ \\
\hline \multicolumn{6}{|l|}{ A. Men } \\
\hline$U R \times 1[$ Yrs since $\operatorname{grad}=1]$ & $\begin{array}{c}-0.048^{* * *} \\
(0.012)\end{array}$ & $\begin{array}{l}-17.4 \\
(35.8)\end{array}$ & $\begin{array}{c}57.7 \\
(40.0)\end{array}$ & $\begin{array}{c}-0.696^{* * * *} \\
(0.164)\end{array}$ & $\begin{array}{c}0.004 \\
(0.014)\end{array}$ \\
\hline$U R \times 1[$ Yrs since $\operatorname{grad}=2-3]$ & $\begin{array}{l}-0.009 \\
(0.010)\end{array}$ & $\begin{array}{c}-3.4 \\
(37.5)\end{array}$ & $\begin{array}{c}27.5 \\
(29.0)\end{array}$ & $\begin{array}{l}-0.096 \\
(0.150)\end{array}$ & $\begin{array}{l}-0.000 \\
(0.009)\end{array}$ \\
\hline$U R \times 1[$ Yrs since grad $=4-6]$ & $\begin{array}{c}-0.022 * * * \\
(0.008)\end{array}$ & $\begin{array}{c}-104.1 * * * \\
(31.9)\end{array}$ & $\begin{array}{c}-62.2^{* *} \\
(26.1)\end{array}$ & $\begin{array}{c}-0.336 * * * \\
(0.127)\end{array}$ & $\begin{array}{l}-0.008 \\
(0.006)\end{array}$ \\
\hline$U R \times 1[$ Yrs since $\operatorname{grad}=7-9]$ & $\begin{array}{c}-0.016^{* * *} \\
(0.005)\end{array}$ & $\begin{array}{c}-59.1 * * \\
(29.4)\end{array}$ & $\begin{array}{l}-23.3 \\
(25.9)\end{array}$ & $\begin{array}{c}-0.252 * * * \\
(0.084)\end{array}$ & $\begin{array}{l}-0.001 \\
(0.008)\end{array}$ \\
\hline$U R \times 1[$ Yrs since $\operatorname{grad}=10-12]$ & $\begin{array}{c}-0.008^{* *} \\
(0.004)\end{array}$ & $\begin{array}{l}-45.1 \\
(42.0)\end{array}$ & $\begin{array}{l}-18.8 \\
(41.0)\end{array}$ & $\begin{array}{l}-0.089 \\
(0.065)\end{array}$ & $\begin{array}{l}-0.002 \\
(0.009)\end{array}$ \\
\hline$U R \times 1[$ Yrs since $\operatorname{grad}=13-15]$ & $\begin{array}{l}-0.004 \\
(0.003)\end{array}$ & $\begin{array}{l}-18.7 \\
(40.6)\end{array}$ & $\begin{array}{l}-1.0 \\
(40.0)\end{array}$ & $\begin{array}{l}-0.053 \\
(0.056)\end{array}$ & $\begin{array}{c}0.004 \\
(0.010)\end{array}$ \\
\hline$U R \times 1[$ Yrs since $\operatorname{grad}=16+]$ & $\begin{array}{c}0.002 \\
(0.003)\end{array}$ & $\begin{array}{c}5.8 \\
(35.3)\end{array}$ & $\begin{array}{c}-1.2 \\
(38.2)\end{array}$ & $\begin{array}{c}0.045 \\
(0.047)\end{array}$ & $\begin{array}{c}0.005 \\
(0.010)\end{array}$ \\
\hline Adjusted $R^{2}$ & 0.077 & 0.155 & 0.140 & 0.088 & 0.236 \\
\hline Observations & 22,856 & 22,617 & 20,254 & 22,617 & 20,051 \\
\hline Mean of $Y$ & 0.897 & $2,870.8$ & $3,205.7$ & 13.172 & 14.858 \\
\hline \multicolumn{6}{|l|}{ B. Women } \\
\hline$U R \times 1[$ Yrs since $\operatorname{grad}=1]$ & $\begin{array}{c}-0.028^{* *} \\
(0.012)\end{array}$ & $\begin{array}{c}-36.0^{* *} \\
(17.3)\end{array}$ & $\begin{array}{c}9.1 \\
(20.6)\end{array}$ & $\begin{array}{c}-0.344 * * \\
(0.158)\end{array}$ & $\begin{array}{c}-0.020^{*} \\
(0.012)\end{array}$ \\
\hline$U R \times 1[$ Yrs since $\operatorname{grad}=2-3]$ & $\begin{array}{c}0.001 \\
(0.008)\end{array}$ & $\begin{array}{c}-8.7 \\
(15.1)\end{array}$ & $\begin{array}{c}-3.8 \\
(16.4)\end{array}$ & $\begin{array}{l}-0.010 \\
(0.117)\end{array}$ & $\begin{array}{l}-0.001 \\
(0.009)\end{array}$ \\
\hline$U R \times 1[$ Yrs since grad $=4-6]$ & $\begin{array}{c}0.002 \\
(0.009)\end{array}$ & $\begin{array}{l}-6.3 \\
(23.7)\end{array}$ & $\begin{array}{l}-15.7 \\
(19.1)\end{array}$ & $\begin{array}{l}-0.019 \\
(0.143)\end{array}$ & $\begin{array}{l}-0.002 \\
(0.009)\end{array}$ \\
\hline$U R \times 1[$ Yrs since grad $=7-9]$ & $\begin{array}{c}0.009 \\
(0.009)\end{array}$ & $\begin{array}{c}7.2 \\
(24.9)\end{array}$ & $\begin{array}{l}-18.0 \\
(26.2)\end{array}$ & $\begin{array}{c}0.097 \\
(0.131)\end{array}$ & $\begin{array}{c}0.003 \\
(0.013)\end{array}$ \\
\hline$U R \times 1[$ Yrs since $\operatorname{grad}=10-12]$ & $\begin{array}{c}0.012 \\
(0.010)\end{array}$ & $\begin{array}{c}6.5 \\
(28.5)\end{array}$ & $\begin{array}{l}-46.5 \\
(31.3)\end{array}$ & $\begin{array}{c}0.120 \\
(0.149)\end{array}$ & $\begin{array}{l}-0.000 \\
(0.012)\end{array}$ \\
\hline$U R \times 1[$ Yrs since grad $=13-15]$ & $\begin{array}{c}0.010 \\
(0.010)\end{array}$ & $\begin{array}{c}22.7 \\
(27.4)\end{array}$ & $\begin{array}{l}-6.7 \\
(33.7)\end{array}$ & $\begin{array}{c}0.097 \\
(0.146)\end{array}$ & $\begin{array}{c}0.012 \\
(0.014)\end{array}$ \\
\hline$U R \times 1[$ Yrs since $\operatorname{grad}=16+]$ & $\begin{array}{c}0.002 \\
(0.008)\end{array}$ & $\begin{array}{c}30.9 \\
(26.6)\end{array}$ & $\begin{array}{c}38.5 \\
(35.4)\end{array}$ & $\begin{array}{c}0.008 \\
(0.125)\end{array}$ & $\begin{array}{c}0.031 * * \\
(0.013)\end{array}$ \\
\hline Adjusted $R^{2}$ & 0.024 & 0.037 & 0.100 & 0.028 & 0.109 \\
\hline Observations & 20,795 & 20,686 & 11,906 & 20,686 & 11,549 \\
\hline Mean of $Y$ & 0.578 & $1,145.4$ & $1,990.0$ & 8.037 & 14.396 \\
\hline
\end{tabular}

Notes. Monthly earnings are inflation-adjusted to $2015 \mathrm{KRW}$, where 1 USD is worth approximately 1,100 KRW. Regressions include a cubic function of college graduation year, and fixed effects for the region of college graduation, years since graduation, and calendar year. Controls for background characteristics include father's years of education, father's years of education squared, dummies for parents' job status at age 14 (standard worker, non-standard worker, business owner hiring employees, business owner with no employee), and an indicator for 4-year college graduates. Missing values in background covariates are imputed using mean values, and dummies for missing observations are also controlled for. Robust standard errors in parentheses are clustered at the level of graduation year by region. * $p<0.10, * * p<0.05, * * * p<0.01$ ${ }^{a}$ In thousands of $2015 \mathrm{KRW}$.

${ }^{b}$ When constructing log earnings for individuals who are unemployed or not in the labor force, we impute zero earnings with $1 \mathrm{KRW}$ before taking the logarithm. 
Table S2: Effects of National Unemployment Rate at Graduation on Job Quality

\begin{tabular}{|c|c|c|c|c|}
\hline & $\begin{array}{l}\text { Work hours } \\
\text { (1) }\end{array}$ & $\begin{array}{c}\text { Full-time emp. } \\
\text { (2) }\end{array}$ & $\begin{array}{c}\text { Standard emp. } \\
\text { (3) }\end{array}$ & $\begin{array}{c}\text { Self-employed } \\
\text { (4) }\end{array}$ \\
\hline \multicolumn{5}{|l|}{ A. Men } \\
\hline \multirow[t]{2}{*}{$U R \times 1[$ Yrs since $\operatorname{grad}=1]$} & -0.460 & -0.001 & -0.020 & 0.001 \\
\hline & $(0.463)$ & (0.008) & $(0.014)$ & $(0.004)$ \\
\hline \multirow{2}{*}{$U R \times 1[$ Yrs since $\operatorname{grad}=2-3]$} & 0.086 & -0.001 & $0.012 *$ & $0.011^{* *}$ \\
\hline & $(0.283)$ & $(0.007)$ & $(0.007)$ & $(0.005)$ \\
\hline \multirow{2}{*}{$U R \times 1[$ Yrs since grad $=4-6]$} & -0.022 & -0.001 & 0.001 & -0.003 \\
\hline & (0.188) & (0.002) & $(0.005)$ & (0.004) \\
\hline \multirow{2}{*}{$U R \times 1[$ Yrs since grad $=7-9]$} & 0.202 & 0.002 & 0.003 & -0.005 \\
\hline & $(0.190)$ & $(0.003)$ & $(0.006)$ & $(0.005)$ \\
\hline \multirow[t]{2}{*}{$U R \times 1[$ Yrs since $\operatorname{grad}=10-12]$} & -0.110 & $0.004^{*}$ & 0.002 & -0.005 \\
\hline & $(0.168)$ & $(0.002)$ & $(0.006)$ & $(0.006)$ \\
\hline \multirow[t]{2}{*}{$U R \times 1[$ Yrs since $\operatorname{grad}=13-15]$} & -0.133 & 0.001 & 0.005 & 0.003 \\
\hline & $(0.176)$ & (0.002) & $(0.006)$ & $(0.007)$ \\
\hline \multirow[t]{2}{*}{$U R \times 1[$ Yrs since $\operatorname{grad}=16+]$} & 0.189 & 0.001 & 0.005 & 0.004 \\
\hline & $(0.157)$ & (0.002) & (0.006) & (0.008) \\
\hline Adjusted $R^{2}$ & 0.048 & 0.010 & 0.021 & 0.044 \\
\hline Observations & 20,483 & 17,132 & 16,678 & 22,856 \\
\hline Mean of $Y$ & 49.008 & 0.984 & 0.898 & 0.137 \\
\hline \multicolumn{5}{|l|}{ B. Women } \\
\hline \multirow[t]{2}{*}{$U R \times 1[$ Yrs since $\operatorname{grad}=1]$} & 0.325 & 0.004 & -0.014 & -0.000 \\
\hline & $(0.491)$ & (0.011) & (0.013) & $(0.004)$ \\
\hline \multirow[t]{2}{*}{$U R \times 1[$ Yrs since $\operatorname{grad}=2-3]$} & 0.045 & -0.004 & 0.009 & -0.001 \\
\hline & $(0.356)$ & (0.008) & $(0.010)$ & $(0.003)$ \\
\hline \multirow[t]{2}{*}{$U R \times 1[$ Yrs since grad $=4-6]$} & 0.082 & 0.004 & $-0.020 * *$ & -0.004 \\
\hline & $(0.254)$ & $(0.005)$ & (0.008) & $(0.004)$ \\
\hline \multirow[t]{2}{*}{$U R \times 1[$ Yrs since $\mathrm{grad}=7-9]$} & 0.258 & 0.004 & 0.002 & -0.004 \\
\hline & $(0.299)$ & $(0.005)$ & (0.009) & $(0.003)$ \\
\hline \multirow[t]{2}{*}{$U R \times 1[$ Yrs since $\operatorname{grad}=10-12]$} & 0.326 & $0.010^{*}$ & 0.001 & -0.002 \\
\hline & $(0.285)$ & (0.005) & (0.009) & $(0.004)$ \\
\hline \multirow[t]{2}{*}{$U R \times 1[$ Yrs since $\operatorname{grad}=13-15]$} & 0.051 & -0.003 & -0.016 & -0.001 \\
\hline & $(0.259)$ & $(0.006)$ & $(0.010)$ & $(0.006)$ \\
\hline \multirow[t]{2}{*}{$U R \times 1[$ Yrs since $\operatorname{grad}=16+]$} & $0.449^{*}$ & $0.013^{*}$ & 0.012 & 0.007 \\
\hline & $(0.242)$ & (0.008) & $(0.013)$ & $(0.005)$ \\
\hline Adjusted $R^{2}$ & 0.065 & 0.024 & 0.032 & 0.030 \\
\hline Observations & 12,004 & 10,192 & 9,922 & 20,795 \\
\hline Mean of $Y$ & 42.293 & 0.922 & 0.788 & 0.069 \\
\hline
\end{tabular}

Notes. Work hours are examined for the employed. The probability of having a full-time or standard employment arrangement is analyzed for wage workers. Regressions include a cubic function of college graduation year, and fixed effects for the region of college graduation, years since graduation, and calendar year. Controls for background characteristics include father's years of education, father's years of education squared, dummies for parents' job status at age 14 (standard worker, non-standard worker, business owner hiring employees, business owner with no employee), and an indicator for 4-year college graduates. Missing values in background covariates are imputed using mean values, and dummies for missing observations are also controlled for. Robust standard errors in parentheses are clustered at the level of graduation year by region. * $p<0.10, * * p<0.05, * * * p<0.01$ 
Table S3: Long-Term Effects of National Unemployment Rate at Graduation on Spouse Characteristics

\begin{tabular}{|c|c|c|c|c|c|c|}
\hline & \multicolumn{2}{|c|}{ Father's edu. level } & \multicolumn{4}{|c|}{ Parent's job status at age 14} \\
\hline & $\begin{array}{c}\text { Less } \\
\text { than HS } \\
(1)\end{array}$ & $\begin{array}{c}\text { HS or } \\
\text { more } \\
(2)\end{array}$ & $\begin{array}{l}\text { Standard } \\
\text { worker } \\
(3)\end{array}$ & $\begin{array}{l}\text { Non-standard } \\
\text { worker } \\
\text { (4) }\end{array}$ & $\begin{array}{c}\text { Busi. owner } \\
\text { (with employee) } \\
\text { (5) }\end{array}$ & $\begin{array}{c}\text { Busi. owner } \\
\text { (no employee) } \\
(6)\end{array}$ \\
\hline \multicolumn{7}{|l|}{ A. Men } \\
\hline National $U R$ & $\begin{array}{c}0.006 \\
(0.013)\end{array}$ & $\begin{array}{c}-0.006 \\
(0.013)\end{array}$ & $\begin{array}{c}0.008 \\
(0.014)\end{array}$ & $\begin{array}{c}0.000 \\
(0.006)\end{array}$ & $\begin{array}{l}-0.012 \\
(0.011)\end{array}$ & $\begin{array}{c}0.000 \\
(0.017)\end{array}$ \\
\hline Adjusted $R^{2}$ & 0.078 & 0.075 & 0.025 & 0.015 & 0.003 & 0.052 \\
\hline Observations & 1,664 & 1,664 & 1,643 & 1,643 & 1,643 & 1,643 \\
\hline Mean of $Y$ & 0.434 & 0.543 & 0.397 & 0.054 & 0.125 & 0.386 \\
\hline \multicolumn{7}{|l|}{ B. Women } \\
\hline National $U R$ & $\begin{array}{l}-0.024 \\
(0.016)\end{array}$ & $\begin{array}{c}0.024 \\
(0.015)\end{array}$ & $\begin{array}{l}0.030 * \\
(0.016)\end{array}$ & $\begin{array}{l}-0.003 \\
(0.009)\end{array}$ & $\begin{array}{l}-0.006 \\
(0.010)\end{array}$ & $\begin{array}{l}-0.021 \\
(0.017)\end{array}$ \\
\hline Adjusted $R^{2}$ & 0.059 & 0.054 & 0.027 & -0.003 & -0.005 & 0.034 \\
\hline Observations & 1,505 & 1,505 & 1,496 & 1,496 & 1,496 & 1,496 \\
\hline Mean of $Y$ & 0.419 & 0.550 & 0.373 & 0.067 & 0.136 & 0.368 \\
\hline
\end{tabular}

Notes. Regressions include a cubic function of college graduation year, and fixed effects for the region of college graduation and years since graduation. Controls for background characteristics include father's years of education, father's years of education squared, dummies for parents' job status at age 14 (standard worker, non-standard worker, business owner hiring employees, business owner with no employee), and an indicator for 4-year college graduates. Missing values in background covariates are imputed using mean values, and dummies for missing observations are also controlled for. Robust standard errors in parentheses are clustered at the level of graduation year by region. * $p<0.10, * * p<0.05, * * * p<0.01$ 
Table S4: Effects of National Unemployment Rate at Graduation on Consumption, Asset Holdings, and Living Arrangements

\begin{tabular}{|c|c|c|c|c|c|c|c|}
\hline & $\begin{array}{c}\text { Log expenditures } \\
\text { per capita } \\
\text { (1) }\end{array}$ & $\begin{array}{c}\log \operatorname{debt}^{a, b} \\
(2) \\
\end{array}$ & $\begin{array}{c}\text { Log fin. } \\
\text { assets }^{a, b} \\
(3)\end{array}$ & $\begin{array}{c}\text { Log deposits }^{a, b} \\
(4) \\
\end{array}$ & $\begin{array}{c}\text { Log fin. assets }{ }^{a, b} \\
\text { (excl. deposits) } \\
(5)\end{array}$ & $\begin{array}{c}\text { Home } \\
\text { ownership }^{a} \\
(6) \\
\end{array}$ & $\begin{array}{l}\text { Coresidence } \\
\text { with parents } \\
\text { (7) } \\
\end{array}$ \\
\hline \multicolumn{8}{|l|}{ A. Men } \\
\hline$U R \times 1[$ Yrs since $\operatorname{grad}=1-3]$ & $\begin{array}{c}0.007 \\
(0.008)\end{array}$ & $\begin{array}{l}-0.095 \\
(0.157)\end{array}$ & $\begin{array}{c}-0.235^{*} \\
(0.139)\end{array}$ & $\begin{array}{c}-0.335^{* *} \\
(0.150)\end{array}$ & $\begin{array}{l}-0.041 \\
(0.157)\end{array}$ & $\begin{array}{l}-0.010 \\
(0.011)\end{array}$ & $\begin{array}{l}-0.004 \\
(0.008)\end{array}$ \\
\hline$U R \times 1[$ Yrs since $\operatorname{grad}=4-6]$ & $\begin{array}{c}0.003 \\
(0.007)\end{array}$ & $\begin{array}{c}0.057 \\
(0.168)\end{array}$ & $\begin{array}{l}-0.127 \\
(0.144)\end{array}$ & $\begin{array}{l}-0.205 \\
(0.136)\end{array}$ & $\begin{array}{l}-0.073 \\
(0.149)\end{array}$ & $\begin{array}{l}-0.006 \\
(0.009)\end{array}$ & $\begin{array}{l}0.017 * \\
(0.010)\end{array}$ \\
\hline$U R \times 1[$ Yrs since $\operatorname{grad}=7-9]$ & $\begin{array}{l}-0.001 \\
(0.007)\end{array}$ & $\begin{array}{c}0.119 \\
(0.134)\end{array}$ & $\begin{array}{c}-0.311 * * * \\
(0.119)\end{array}$ & $\begin{array}{c}-0.235^{*} \\
(0.139)\end{array}$ & $\begin{array}{c}-0.340 * * * \\
(0.106)\end{array}$ & $\begin{array}{l}-0.002 \\
(0.007)\end{array}$ & $\begin{array}{c}0.031 * * * \\
(0.009)\end{array}$ \\
\hline$U R \times 1[$ Yrs since $\operatorname{grad}=10-12]$ & $\begin{array}{l}-0.003 \\
(0.007)\end{array}$ & $\begin{array}{c}0.033 \\
(0.151)\end{array}$ & $\begin{array}{c}0.028 \\
(0.130)\end{array}$ & $\begin{array}{c}0.103 \\
(0.140)\end{array}$ & $\begin{array}{l}-0.079 \\
(0.126)\end{array}$ & $\begin{array}{l}-0.014 \\
(0.008)\end{array}$ & $\begin{array}{c}0.018 * * * \\
(0.006)\end{array}$ \\
\hline$U R \times 1[$ Yrs since $\operatorname{grad}=13-15]$ & $\begin{array}{l}-0.008 \\
(0.007)\end{array}$ & $\begin{array}{c}0.074 \\
(0.167)\end{array}$ & $\begin{array}{l}-0.143 \\
(0.095)\end{array}$ & $\begin{array}{l}-0.043 \\
(0.105)\end{array}$ & $\begin{array}{l}-0.157 \\
(0.138)\end{array}$ & $\begin{array}{c}-0.018 * \\
(0.010)\end{array}$ & $\begin{array}{c}0.005 \\
(0.006)\end{array}$ \\
\hline$U R \times 1[$ Yrs since $\operatorname{grad}=16+]$ & $\begin{array}{l}-0.002 \\
(0.007)\end{array}$ & $\begin{array}{c}0.109 \\
(0.124)\end{array}$ & $\begin{array}{l}-0.023 \\
(0.100)\end{array}$ & $\begin{array}{l}-0.034 \\
(0.123)\end{array}$ & $\begin{array}{l}-0.019 \\
(0.105)\end{array}$ & $\begin{array}{l}-0.012 * \\
(0.007)\end{array}$ & $\begin{array}{c}0.000 \\
(0.006)\end{array}$ \\
\hline Adjusted $R^{2}$ & 0.163 & 0.024 & 0.028 & 0.014 & 0.106 & 0.031 & 0.239 \\
\hline Observations & 20,706 & 22,268 & 22,267 & 22,089 & 22,266 & 22,256 & 22,856 \\
\hline Mean of $Y$ & 13.574 & 9.281 & 12.967 & 11.107 & 6.681 & 0.626 & 0.261 \\
\hline \multicolumn{8}{|l|}{ B. Women } \\
\hline$U R \times 1[$ Yrs since $\operatorname{grad}=1-3]$ & $\begin{array}{l}-0.008 \\
(0.011)\end{array}$ & $\begin{array}{l}-0.123 \\
(0.206)\end{array}$ & $\begin{array}{l}-0.208 \\
(0.133)\end{array}$ & $\begin{array}{l}-0.192 \\
(0.162)\end{array}$ & $\begin{array}{l}-0.167 \\
(0.163)\end{array}$ & $\begin{array}{c}0.004 \\
(0.009)\end{array}$ & $\begin{array}{l}-0.001 \\
(0.008)\end{array}$ \\
\hline$U R \times 1[$ Yrs since $\operatorname{grad}=4-6]$ & $\begin{array}{l}-0.020 * * * \\
(0.007)\end{array}$ & $\begin{array}{c}0.197 \\
(0.151)\end{array}$ & $\begin{array}{l}-0.037 \\
(0.119)\end{array}$ & $\begin{array}{l}0.000 \\
(0.114)\end{array}$ & $\begin{array}{l}-0.182 \\
(0.118)\end{array}$ & $\begin{array}{c}0.008 \\
(0.008)\end{array}$ & $\begin{array}{c}0.001 \\
(0.008)\end{array}$ \\
\hline$U R \times 1[$ Yrs since $\operatorname{grad}=7-9]$ & $\begin{array}{l}-0.003 \\
(0.007)\end{array}$ & $\begin{array}{l}-0.042 \\
(0.178)\end{array}$ & $\begin{array}{l}-0.158 \\
(0.115)\end{array}$ & $\begin{array}{l}-0.216^{*} \\
(0.126)\end{array}$ & $\begin{array}{l}-0.207^{*} \\
(0.116)\end{array}$ & $\begin{array}{l}-0.003 \\
(0.011)\end{array}$ & $\begin{array}{l}-0.005 \\
(0.007)\end{array}$ \\
\hline$U R \times 1[$ Yrs since $\operatorname{grad}=10-12]$ & $\begin{array}{c}-0.013 * \\
(0.007)\end{array}$ & $\begin{array}{c}0.063 \\
(0.137)\end{array}$ & $\begin{array}{c}0.032 \\
(0.111)\end{array}$ & $\begin{array}{c}0.040 \\
(0.129)\end{array}$ & $\begin{array}{l}-0.081 \\
(0.115)\end{array}$ & $\begin{array}{l}-0.005 \\
(0.009)\end{array}$ & $\begin{array}{l}0.011^{*} \\
(0.006)\end{array}$ \\
\hline$U R \times 1[$ Yrs since $\operatorname{grad}=13-15]$ & $\begin{array}{l}-0.004 \\
(0.006)\end{array}$ & $\begin{array}{l}0.225^{*} \\
(0.118)\end{array}$ & $\begin{array}{c}0.091 \\
(0.110)\end{array}$ & $\begin{array}{c}0.149 \\
(0.129)\end{array}$ & $\begin{array}{l}-0.055 \\
(0.123)\end{array}$ & $\begin{array}{l}-0.010 \\
(0.009)\end{array}$ & $\begin{array}{l}0.008 \\
(0.005)\end{array}$ \\
\hline$U R \times 1[$ Yrs since $\operatorname{grad}=16+]$ & $\begin{array}{l}-0.001 \\
(0.007)\end{array}$ & $\begin{array}{c}0.011 \\
(0.140)\end{array}$ & $\begin{array}{l}0.152^{*} \\
(0.086)\end{array}$ & $\begin{array}{c}0.052 \\
(0.149)\end{array}$ & $\begin{array}{c}0.177 \\
(0.120)\end{array}$ & $\begin{array}{l}-0.001 \\
(0.009)\end{array}$ & $\begin{array}{c}0.001 \\
(0.005)\end{array}$ \\
\hline Adjusted $R^{2}$ & 0.183 & 0.028 & 0.028 & 0.014 & 0.112 & 0.0305 & 0.290 \\
\hline Observations & 18,808 & 20,305 & 20,302 & 20,128 & 20,302 & 20,296 & 20,795 \\
\hline Mean of $Y$ & 13.558 & 9.355 & 13.216 & 11.362 & 6.827 & 0.642 & 0.291 \\
\hline
\end{tabular}


Table S5: Effects of National Unemployment Rate at Graduation on Various Outcomes, OLS and IV Estimation

\begin{tabular}{|c|c|c|c|c|c|c|c|c|c|c|}
\hline & \multicolumn{5}{|c|}{ Men } & \multicolumn{5}{|c|}{ Women } \\
\hline & OLS & IV & $\begin{array}{c}\text { First stage } \\
F \text {-statistic }\end{array}$ & Mean & Obs. & OLS & IV & $\begin{array}{c}\text { First stage } \\
F \text {-statistic }\end{array}$ & Mean & Obs. \\
\hline \multicolumn{11}{|c|}{ A. Employment and earnings (experience years 1-10) } \\
\hline Employed & $\begin{array}{c}-0.016^{* * *} \\
(0.005)\end{array}$ & $\begin{array}{c}-0.030 * \\
(0.016)\end{array}$ & 20.3 & 0.856 & 11,954 & $\begin{array}{c}0.005 \\
(0.007)\end{array}$ & $\begin{array}{l}-0.015 \\
(0.015)\end{array}$ & 46.1 & 0.602 & 11,339 \\
\hline Earnings $^{a}$ & $\begin{array}{c}-58.7 * * * \\
(21.3)\end{array}$ & $\begin{array}{c}-102.3^{*} \\
(60.9)\end{array}$ & 20.9 & $2,234.1$ & 11,807 & $\begin{array}{c}2.0 \\
(17.4)\end{array}$ & $\begin{array}{l}-36.6 \\
(34.6)\end{array}$ & 47.4 & $1,086.3$ & 11,278 \\
\hline Earnings (employed only) ${ }^{a}$ & $\begin{array}{l}-26.9 \\
(19.3)\end{array}$ & $\begin{array}{l}-55.7 \\
(50.6)\end{array}$ & 124.0 & $2,616.9$ & 10,080 & $\begin{array}{l}-14.6 \\
(16.5)\end{array}$ & $\begin{array}{l}-13.7 \\
(29.3)\end{array}$ & 36.7 & $1,811.2$ & 6,764 \\
\hline Log earnings $b$ & $\begin{array}{c}-0.245^{* * *} * \\
(0.077)\end{array}$ & $\begin{array}{l}-0.381 \\
(0.256)\end{array}$ & 20.9 & 12.408 & 11,807 & $\begin{array}{c}0.044 \\
(0.097)\end{array}$ & $\begin{array}{l}-0.197 \\
(0.221)\end{array}$ & 47.4 & 8.464 & 11,278 \\
\hline Log earnings (employed only) ${ }^{b}$ & $\begin{array}{l}-0.002 \\
(0.006)\end{array}$ & $\begin{array}{l}-0.014 \\
(0.017)\end{array}$ & 124.2 & 14.685 & 9,976 & $\begin{array}{l}-0.002 \\
(0.009)\end{array}$ & $\begin{array}{c}0.004 \\
(0.013)\end{array}$ & 38.2 & 14.322 & 6,665 \\
\hline \multicolumn{11}{|c|}{ B. Marriage and fertility (as of the most recent survey year) } \\
\hline Ever married & $\begin{array}{c}-0.022 * * \\
(0.011)\end{array}$ & $\begin{array}{c}-0.072 * * \\
(0.032)\end{array}$ & 177.4 & 0.726 & 2,474 & $\begin{array}{l}-0.011 \\
(0.011)\end{array}$ & $\begin{array}{l}-0.007 \\
(0.017)\end{array}$ & 274.0 & 0.714 & 2,320 \\
\hline Any children & $\begin{array}{c}-0.017 * \\
(0.010)\end{array}$ & $\begin{array}{l}-0.001 \\
(0.030)\end{array}$ & 177.4 & 0.639 & 2,474 & $\begin{array}{c}0.009 \\
(0.010)\end{array}$ & $\begin{array}{c}0.028 \\
(0.020)\end{array}$ & 274.0 & 0.625 & 2,320 \\
\hline Any children (ever married only) & $\begin{array}{l}-0.003 \\
(0.013)\end{array}$ & $\begin{array}{c}0.023 \\
(0.109)\end{array}$ & 38.1 & 0.880 & 1,796 & $\begin{array}{c}0.030 * * * \\
(0.010)\end{array}$ & $\begin{array}{l}0.049 * \\
(0.028)\end{array}$ & 77.8 & 0.876 & 1,656 \\
\hline Number of children & $\begin{array}{l}-0.028 \\
(0.019)\end{array}$ & $\begin{array}{c}0.031 \\
(0.065)\end{array}$ & 177.4 & 1.126 & 2,474 & $\begin{array}{c}0.046^{* *} \\
(0.018)\end{array}$ & $\begin{array}{c}0.097 * * \\
(0.039)\end{array}$ & 274.0 & 1.096 & 2,320 \\
\hline Number of children (ever married only) & $\begin{array}{l}-0.016 \\
(0.027)\end{array}$ & $\begin{array}{l}-0.053 \\
(0.342)\end{array}$ & 38.1 & 1.551 & 1,796 & $\begin{array}{c}0.097 * * * \\
(0.021)\end{array}$ & $\begin{array}{c}0.156^{* * * *} \\
(0.056)\end{array}$ & 77.8 & 1.535 & 1,656 \\
\hline \multicolumn{11}{|c|}{ C. Consumption and asset holdings (experience years 1-10) } \\
\hline Log expenditure per capita ${ }^{b}$ & $\begin{array}{c}0.005 \\
(0.005)\end{array}$ & $\begin{array}{c}0.005 \\
(0.020)\end{array}$ & 28.4 & 13.508 & 11,317 & $\begin{array}{c}-0.010^{*} \\
(0.006)\end{array}$ & $\begin{array}{c}-0.022 * \\
(0.012)\end{array}$ & 35.4 & 13.484 & 10,735 \\
\hline Log debt ${ }^{b}$ & $\begin{array}{c}0.090 \\
(0.111)\end{array}$ & $\begin{array}{c}0.131 \\
(0.323)\end{array}$ & 23.8 & 8.411 & 11,366 & $\begin{array}{c}0.088 \\
(0.099)\end{array}$ & $\begin{array}{c}0.165 \\
(0.213)\end{array}$ & 37.0 & 8.571 & 10,850 \\
\hline Log financial assets $b$ & $\begin{array}{c}-0.162^{*} \\
(0.096)\end{array}$ & $\begin{array}{c}-0.455^{*} \\
(0.256)\end{array}$ & 23.9 & 12.751 & 11,365 & $\begin{array}{l}-0.114 \\
(0.084)\end{array}$ & $\begin{array}{l}-0.042 \\
(0.167)\end{array}$ & 37.0 & 12.894 & 10,847 \\
\hline Log deposits ${ }^{b}$ & $\begin{array}{c}-0.198 * * \\
(0.097)\end{array}$ & $\begin{array}{c}-0.555 * * \\
(0.273)\end{array}$ & 24.4 & 11.249 & 11,275 & $\begin{array}{l}-0.106 \\
(0.093)\end{array}$ & $\begin{array}{l}-0.005 \\
(0.180)\end{array}$ & 36.6 & 11.456 & 10,753 \\
\hline Log financial assets (excl. deposits) ${ }^{b}$ & $\begin{array}{l}-0.145 \\
(0.089)\end{array}$ & $\begin{array}{l}-0.310 \\
(0.235)\end{array}$ & 23.9 & 5.725 & 11,364 & $\begin{array}{c}-0.182 * * \\
(0.089)\end{array}$ & $\begin{array}{l}-0.113 \\
(0.163)\end{array}$ & 37.0 & 5.765 & 10,847 \\
\hline Home ownership & $\begin{array}{l}-0.005 \\
(0.005)\end{array}$ & $\begin{array}{c}-0.036 * \\
(0.020)\end{array}$ & 24.0 & 0.577 & 11,359 & $\begin{array}{c}0.004 \\
(0.007)\end{array}$ & $\begin{array}{c}0.040 * * * \\
(0.012)\end{array}$ & 37.4 & 0.604 & 10,844 \\
\hline
\end{tabular}

Notes. For the OLS estimation, see the notes under Table 2 for the labor market outcomes in panel A, see Table 4 for the family formation outcomes in panel B, and see Table S4 for the financial outcomes in panel C.

In the IV estimation, national $U R$ at actual year of college graduation is instrumented with national $U R$ at predicted year of college graduation. A cubic function of college graduation year and years since graduation are instrumented with a cubic function of predicted college graduation year and years since predicted year of graduation, respectively. The IV regressions include fixed effects for the region of college graduation and calendar year in panels A and C, and fixed effects for the region of college graduation in panel B. Control for 4-year college graduates. Missing values in background covariates are imputed using mean values, and dummies for missing observations are also controlled for. Robust standard errors in parentheses are clustered at the level of predicted graduation year by region of college.
$* p<0.10, * * p<0.05, * * * p<0.01$

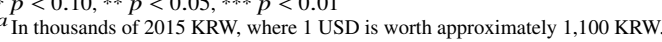

${ }^{b}$ Before taking the logarithm, the values are inflation-adjusted to $2015 \mathrm{KRW}$ and zeros are imputed with $1 \mathrm{KRW}$. 
Table S6: Effects of Economic Conditions at Graduation on Various Outcomes, Using Alternative Treatment Variables

\begin{tabular}{|c|c|c|c|c|c|c|c|c|c|c|}
\hline & \multicolumn{5}{|c|}{ Men } & \multicolumn{5}{|c|}{ Women } \\
\hline & $\begin{array}{c}\text { National } \\
\quad U R\end{array}$ & $\begin{array}{c}\text { Regional } \\
U R\end{array}$ & $D C$ & Mean & Obs. & $\begin{array}{c}\text { National } \\
U R\end{array}$ & $\begin{array}{c}\text { Regional } \\
U R\end{array}$ & $D C$ & Mean & Obs. \\
\hline \multicolumn{11}{|c|}{ A. Employment and earnings (experience years 1-10) } \\
\hline Employed & $\begin{array}{c}-0.016 * * * \\
(0.005)\end{array}$ & $\begin{array}{c}-0.011 * * \\
(0.005)\end{array}$ & $\begin{array}{c}-0.062 * * * \\
(0.021)\end{array}$ & 0.856 & 11,954 & $\begin{array}{c}0.005 \\
(0.007)\end{array}$ & $\begin{array}{c}0.005 \\
(0.007)\end{array}$ & $\begin{array}{c}0.014 \\
(0.027)\end{array}$ & 0.602 & 11,339 \\
\hline Earnings $^{a}$ & $\begin{array}{c}-58.7 * * * \\
(21.3)\end{array}$ & $\begin{array}{c}-41.5^{*} \\
(23.6)\end{array}$ & $\begin{array}{c}-210.1 * * \\
(90.5)\end{array}$ & $2,234.1$ & 11,807 & $\begin{array}{c}2.0 \\
(17.4)\end{array}$ & $\begin{array}{c}4.3 \\
(16.5)\end{array}$ & $\begin{array}{l}-8.0 \\
(68.5)\end{array}$ & $1,086.3$ & 11,278 \\
\hline Earnings (employed only) ${ }^{a}$ & $\begin{array}{l}-26.9 \\
(19.3)\end{array}$ & $\begin{array}{l}-22.6 \\
(20.8)\end{array}$ & $\begin{array}{l}-94.2 \\
(79.3)\end{array}$ & $2,616.9$ & 10,080 & $\begin{array}{l}-14.6 \\
(16.5)\end{array}$ & $\begin{array}{l}-9.1 \\
(15.4)\end{array}$ & $\begin{array}{l}-65.4 \\
(64.3)\end{array}$ & $1,811.2$ & 6,764 \\
\hline Log earnings ${ }^{b}$ & $\begin{array}{c}-0.245^{* * *} \\
(0.077)\end{array}$ & $\begin{array}{c}-0.162 * \\
(0.083)\end{array}$ & $\begin{array}{c}-0.927 * * * \\
(0.327)\end{array}$ & 12.408 & 11,807 & $\begin{array}{c}0.044 \\
(0.097)\end{array}$ & $\begin{array}{c}0.059 \\
(0.097)\end{array}$ & $\begin{array}{c}0.029 \\
(0.376)\end{array}$ & 8.464 & 11,278 \\
\hline Log earnings (employed only) ${ }^{b}$ & $\begin{array}{l}-0.002 \\
(0.006)\end{array}$ & $\begin{array}{c}0.000 \\
(0.006)\end{array}$ & $\begin{array}{l}-0.005 \\
(0.024)\end{array}$ & 14.685 & 9,976 & $\begin{array}{l}-0.002 \\
(0.009)\end{array}$ & $\begin{array}{l}-0.000 \\
(0.008)\end{array}$ & $\begin{array}{l}-0.010 \\
(0.034)\end{array}$ & 14.322 & 6,665 \\
\hline \multicolumn{11}{|c|}{ B. Marriage and fertility (as of the most recent survey year) } \\
\hline Ever married & $\begin{array}{c}-0.022 * * \\
(0.011)\end{array}$ & $\begin{array}{l}-0.013 \\
(0.009)\end{array}$ & $\begin{array}{c}-0.094 * * \\
(0.043)\end{array}$ & 0.726 & 2,474 & $\begin{array}{l}-0.011 \\
(0.011)\end{array}$ & $\begin{array}{c}-0.015^{*} \\
(0.008)\end{array}$ & $\begin{array}{l}-0.056 \\
(0.042)\end{array}$ & 0.714 & 2,320 \\
\hline Any children & $\begin{array}{c}-0.017^{*} \\
(0.010)\end{array}$ & $\begin{array}{l}-0.009 \\
(0.008)\end{array}$ & $\begin{array}{c}-0.074^{*} \\
(0.039)\end{array}$ & 0.639 & 2,474 & $\begin{array}{c}0.009 \\
(0.010)\end{array}$ & $\begin{array}{l}-0.001 \\
(0.008)\end{array}$ & $\begin{array}{c}0.019 \\
(0.039)\end{array}$ & 0.625 & 2,320 \\
\hline Any children (ever married only) & $\begin{array}{l}-0.003 \\
(0.013)\end{array}$ & $\begin{array}{l}-0.002 \\
(0.010)\end{array}$ & $\begin{array}{l}-0.008 \\
(0.049)\end{array}$ & 0.880 & 1,796 & $\begin{array}{c}0.030 * * * \\
(0.010)\end{array}$ & $\begin{array}{c}0.014 \\
(0.010)\end{array}$ & $\begin{array}{c}0.105^{* * *} * \\
(0.040)\end{array}$ & 0.876 & 1,656 \\
\hline Number of children & $\begin{array}{l}-0.028 \\
(0.019)\end{array}$ & $\begin{array}{l}-0.011 \\
(0.015)\end{array}$ & $\begin{array}{l}-0.114 \\
(0.081)\end{array}$ & 1.126 & 2,474 & $\begin{array}{c}0.046^{* *} \\
(0.018)\end{array}$ & $\begin{array}{c}0.015 \\
(0.017)\end{array}$ & $\begin{array}{c}0.138 * * \\
(0.068)\end{array}$ & 1.096 & 2,320 \\
\hline Number of children (ever married only) & $\begin{array}{l}-0.016 \\
(0.027)\end{array}$ & $\begin{array}{l}-0.002 \\
(0.020) \\
\end{array}$ & $\begin{array}{l}-0.026 \\
(0.110)\end{array}$ & 1.551 & 1,796 & $\begin{array}{c}0.097^{* * * *} \\
(0.021)\end{array}$ & $\begin{array}{l}0.041^{*} \\
(0.023)\end{array}$ & $\begin{array}{c}0.318^{* * * *} \\
(0.085)\end{array}$ & 1.535 & 1,656 \\
\hline \multicolumn{11}{|c|}{ C. Consumption and asset holdings (experience years 1-10) } \\
\hline Log expenditure per capita ${ }^{b}$ & $\begin{array}{c}0.005 \\
(0.005)\end{array}$ & $\begin{array}{c}0.003 \\
(0.005)\end{array}$ & $\begin{array}{c}0.018 \\
(0.020)\end{array}$ & 13.508 & 11,317 & $\begin{array}{c}-0.010^{*} \\
(0.006)\end{array}$ & $\begin{array}{l}-0.007 \\
(0.005)\end{array}$ & $\begin{array}{c}-0.042 * * \\
(0.021)\end{array}$ & 13.484 & 10,735 \\
\hline $\log \operatorname{debt}^{b}$ & $\begin{array}{c}0.090 \\
(0.111)\end{array}$ & $\begin{array}{l}0.126 \\
(0.103)\end{array}$ & $\begin{array}{c}0.178 \\
(0.460)\end{array}$ & 8.411 & 11,366 & $\begin{array}{c}0.088 \\
(0.099)\end{array}$ & $\begin{array}{c}0.045 \\
(0.092)\end{array}$ & $\begin{array}{c}0.374 \\
(0.380)\end{array}$ & 8.571 & 10,850 \\
\hline Log financial assets ${ }^{b}$ & $\begin{array}{c}-0.162^{*} \\
(0.096)\end{array}$ & $\begin{array}{c}-0.198^{*} \\
(0.101)\end{array}$ & $\begin{array}{c}-0.739 * \\
(0.381)\end{array}$ & 12.751 & 11,365 & $\begin{array}{l}-0.114 \\
(0.084)\end{array}$ & $\begin{array}{c}-0.139^{*} \\
(0.082)\end{array}$ & $\begin{array}{l}-0.276 \\
(0.324)\end{array}$ & 12.894 & 10,847 \\
\hline Log deposits ${ }^{b}$ & $\begin{array}{c}-0.198 * * \\
(0.097)\end{array}$ & $\begin{array}{c}-0.234 * * \\
(0.097)\end{array}$ & $\begin{array}{c}-0.853^{* *} \\
(0.388)\end{array}$ & 11.249 & 11,275 & $\begin{array}{l}-0.106 \\
(0.093)\end{array}$ & $\begin{array}{l}-0.117 \\
(0.092)\end{array}$ & $\begin{array}{l}-0.399 \\
(0.356)\end{array}$ & 11.456 & 10,753 \\
\hline Log financial assets (excl. deposits) ${ }^{b}$ & $\begin{array}{l}-0.145 \\
(0.089)\end{array}$ & $\begin{array}{l}-0.095 \\
(0.094)\end{array}$ & $\begin{array}{c}-0.676^{*} \\
(0.355)\end{array}$ & 5.725 & 11,364 & $\begin{array}{c}-0.182 * * \\
(0.089)\end{array}$ & $\begin{array}{c}-0.221 * * * \\
(0.077)\end{array}$ & $\begin{array}{l}-0.444 \\
(0.341)\end{array}$ & 5.765 & 10,847 \\
\hline Home ownership & $\begin{array}{l}-0.005 \\
(0.005)\end{array}$ & $\begin{array}{c}-0.012 * * \\
(0.005)\end{array}$ & $\begin{array}{l}-0.032 \\
(0.022)\end{array}$ & 0.577 & 11,359 & $\begin{array}{c}0.004 \\
(0.007)\end{array}$ & $\begin{array}{c}0.003 \\
(0.006)\end{array}$ & $\begin{array}{c}0.022 \\
(0.026)\end{array}$ & 0.604 & 10,844 \\
\hline
\end{tabular}

Notes. Regressions include a cubic function of college graduation year, and fixed effects for the region of college graduation and years since graduation. In panels A and C, calendar year fixed effects are also included in the regressions. Controls for background characteristics include father's years of education, father's years of education squared, dummies for parents' job status at age 14 (standard worker, non-standard worker, business owner hiring employees, business owner with no employee), and an indicator for 4-year college graduates. Missing values in background covariates are imputed using mean values, and dummies for missing observations are also controlled for. $* p<0.10, * * p<0.05, * * * p<0.01$

${ }^{a}$ In thousands of $2015 \mathrm{KRW}$, where $1 \mathrm{USD}$ is worth approximately $1,100 \mathrm{KRW}$.

${ }^{b}$ Before taking the logarithm, the values are inflation-adjusted to $2015 \mathrm{KRW}$ and zeros are imputed with $1 \mathrm{KRW}$. 
Table S7: Reduced Form Results Using Predicted Unemployment Rate, by Data Source

\begin{tabular}{|c|c|c|c|c|c|c|}
\hline & $\begin{array}{c}\text { Employed } \\
\text { (1) }\end{array}$ & $\begin{array}{c}\text { Ever } \\
\text { married } \\
(2)\end{array}$ & $\begin{array}{c}\text { Any } \\
\text { children } \\
(3)\end{array}$ & $\begin{array}{c}\text { Any children } \\
\text { (ever married) } \\
\text { (4) }\end{array}$ & $\begin{array}{c}\mathbf{N} \text { of } \\
\text { children } \\
(5)\end{array}$ & $\begin{array}{c}\mathbf{N} \text { of children } \\
\text { (ever married) } \\
(6)\end{array}$ \\
\hline \multicolumn{7}{|l|}{ A. Men } \\
\hline & \multicolumn{6}{|c|}{ KLIPS } \\
\hline Predicted $U R$ & $\begin{array}{l}-0.002 \\
(0.006)\end{array}$ & $\begin{array}{l}-0.001 \\
(0.008)\end{array}$ & $\begin{array}{c}0.003 \\
(0.011)\end{array}$ & $\begin{array}{c}0.010 \\
(0.011)\end{array}$ & $\begin{array}{c}0.005 \\
(0.020)\end{array}$ & $\begin{array}{c}0.017 \\
(0.024)\end{array}$ \\
\hline Adjusted $R^{2}$ & 0.111 & 0.274 & 0.288 & 0.109 & 0.305 & 0.170 \\
\hline Observations & 11,954 & 2,474 & 2,474 & 1,796 & 2,474 & 1,796 \\
\hline \multirow[t]{2}{*}{ Mean of $Y$} & 0.856 & 0.726 & 0.639 & 0.880 & 1.126 & 1.551 \\
\hline & EAPS & \multicolumn{5}{|c|}{ Census } \\
\hline Predicted $U R$ & $\begin{array}{c}-0.005 * * \\
(0.002)\end{array}$ & $\begin{array}{c}-0.002 * * \\
(0.001)\end{array}$ & $\begin{array}{l}-0.002 \\
(0.002)\end{array}$ & $\begin{array}{l}-0.002 \\
(0.001)\end{array}$ & $\begin{array}{l}-0.003 \\
(0.004)\end{array}$ & $\begin{array}{l}-0.002 \\
(0.003)\end{array}$ \\
\hline Adjusted $R^{2}$ & 0.163 & 0.291 & 0.233 & 0.044 & 0.341 & 0.194 \\
\hline Observations & 741,884 & 175,042 & 175,042 & 121,646 & 163,262 & 109,866 \\
\hline Mean of $Y$ & 0.840 & 0.703 & 0.575 & 0.818 & 1.094 & 1.603 \\
\hline
\end{tabular}

\section{B. Women}

\begin{tabular}{|c|c|c|c|c|c|c|}
\hline \multirow[b]{2}{*}{ Predicted $U R$} & \multicolumn{6}{|c|}{ KLIPS } \\
\hline & $\begin{array}{l}-0.007 \\
(0.008)\end{array}$ & $\begin{array}{c}0.003 \\
(0.009)\end{array}$ & $\begin{array}{c}0.014 \\
(0.010)\end{array}$ & $\begin{array}{c}0.018 \\
(0.011)\end{array}$ & $\begin{array}{c}0.046^{* *} \\
(0.019)\end{array}$ & $\begin{array}{c}0.063 * * * \\
(0.023)\end{array}$ \\
\hline Adjusted $R^{2}$ & 0.034 & 0.348 & 0.357 & 0.133 & 0.351 & 0.183 \\
\hline Observations & 11,339 & 2,320 & 2,320 & 1,656 & 2,320 & 1,656 \\
\hline Mean of $Y$ & 0.602 & 0.714 & 0.625 & 0.876 & 1.096 & 1.535 \\
\hline \multirow[b]{2}{*}{ Predicted $U R$} & $E A P S$ & \multicolumn{5}{|c|}{ Census } \\
\hline & $\begin{array}{c}0.000 \\
(0.001)\end{array}$ & $\begin{array}{c}0.003 * * \\
(0.001)\end{array}$ & $\begin{array}{c}0.005 * * * \\
(0.001)\end{array}$ & $\begin{array}{l}-0.001 \\
(0.001)\end{array}$ & $\begin{array}{c}0.015^{* * *} * \\
(0.004)\end{array}$ & $\begin{array}{c}0.010^{* * * *} \\
(0.003)\end{array}$ \\
\hline Adjusted $R^{2}$ & 0.054 & 0.331 & 0.331 & 0.109 & 0.357 & 0.195 \\
\hline Observations & 724,128 & 165,462 & 165,462 & 109,766 & 163,619 & 107,923 \\
\hline Mean of $Y$ & 0.666 & 0.669 & 0.581 & 0.869 & 1.016 & 1.528 \\
\hline
\end{tabular}

Notes. Regressions using the 1998-2017 KLIPS data include a cubic function of predicted college graduation year, and fixed effects for the region of college graduation and years since predicted year of graduation. In column (1), calendar year fixed effects are also included in the regressions. Controls for background characteristics include father's years of education, father's years of education squared, dummies for parents' job status at age 14 (standard worker, non-standard worker, business owner hiring employees, business owner with no employee), and an indicator for 4year college graduates. Missing values in background covariates are imputed using mean values, and dummies for missing observations are also controlled for. Robust standard errors in parentheses are clustered at the level of predicted graduation year by region of college.

Regressions using the 1998-2017 EAPS data control for a cubic function of predicted college graduation year, fixed effects for years since predicted year of graduation and calendar year, and an indicator for 4-year college graduates. Robust standard errors in parentheses are clustered at the level of predicted graduation year.

Regressions using the 2010 and 2015 Census data control for a cubic function of predicted college graduation year, fixed effects for years since predicted year of graduation and region of birth, and an indicator for 4-year college graduates. Robust standard errors in parentheses are clustered at the level of predicted graduation year by region of birth.

$* p<0.10, * * p<0.05, * * * p<0.01$ 